\title{
An arid zone awash with diversity: patterns in the distribution of aquatic invertebrates in the Pilbara region of Western Australia
}

\author{
Adrian M. Pinder ${ }^{1}$, Stuart A. Halse ${ }^{1,2}$, Russell J. Shiel ${ }^{3}$ and Jane M. McRae ${ }^{1,2}$ \\ ${ }^{1}$ Department of Environment and Conservation, PO Box 51, Wanneroo, Western Australia 6946, Australia \\ ${ }^{2}$ Present address: Bennelongia Pty Ltd, 5 Bishop St, Jolimont, Western Australia 6014, Australia \\ ${ }^{3}$ School of Earth and Environmental Sciences, University of Adelaide, Adelaide, South Australia 5005, Australia \\ Corresponding author: email: Adrian.Pinder@dec.wa.gov.au
}

\begin{abstract}
The Pilbara region of Western Australia is an arid zone with an abundance of wetlands, ranging from springs and river pools to salt marshes, claypans, rockpools and gnammas. The Pilbara is also rich in mineral resources, which are being heavily exploited, and most of the region is under pastoral lease, with both land uses potentially having an impact upon aquatic systems. In order to provide information for improved conservation planning, including environmental impact assessment and reserve system design, a survey of wetland fauna was undertaken as part of a broader biodiversity survey of the region. This paper describes patterns in the distribution of the region's aquatic invertebrate diversity and identifies environmental correlates of those patterns. Invertebrates and environmental variables were surveyed at 100 wetlands in spring and autumn between 2003 and 2006. The Pilbara appears to have a particularly diverse fauna for an arid zone, with just over 1000 species collected, an average of 94 species per sample and a maximum sample richness of 226 species. About a fifth of the fauna is known to date only from the Pilbara. The remaining species are western endemics, occur elsewhere in northern and/or inland Australia, or have continental or wider distributions. Most species seem to be widespread in the Pilbara region but rare and/or restricted elements are present, especially in some permanently flowing springs, including those in Millstream and Karijini National Parks, and in ephemeral wetlands such as Fortescue Marsh and freshwater claypans. Faunal composition was not strongly correlated with season, drainage divides, stream order or previously recognised bioregional boundaries. A number of assemblages of species with common patterns of occurrence were identified, each showing unique associations with measured environmental variables. Flow, turbidity, salinity, sediments, macrophytes and hydrological persistence are among the environmental gradients most strongly correlated with occurrence patterns in the fauna.
\end{abstract}

\section{INTRODUCTION}

The Pilbara region of north-western Australia is a geologically and geomorphically distinct and ancient part of the continent (Taylor 1994). It has a harsh climate, with low but mostly seasonal rainfall, resulting from intense tropical lows in summer (many of cyclonic intensity). The combination of these elements, plus extensive groundwater aquifers with surface expressions, has created a diverse array of wetlands, including claypans and clay flats, rockpools in creeks and rocky outcrops, springs, river pools (many of which are permanent) and the large endorheic Fortescue Marsh system. Land use in the Pilbara is almost entirely pastoralism and mining and these activities place considerable pressure on the region's wetlands. Effective protection of these wetlands is currently hampered by very poor knowledge of how aquatic biodiversity is distributed across the region (McKenzie et al. 2002). While a few of the more iconic wetland systems are encompassed by existing reserves (gorge streams in Karijini National Park and the springs and deep permanent river pools in Millstream National Park), the conservation estate covers just $7.75 \%$ of the Pilbara IBRA region in four parks and is not representative of the range of wetlands present in the region. This survey of aquatic invertebrates was part of a broader project (McKenzie et al. 2009), designed to provide information on the distribution of the region's biodiversity for a range of conservation management needs, including reserve system design and environmental impact assessment.

Protection of biodiversity is achieved more easily 

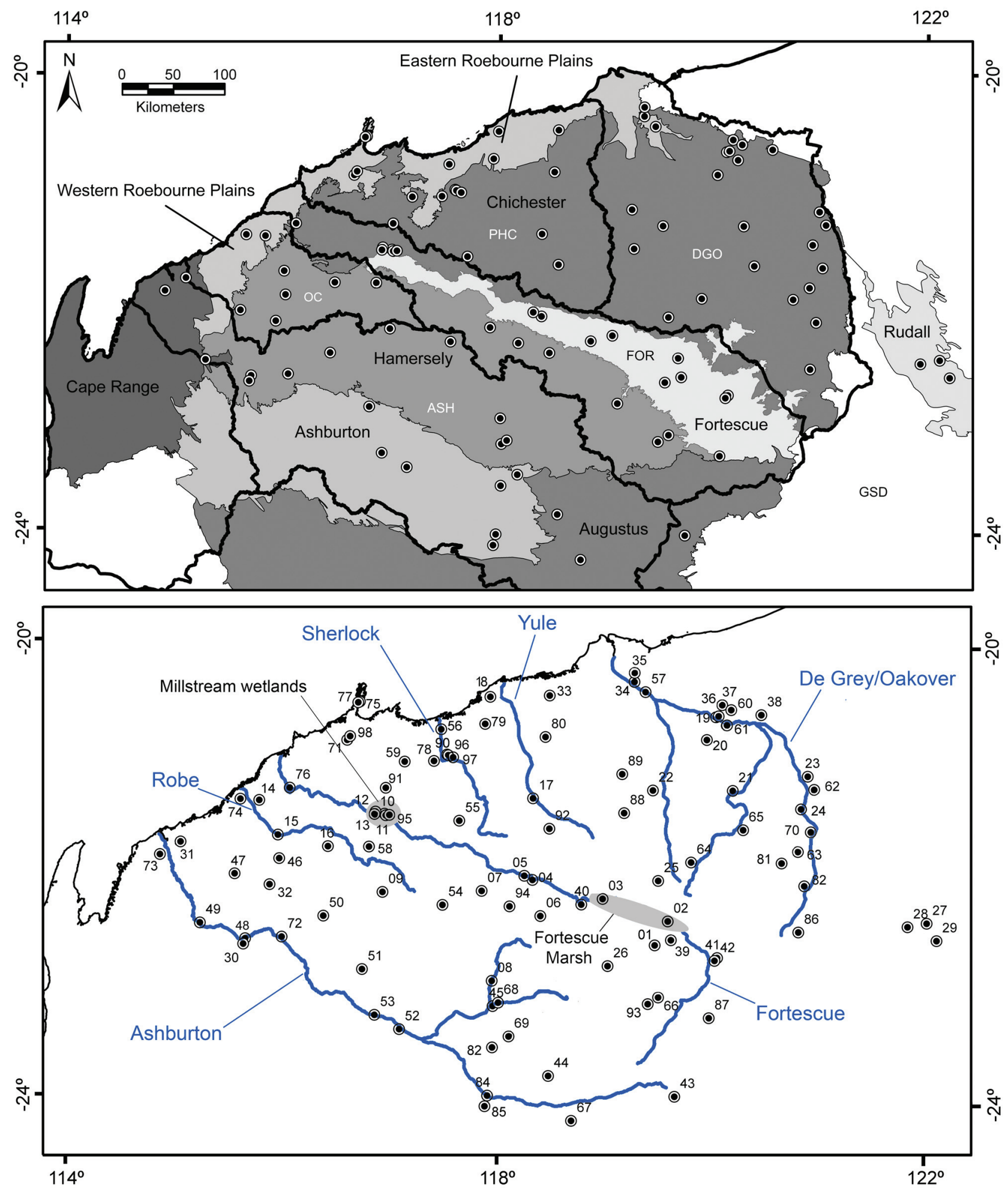

Figure 1 Maps of the Pilbara region showing wetland locations, major rivers, IBRA sub-regions (shaded, with full names) and drainage basins (bounded by bold lines and abbreviated as follows: ASH, Ashburton; OC, Onslow Coast; FOR, Fortescue; PHC, Port Hedland Coast; DGO, De Grey-Oakover; and GSD, Great Sandy Desert. Numbers next to sites in the bottom map are site numbers as per Table 1. 
and efficiently where there is an understanding of what it comprises and how it is distributed across the landscape (Haila and Margules 1996; Vinson and Hawkins 1998; Gaston 2000; Margules et al. 2002). It is assisted further by an understanding of how biodiversity patterning is related to environmental gradients to allow extrapolation beyond the limited area sampled (Nicholls 1989). This type of information is essential to designing an efficient conservation reserve system (Brooks et al. 2004; Pressey 2004), undertaking accurate threatened species and communities assessments (Strayer 2006) and enabling the environmental impacts of land management decisions to be assessed in a regional context (Stork et al. 1996). Such work also provides information on ecological tolerances, which have direct relevance for conservation by providing explanation of changes in animal abundance and distribution (e.g. Pinder et al. 2005)

In Western Australia (WA), comprehensive regional scale aquatic biodiversity assessments have been carried out in the Carnarvon Basin, south of the Pilbara (Halse et al. 2000; Keighery et al. 2000) and in the South-west Agricultural Zone (Halse et al. 2004; Lyons et al. 2004; Pinder et al. 2004). Biodiversity information from these surveys has contributed to conservation programs such as the selection of 'biodiversity recovery catchments' for intensive management in the wheatbelt (Walshe et al. 2004, Quinlan et al. 2009) and selection of land for the conservation estate in the Carnarvon Basin (McKenzie et al. 2000, Brandis 2009). The dataset presented here has already been used for conservation value assessment (e.g. Pinder and Leung 2009; Van Leeuwen 2009) and assessment of likely environmental impacts of resource development proposals in the Pilbara.

This paper examines the distribution of aquatic invertebrates across the region in relation to a range of landscape and environmental variables. The main approach taken is to identify groups of species (assemblages) with similar patterns of distribution across space and time and presumably, therefore, similar responses to environmental gradients. The advantage of identifying groups of species with similar distribution, before analysing the influence of environmental variables on occurrence, is that gradients and thresholds may be identified for the subsets that are masked or underestimated when working with all species together (McKenzie et al. 2004).

\section{The Pilbara region}

For the purposes of this study, what we call the 'Pilbara' region is bounded to the south by the main channel of the Ashburton River and to the east by the De Grey-Oakover River and its tributaries (Figure 1). This area of about $225,000 \mathrm{~km}^{2}$ includes all of the Pilbara IBRA bioregion as well as the some of the northern Gascoyne IBRA region (parts of the Augustus and Ashburton subregions) (Australian Government 2004). A summary of the region's landforms, geology and climate is provided by McKenzie et al. (2009).

The Pilbara region coincides largely with the Pilbara Craton, one of Australia's major geological blocks (Geological Survey of Western Australia 1990). The Craton is characterised by hard rock landscapes that were laid down in Archaean times, 2.5 to 3.5 billion years ago, making them some of the oldest rocks on the planet (Boulter 1986). The basement is exposed as granite and greenstone terrane in the north but overlain by rugged sedimentary strata, volcanic flows and lateritised caps in the south.

Average annual rainfall is $<350 \mathrm{~mm}$, falling mostly in summer as a result of tropical lows and cyclones that cross the Pilbara coast about every second year on average (http://www.bom.gov.au). Average summer rainfall is $150-300 \mathrm{~mm}$ across most of the Pilbara but attenuates south-westward to $<100 \mathrm{~mm}$. Winter rainfall, which occurs as cold fronts pass over the region, has an opposing trend with an average of $50-75 \mathrm{~mm}$ in the west and uplands to $<25 \mathrm{~mm}$ in the east and lowlands. Average maximum temperatures range from $21-30^{\circ} \mathrm{C}$ in winter to $36-42^{\circ} \mathrm{C}$ in summer (Bureau of Meteorology Australia 2008).

In late summer 2002/3 (about six months prior to sampling commencing in August 2003), several low intensity cyclones and tropical lows caused floods in the Ashburton River and upper (but not lower) Fortescue River, and minor flooding in the De Grey-Oakover River. In early March 2004, Cyclone Monty caused severe floods in most major Pilbara river systems (Figure 2), except the Robe River. In late March 2004, Cyclone Fay also caused severe floods, mostly in eastern rivers such as the De Grey and Coongan. Cyclones Clare and Glenda in January and March 2006 resulted in severe floods in the Ashburton, Robe, Fortescue and Port Hedland coast Rivers but only minor flooding in the De Grey-Oakover system. No cyclones affected the Pilbara in summer 2004/5. Winter rains in 2005 resulted in minor flow-pulses across most of the Pilbara (but these are not visible at the scale of Figure 2).

\section{Wetland settings}

Many of the wetland systems in the Pilbara are strongly influenced by the rapid movement of water in the landscape resulting from the combination of intense rainfall events (especially from cyclonic systems) and the largely impervious geology. In addition, the extensive alluvial, sedimentary 
and fractured rock aquifers (Water and Rivers Commission 1996; Johnson and Wright 2001) contribute large quantities of groundwater to surface systems. Flash flooding of smaller, rocky headwater creeks, where flow lasts just hours to days, often leaves small temporary to permanent rockpools (the latter especially in gorges). Such events may occur in either summer or winter but winter rainfall is usually insufficient to cause significant flows in the larger river channels. More substantial rain events, primarily in late summer, result in catastrophic floods, with peak flows frequently in the $100 \mathrm{~s}$ to $1000 \mathrm{~s} \mathrm{~m}^{3} \cdot \mathrm{s}^{-1}$ in lowland reaches of larger rivers. The hydrographs of these scouring floods have very steep rising limbs (lasting only days after a cyclone) with declining flows that last for a few weeks, before the rivers recede to numerous temporary to permanent river pools. Rivers tend to be broad (up to a kilometre in width in lowland areas) and frequently have braided low-flow paths, mostly within the banks of a single channel. Some smaller creeks, especially in the broader valleys and coastal plains, contain highly turbid billabongs and are herein referred to as 'turbid pools'. Permanent pools usually occur where bedrock structures impede hyporheic groundwater flow, where springs discharge groundwater or where cliffs cause flow to scour pools that are sufficiently deep and shaded to persist. Groundwater discharge at springs also creates short sections of permanently flowing creeks, sometimes within the broad channels of middle-order rivers, where they support stands of Melaleuca woodlands.

The Pilbara has few large floodplains except on the Roebourne Plains, where floodwaters from all rivers spread out, and in the middle and upper Fortescue Valley (downstream of Newman). Smaller floodplain areas include the upper catchment of Duck Creek north-west of Karijini National Park and parts of the lower Ashburton River upstream of the coastal plain. In floodplain areas, claypans and clay flats retain water after floods but some also receive water from feeder creeks and local runoff when broadscale flooding does not occur. Claypans are usually small, shallow and ephemeral, although the larger ones retain water for many months after flooding. A regionally significant and very large floodplain wetland is the Fortescue Marsh, which is a terminal wetland for the upper Fortescue River, $100 \mathrm{~km}$ long, bounded downstream by the Goodiarie Hills.

\section{Drainage basins}

There are five drainage basins in the Pilbara (Figure 1). The Ashburton River is $700 \mathrm{~km}$ long and drains the southern slopes of the Hamersley Range and northern slopes of ranges to the south

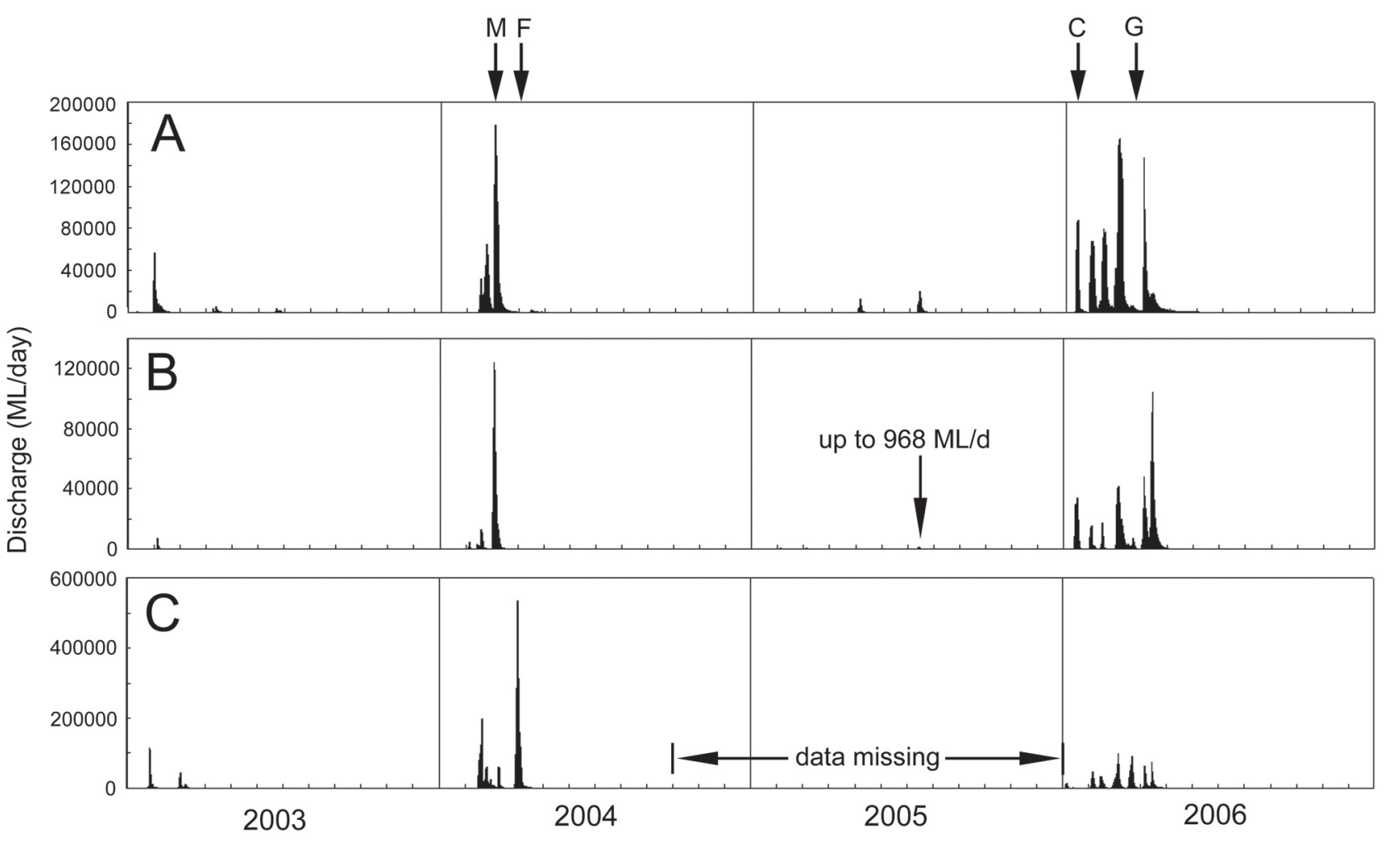

Figure 2 Daily discharge for the period 2003 to 2006 for A, lower Ashburton River at Nanutarra; B, lower Fortescue at Gregory Gorge; and C, lower De Grey River at Coolenar Pool. Arrows above the graphs indicate timing of cyclones ( $\mathrm{M}=$ Monty; $\mathrm{F}=$ Fay; $\mathrm{C}=$ Clare; $\mathrm{G}=$ Glenda). 
of the Pilbara, such as the Collier and Kenneth Ranges. For most of its length it consists of only one main channel supplied by numerous, mostly short $(50-200 \mathrm{~km})$ tributaries. The main channel contains many large permanent pools (e.g. sites 49 and 53).

The Cane and Robe Rivers, flowing off the western-most slopes of the Hamersley Range, dominate the Onslow drainage basin, along with a few smaller channels that mostly contain water only in turbid pools (e.g. site 14) and do not reach the coast as defined channels. The Robe catchment contains a number of springs in river channels such as sites 15 and 16 .

The Fortescue River, $700 \mathrm{~km}$ long, has few significant tributaries and drains the southern slopes of the Chichester Range and the northern and far eastern slopes of the Hamersley Range. The upper Fortescue is essentially endorheic, terminating at the large, brackish to mesosaline Fortescue Marsh (sampled at sites 2 and 3, Figure 1), but with floods also spreading out to the east of the marsh and filling claypans and small creek pools, such as sites 41 and 42 . The marsh would have to be at least $13 \mathrm{~m}$ deep to overflow through the Goodiarie Hills downstream of the marsh and that has never been recorded. The Fortescue thus arises anew downstream of the marsh, where tributaries running off the slopes of the middle Hamersley and Chichester Ranges (e.g. site 94) flow into a valley containing several claypans (e.g. sites 4 and 40). This middle section of the Fortescue is poorly defined, with a braided channel. Farther downstream, the river receives perennial groundwater input from springs (e.g. sites 11 and 13) and the beds of deep permanent pools (e.g. sites 10 and 12) as it passes through the south-western tip of Millstream National Park, after which the lower Fortescue is again a well-defined single channel with numerous permanent pools (e.g. site 76).

Numerous relatively short rivers, such as the Maitland, Sherlock and Yule, form the Port Hedland Coast Basin to the north of the Fortescue Basin. The longer of the rivers arise on the northern slopes of the Chichester Range and flow across the broad Roebourne Plain, while others have ill-defined headwaters on the plain's clay flats. The lower reaches of the Port Hedland Coast rivers contain pools that are clear and spring-fed (site 56), tidally influenced (site 18) or turbid (site 79), while in the Chichester Range the rivers contain numerous springs (site 55). Some shallow pools occur on the rocky Burrup Peninsula near Karratha (e.g. sites 75 and 77).

The large De Grey River Basin occupies most of the eastern third of the Pilbara and includes several major sub-catchments (Oakover, Shaw, Coongan and Nullagine) that form the De Grey River channel after the Oakover-Nullagine confluence.
These major tributaries drain the eastern Chichester Ranges and numerous minor ranges within the basin. The Oakover has some small tributaries arising from the Isabella and Gregory Ranges (site 62) that form the eastern boundary to the Pilbara. Few off-channel wetlands occur in the basin, other than near the lower De Grey (site 35), so springs (site 63) and river pools (site 57) predominate.

Finally, several pools and springs in river channels (sites 27 to 29) in the Rudall River catchment were sampled. This system lies in the Great Sandy Desert Basin to the east of the Pilbara.

\section{METHODS}

\section{Site selection}

In this study, a 'site' refers to a reach or segment of wetland about $200 \mathrm{~m}$ long. Most wetlands were small enough to be confident that the site sampled included all of the major habitats present at the wetland. A total of 100 sites in 98 wetlands were selected to represent the diversity of wetlands present within each drainage basin, with sites distributed across all stream orders and along the length of the major channels (Table 1, Figure 1).

\section{Sampling}

A total of 189 samples were collected from the 100 sites between spring 2003 and spring 2006 (Table 1). Most sites were sampled once in autumn (late April to early June) and once in spring (mid August to late September), except for a few ephemeral sites sampled in late summer after flooding. While this regime was chosen in order to sample both the post-wet season (autumn) and the dry season (spring), a dry summer in 2004/5 and a wet winter in 2005 meant that rainfall patterns during the survey were not entirely representative of long-term annual patterns. Most sites were sampled either in spring and the following autumn (43 sites) or vice-versa (13 sites) (Table 1$)$. The rest were sampled with more than 12 months between samples, either in spring and then autumn (23) or vice-versa (5) or were sampled in spring and the following late summer (2 sites) or vice-versa (1 site), or were sampled in one season only (5 in autumn, 1 in spring and 5 in late summer).

Of the wetlands sampled (Table 1), 18 were claypans and flooded clay flats, ranging from those that were very small $(<0.25 \mathrm{ha})$, shallow $(<$ $20 \mathrm{~cm}$ ) and ephemeral to larger, deeper examples that would hold water for many months after flooding. Eighteen were flowing springs and/or spring-fed creeks. Forty-one were river pools with clear water and coarse sediments and another nine were turbid pools with clay sediments, the latter mostly in smaller creeks. There were also 


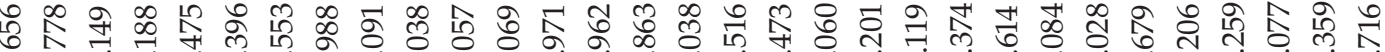

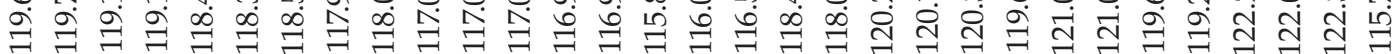

䒘各 तิ त्र

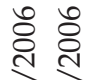

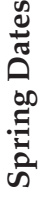

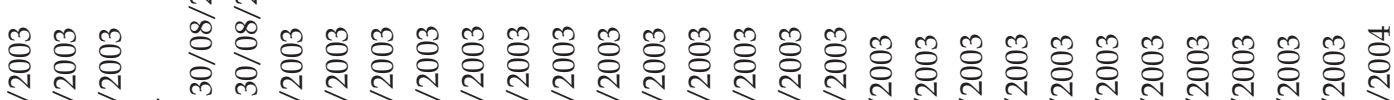

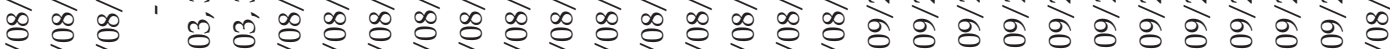

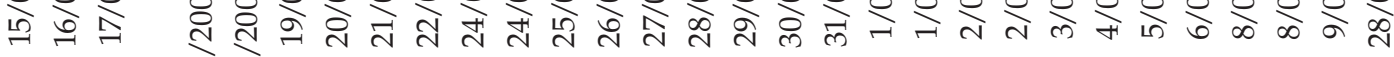
$\infty$

$\stackrel{\infty}{\infty}$

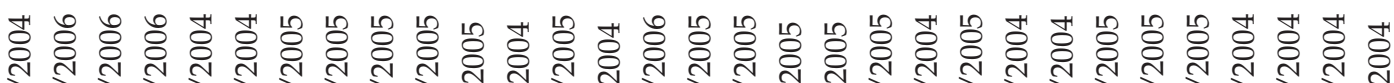

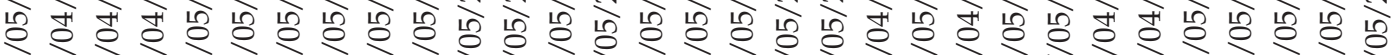
ले ले

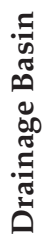

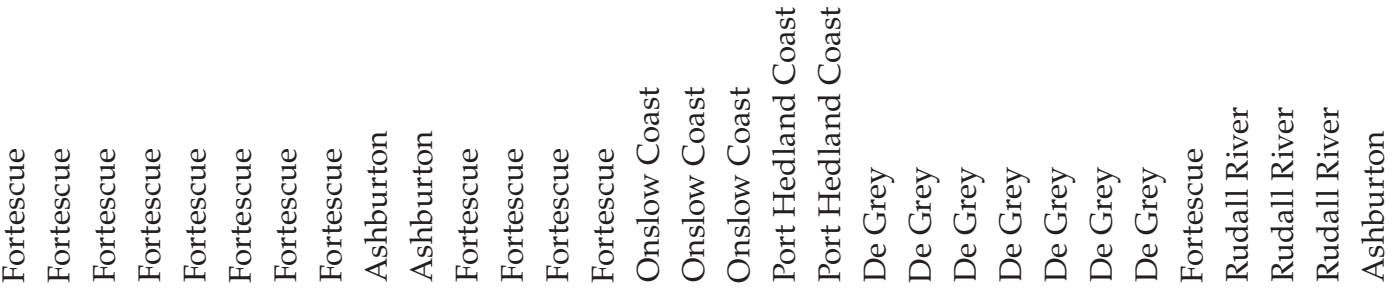

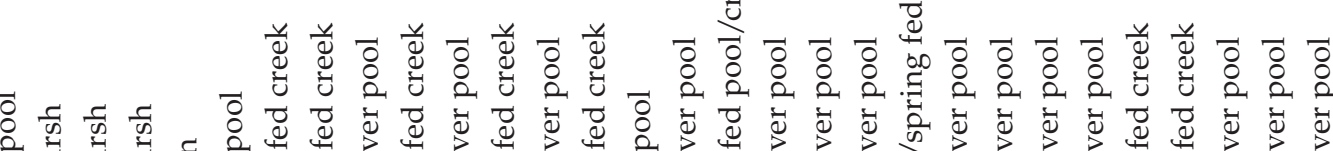

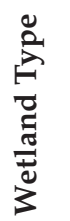

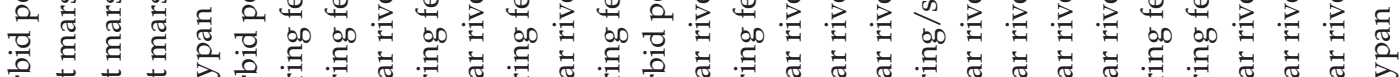

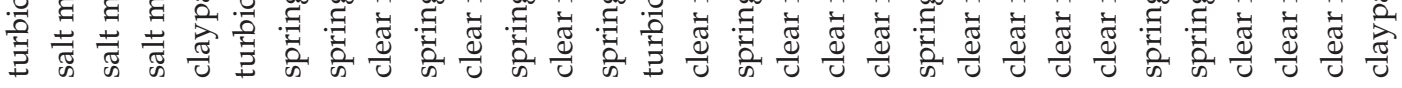

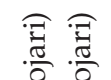

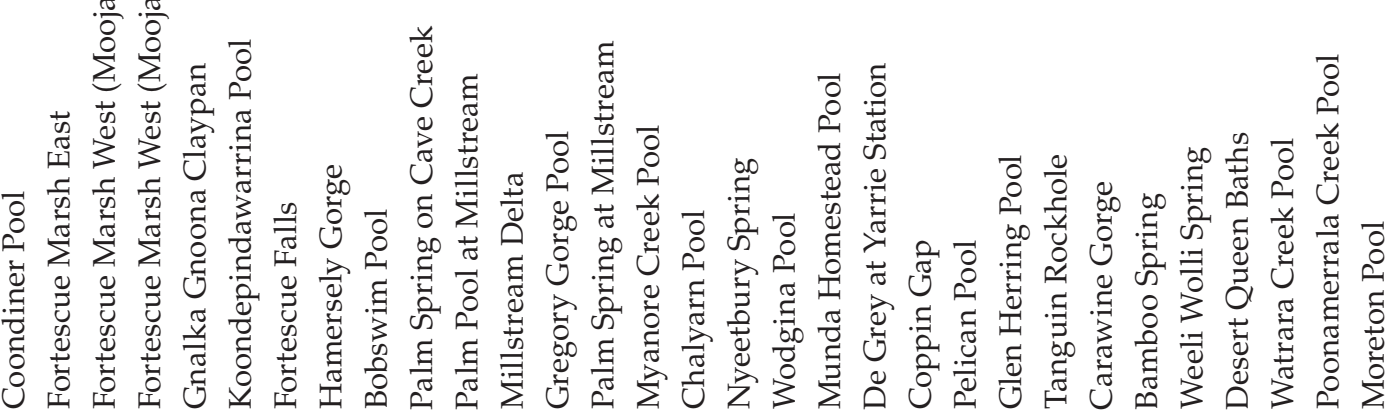




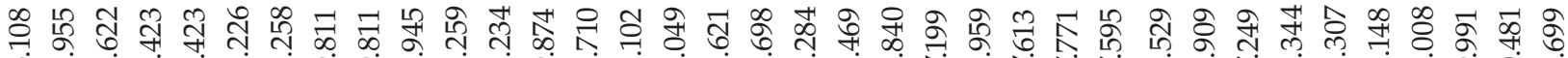

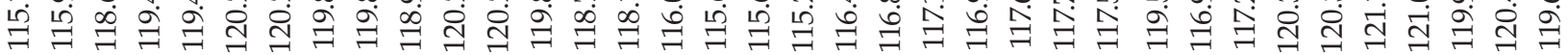

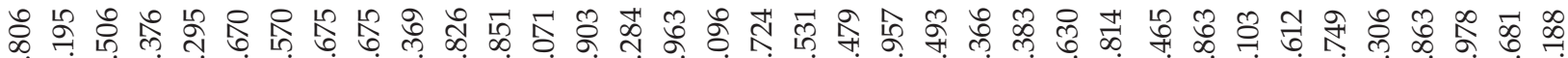

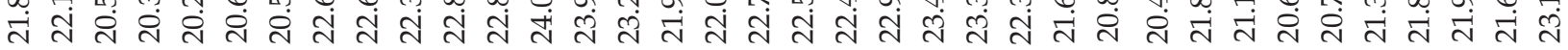

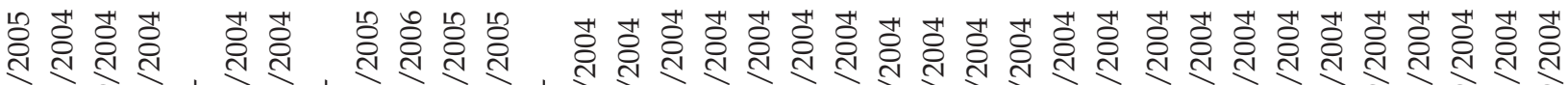

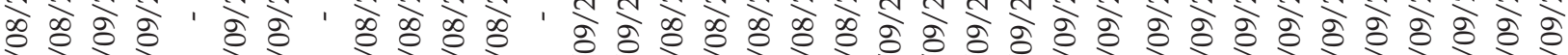

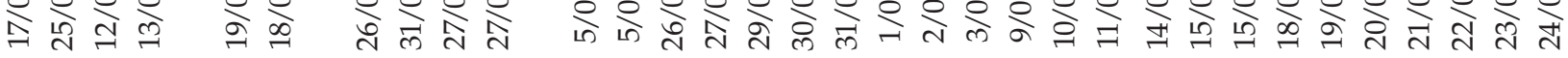

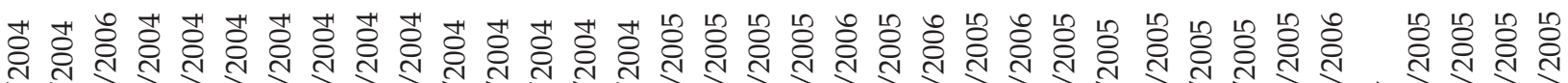

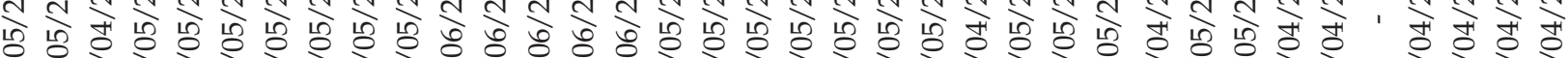

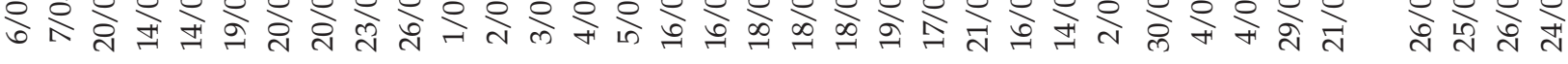

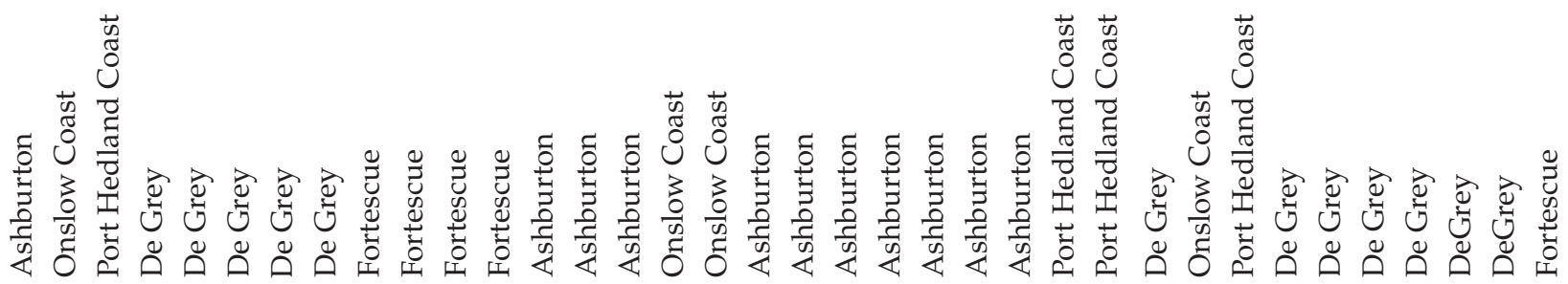
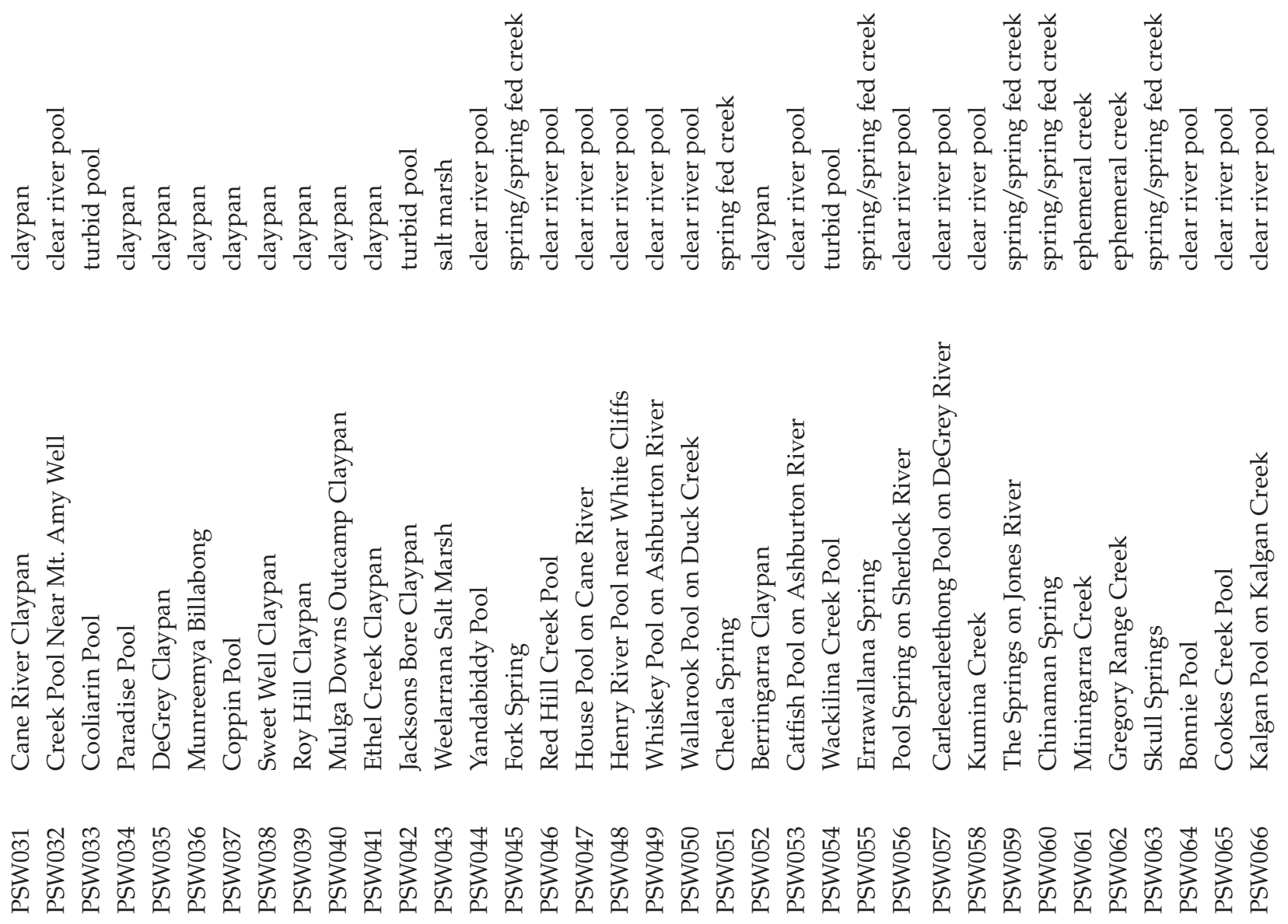


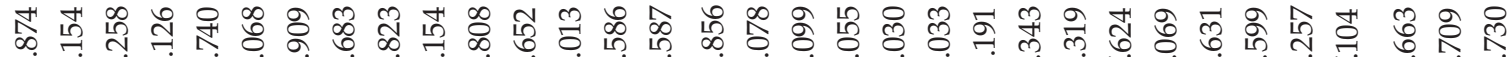

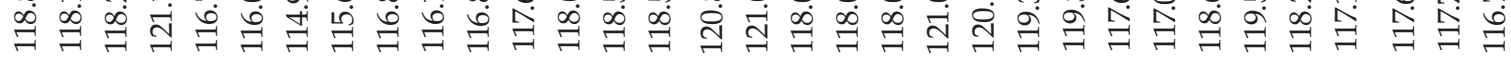

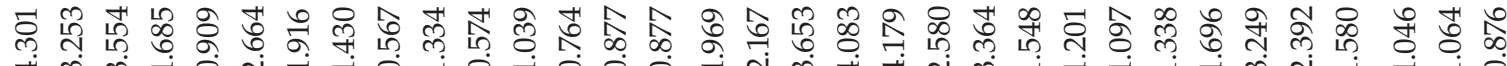

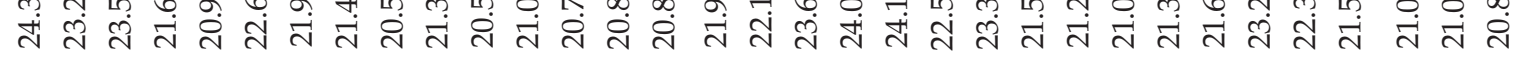

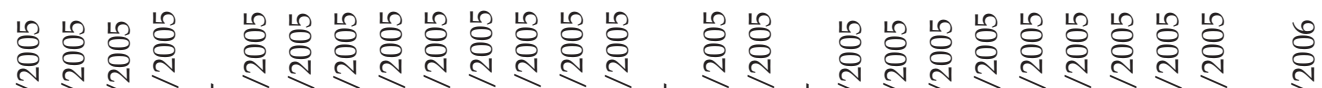

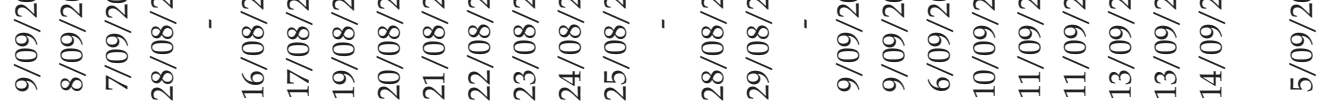

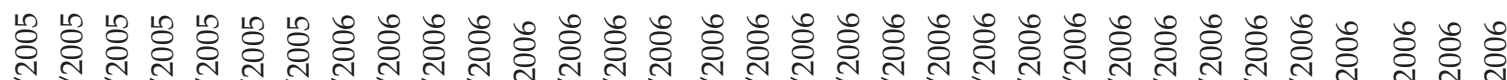

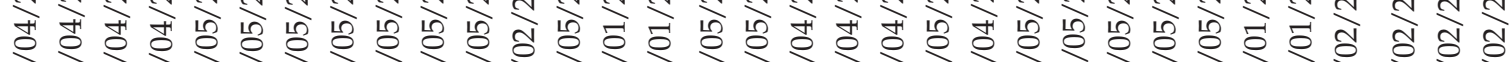

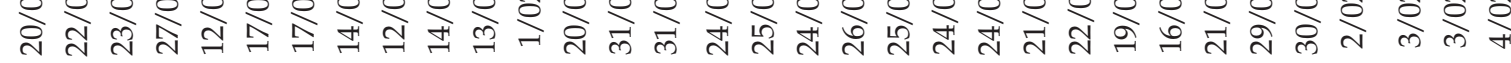
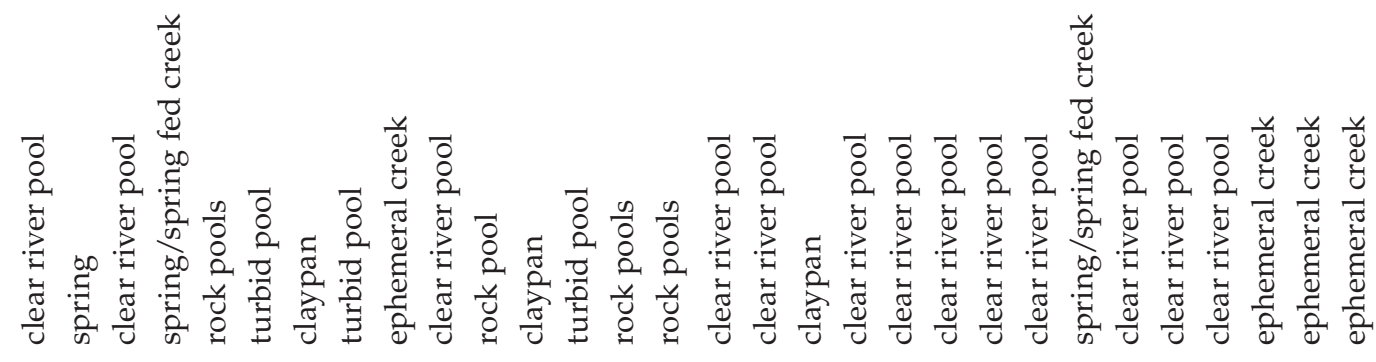

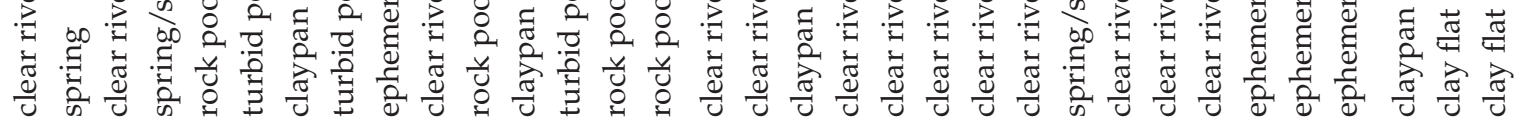

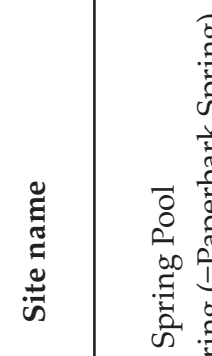

$\frac{\pi}{2} \frac{\pi}{8}$

के

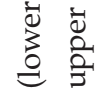

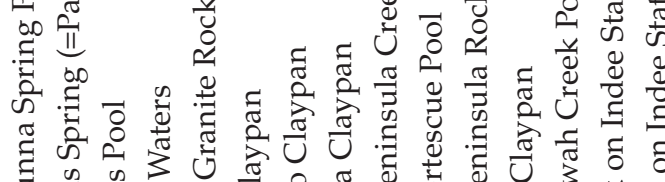

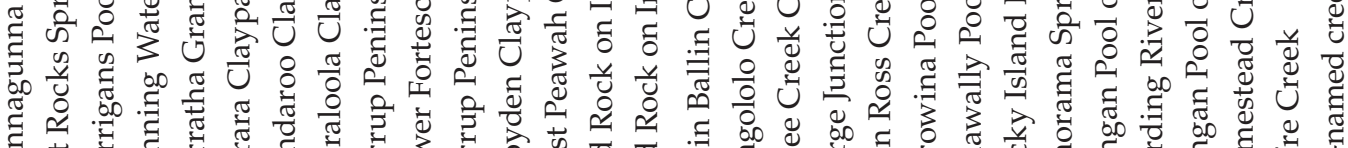

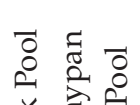

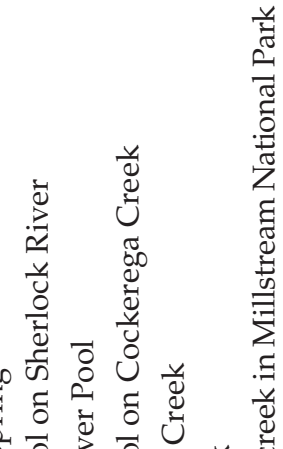

的 $\frac{\pi}{\pi} \frac{\pi}{\frac{\pi}{\pi}}$

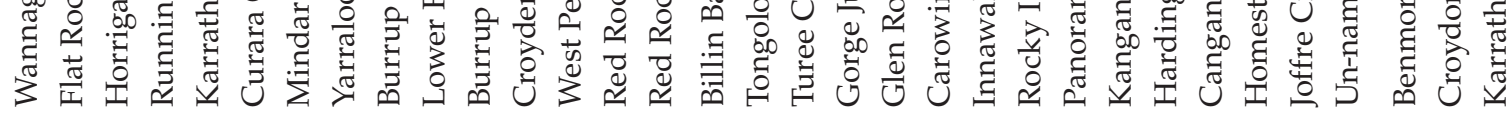

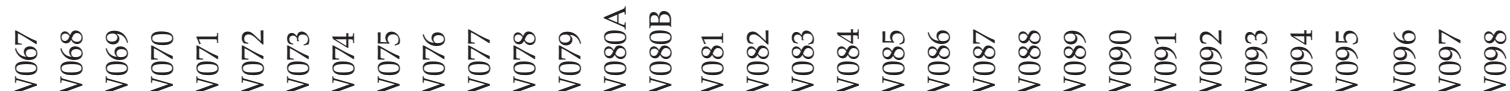

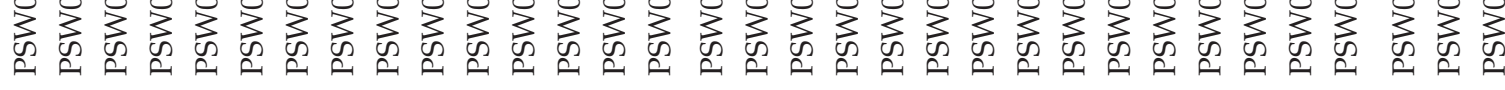


six ephemeral creeks, four rockpools (or groups of pools) on granite or basalt outcrops, and two salt marshes (three sites at Fortescue Marsh and one in Weelarrana Marsh).

On each sampling occasion, two invertebrate samples were collected: one benthic sample using a $250 \mu \mathrm{m}$ mesh net to sample the major habitats within wadeable depth (e.g. open water, sediments, detritus, submerged vegetation and streambed of flowing areas, where present), and a plankton sample using a $50 \mu \mathrm{m}$ mesh net to sample the water column and submerged vegetation in the same area as the first sample. Each sample involved sweeping for a total of $50 \mathrm{~m}$ (usually not contiguous). The benthic samples were preserved in $100 \%$ ethanol while the plankton sample was preserved in buffered formalin. All samples were sieved and sorted in the laboratory under dissecting microscopes and representatives of each taxon seen during sorting were removed and preserved in $100 \%$ ethanol. The entire content of each sample was sorted.

Conductivity and $\mathrm{pH}$ were measured in the field with a handheld meter. Depth was recorded as the maximum depth at which invertebrates were sampled (usually $<1.5 \mathrm{~m}$ ). Other than deep river pools, this approximated the depth of the wetland.

Water samples were collected approximately $15 \mathrm{~cm}$ below the water surface for laboratory analysis of total dissolved solids (American Public Health Association [APHA] method 2540C, 21 $1^{\text {st }}$ ed.), nephelometric turbidity (using a Hach Model $2100 \mathrm{~N}$ turbidimeter), colour (spectrophotometric absorbance at $465 \mathrm{~nm}$ in a $4 \mathrm{~cm}$ cell compared to platinum-cobalt standards), alkalinity (titration), hardness (calculated from concentrations of $\mathrm{Ca}^{2+}$ and $\left.\mathrm{Mg}^{2+}\right), \mathrm{Cl}^{-}$(measured colorimetrically using APHA method 4500-Cl- E $21^{\text {st }}$ ed.), $\mathrm{HCO}_{3}{ }^{-}$and $\mathrm{CO}_{3}{ }^{2-}$ (acid titration), other major ions including silica (by inductively coupled emission spectroscopy), total filterable nitrogen and phosphorus (persulphate oxidation and colorimetric determination) and filterable nitrate/nitrite (colorimetric determination after conversion of nitrate to nitrite). The concentration of total dissolved solids was used as a measure of salinity, except for some highly turbid waters where sum of major ions was used due to inability to remove suspended particulates. Samples for nutrient analyses were passed through a filter paper of pore size $0.45 \mu \mathrm{m}$ and frozen in the field, except for highly turbid samples, which were frozen unfiltered and centrifuged prior to analysis. Chlorophyll ' $a$ ', ' $b$ ', 'c' and phaeophytin 'a' were measured (APHA method 1020, 21 ${ }^{\text {st }}$ ed.) from phytoplankton retained on glass-fibre paper after filtering at least $500 \mathrm{ml}$ of water. Chlorophyll fractions were combined for analysis.

Percentage areal cover of submerged plants was estimated for each plant community type across the area sampled for invertebrates and the values summed to give a total for the site. Plant community type here refers to gross differences in composition and density (e.g. 'sparse Chara' versus 'dense Chara' or mixed 'Potamogeton/Myriophyllum' at a single site). Biomass was sampled by removing living material (excluding roots) from six $25 \times$ $25 \mathrm{~cm}$ quadrats within each submerged plant community and washing to remove dead and inorganic material. Quadrats were selected by repeatedly throwing a square metal frame into the plant community several meters away from the thrower. These samples were air dried in the field

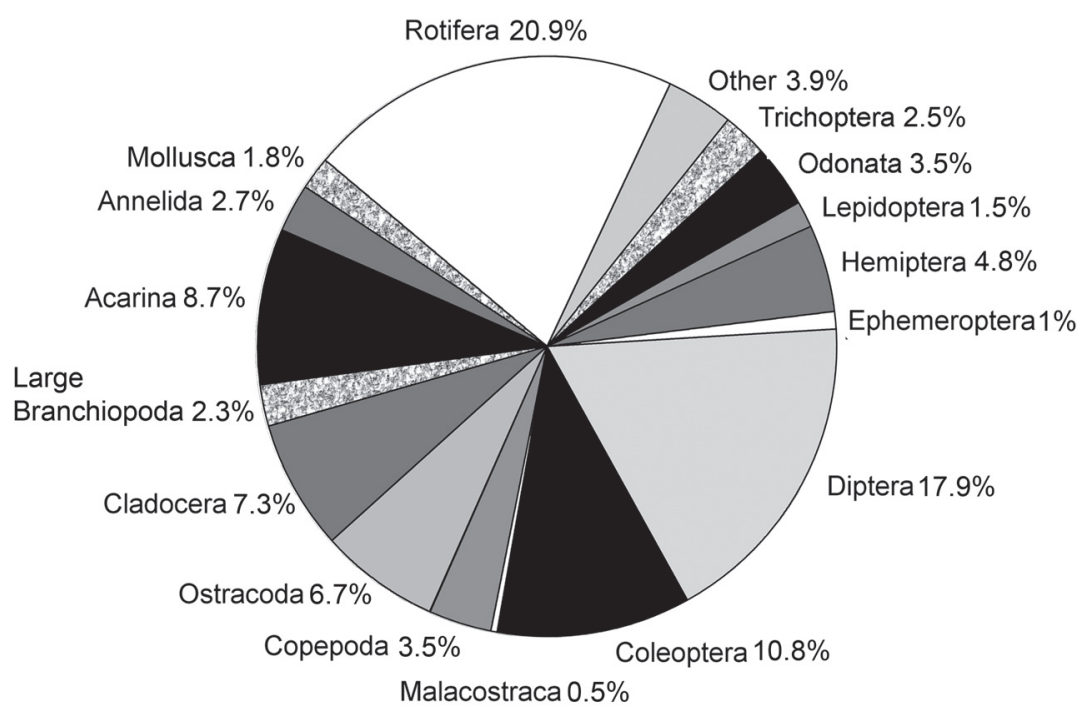

Figure 3 Relative species richness of the Pilbara aquatic invertebrate fauna by major taxonomic group. 

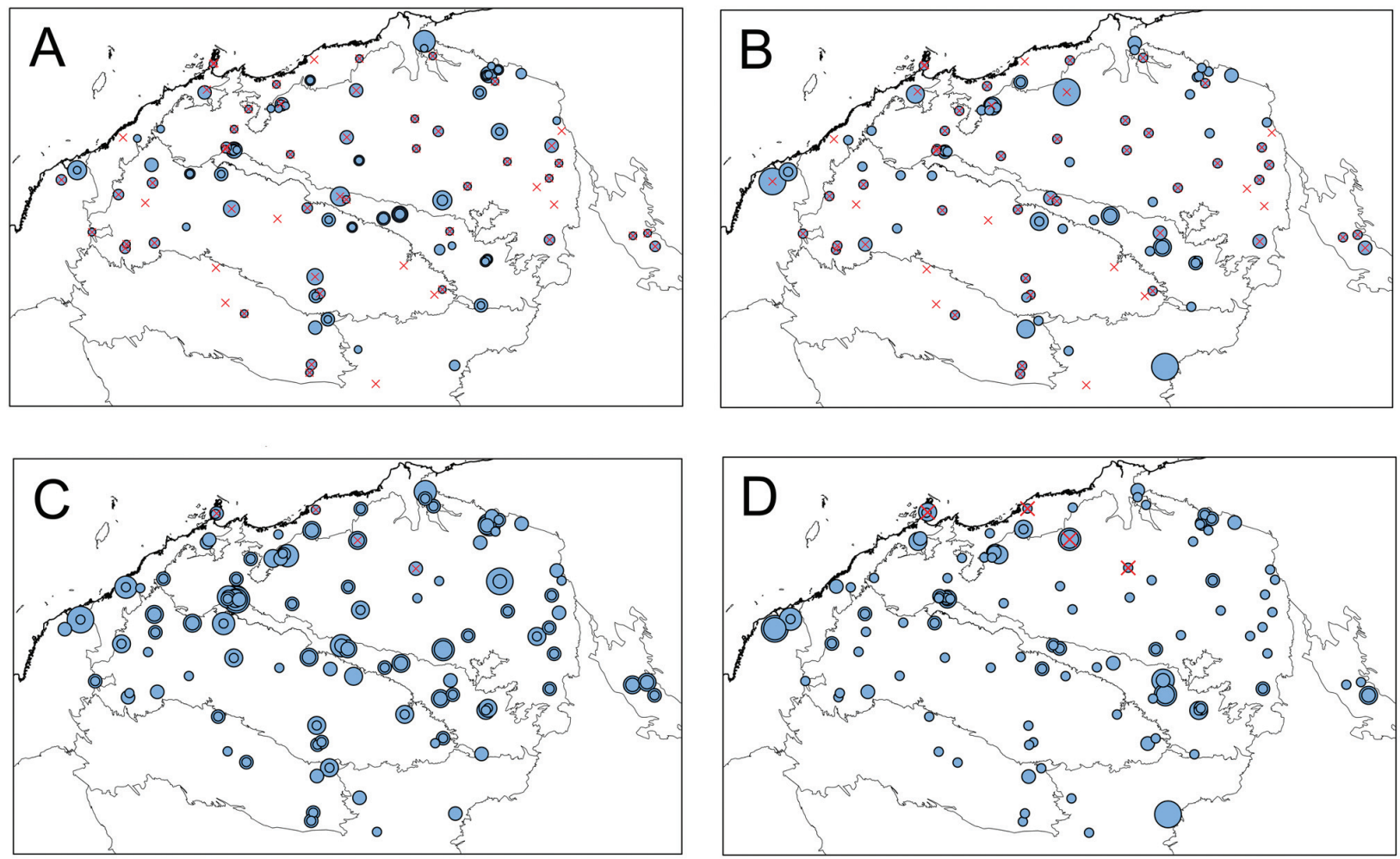

Figure 4 Richness and proportional richness of rare taxa per sample: A, richness of singleton taxa $($ maximum $=6)$; $B$, richness of singleton taxa as a proportion of total richness in the sample (maximum $=13 \%$ ); $\mathrm{C}$, richness of taxa with $\leq 5$ records (maximum $=21$ ); $\mathrm{D}$, richness of taxa with $\leq 5$ records as a proportion of richness in the sample (maximum $46 \%$ ). Symbol size is proportional to richness or proportion of richness and samples with no relevant taxa are represented by an ' $x$ '. Lines on maps are IBRA regions. Some small symbols are hidden by larger symbols representing a different season at the same site.

within calico bags, dried at $100^{\circ} \mathrm{C}$ for $48 \mathrm{~h}$ in the laboratory and weighed to the nearest $0.01 \mathrm{~g}$. Dry weight of each community type was then scaled according to the estimated percent coverage of that community (as above), and scaled dry weights of all communities were summed to estimate submerged plant biomass per $\mathrm{m}^{2}$. Percent areal cover of emergent plants was estimated for the whole site. Percentage cover of emergent macrophytes across the area sampled for invertebrates was also estimated by eye.

Percentage areal cover (at the bed surface) of three substrate classes was estimated in the field (bedrock+boulder, cobble+pebble and fine sediments). At least $500 \mathrm{ml}$ of sediment was collected from several points within the area(s) of fine sediments and this was analysed in the laboratory for particle size composition (gravel $=2$ to $\leq 32 \mathrm{~mm}$, sand $=0.02$ to $\leq 2 \mathrm{~mm}$ and silt+clay $=<$ $0.02 \mathrm{~mm}$ ). The percentage of each of these fine size classes was scaled by the estimated percent areal coverage of fine sediments in the field. Sediments from some wetlands were sampled only in one season if it could be safely assumed that sediment composition had not changed (e.g. claypans).
Organic content within the fine sediments was determined by Metson's colorimetric modification of the Walkley and Black method (Metson 1956).

Strahler stream order (Strahler 1952) and distances between wetland stream channels (for lotic sites) were determined from 1:250,000 topographic maps. Straight-line distance from coast and geodesic distances between sites were calculated using GIS software. Altitude was determined using site localities and a digital elevation model and these were used to calculate climate variables using Anuclim (Australian National University 2000). In the absence of hydrological data for most wetlands, wetlands were assigned subjectively one of four permanency values. These were $1=$ ephemeral (wetland would be dry for much longer periods than wet in most years), 2 = seasonal/episodic (would retain water for extended periods after flooding but would dry out in most years), $3=$ near permanent (wetland would retain water all year in most years but would dry out during prolonged dry periods), $4=$ permanent (wetland would never dry out under current climatic regime). Characteristics of pools used to assign wetlands to a hydroperiod class 
included local knowledge, depth, size, setting (e.g. within a gorge or exposed), presence of springs and/or barriers to hyporheic flow.

\section{Invertebrate identification}

Invertebrates from the benthic and plankton samples were combined prior to being identified to species level. Morphospecies names were assigned to undescribed species or to species that were represented only by immature stages that could not be associated with described adults. The taxon code listed in Appendix 2 is a phylogenetically based system maintained by the Victorian Environmental Protection Authority. All identifications are consistent with a survey of the Wheatbelt region of WA (Pinder et al. 2004) and most (other than the dipterans) are consistent with a survey of the southern Carnarvon Basin (Halse et al. 2000). Consistency of identification was achieved by the use of a voucher collection consisting of specimens verified or determined by specialists (see Acknowledgements) with the notable exception of dipterans. While most cladocerans and rotifers have been identified to species level, some are associated only tentatively with named species and further work is required to resolve these identifications.

\section{Data analysis}

\section{Sampling efficiency}

Three sites (a claypan, a river pool and a spring) were sampled by taking five replicate $10 \mathrm{~m}$ sweeps rather than one $50 \mathrm{~m}$ sweep for both plankton and benthos in order to estimate sampling efficiency, with each $10 \mathrm{~m}$ sample being taken through the same combination of habitats. Both regional and wetland sampling efficiency was analysed using the EstimateS software (Colwell 2004) to run the Chao2 species richness estimator adapted from (Chao 1987) and the ICE estimator (Incidence-based Coverage Estimator) adapted from Lee and Chao (1994).

\section{Diversity}

Sample richness (alpha diversity) refers to the number of species recorded at a wetland on a particular date. Beta diversity is the rate of species turnover between sampling events. Whittaker's $B_{w}$ was used as a measure of beta diversity because of its simplicity, robustness to inconsistencies between datasets, such as alpha richness and sample size (Wilson and Shmida 1984), and usefulness for presence/absence data and measuring 'overall' regional beta diversity rather than changes in species turnover along a gradient (Wilson and Shmida 1984; Magurran 2004). Regional richness refers to the number of species collected during the whole survey or estimated to occur in the region.

\section{Community composition and broadscale factors}

Non-metric multidimensional scaling (nMDS, 50 starts) and analysis of similarity (anosim) routines in Primer (Primer-E Ltd. 2008) were used to examine relationships between wetland community composition and a priori wetland type, stream order, season, hydroperiod class, IBRA subregion and drainage basin. Primer's Bray-Curtis similarity index was used and the anosim analyses were run with 999 randomisations. Combinations of wetland type and IBRA subregion or drainage basin with few representatives ( $<4$ samples) were excluded to avoid the effects of outliers. Twodimensional ordinations are shown unless 3D ordinations were more informative and/or had more acceptable stress.

\section{Modelling assemblage distributions}

Several assemblages, each comprising species with similar patterns of occurrence and, presumably therefore, with similar responses to environmental gradients, were recognised from a matrix of species occurrences by sample, with species and samples ordered by hierarchical cluster analyses (un-weighted pair grouping using arithmetic averaging [UPGMA] using default beta of -0.1 in PATN 3.11, Belbin 2006). Two-step and Bray-Curtis dissimilarity indices were used for species and samples respectively. Singleton species, protozoans and some taxa, such as nematodes, likely to represent multiple species (as indicated in Appendix 2), were excluded from analyses.

Assemblages comprising species with similar environmental responses should occur at different sites as compositionally nested subsets. That is, at a location and time where environmental variables are suboptimal, the assemblage should be a species-poor subset of what it is at a location and time where environmental conditions are more favourable (McKenzie et al. 2004). For example, an assemblage of species primarily united by a physiological requirement for freshwater will be poorly represented in a brackish water site, but the species that do occur will be a subset of those occurring where water is fresher. Other species might be more likely to occur in the brackish site but they would belong to another assemblage. When such assemblages can be identified, richness-environment relationships provide insights into the environmental requirements of the component members of the assemblage. We assessed nestedness qualitatively, using nMDS ordinations to determine whether composition of each assemblage converges as richness increases (not shown). Where this was not the case, the assemblage was subdivided and each sub- 


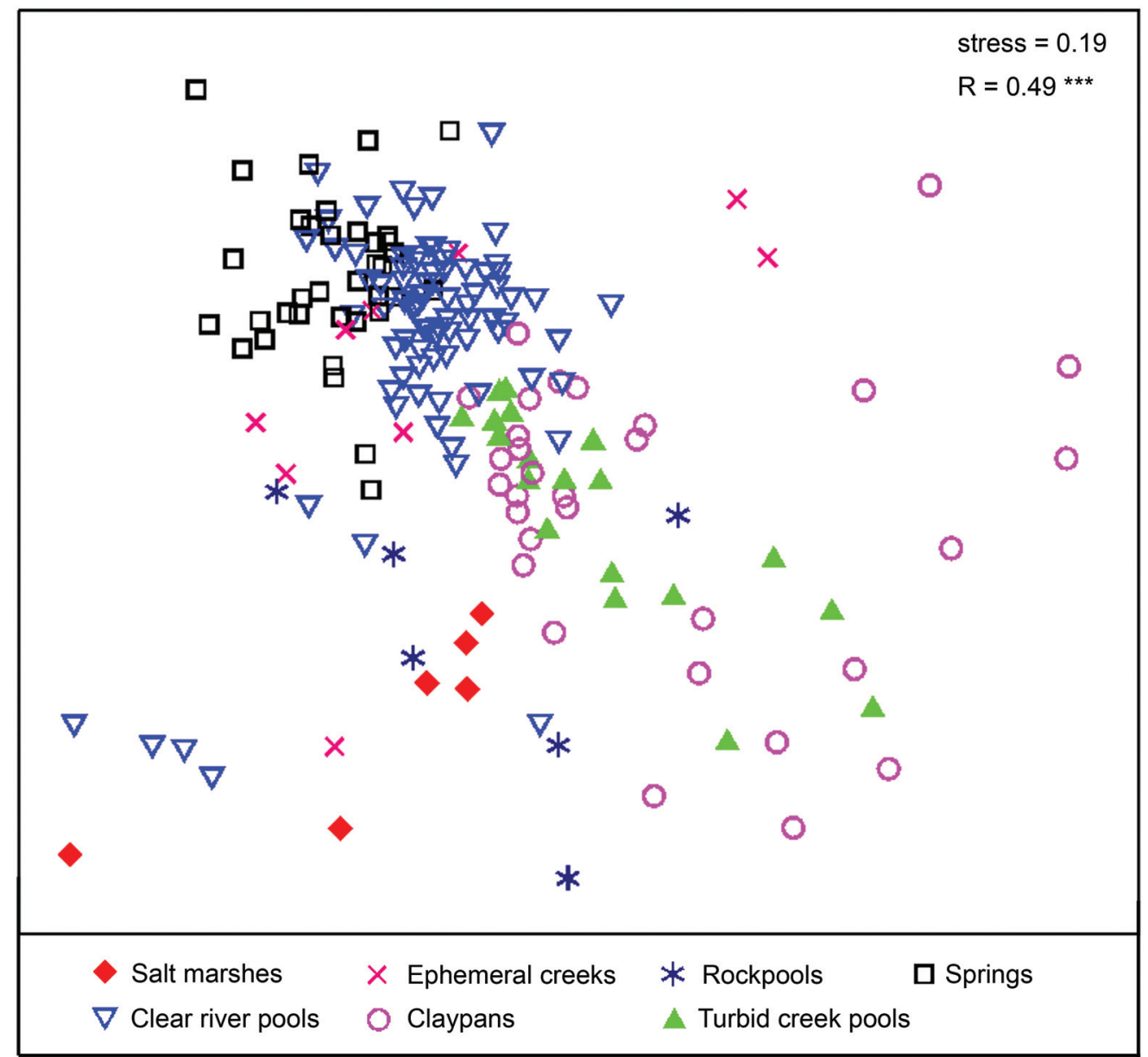

Figure 5 2D nMDS ordination of all samples according to species composition from $a$ priori wetland types as indicated, with Anosim global R and significance. Axis labels not shown because data rotated to maximize use of the space.

assemblage tested again, sometimes with the result that some or all of the original assemblage was not modeled. Leathwick et al.'s (2005) MARS package for R (R Development Core Team 2008) was used to model assemblage richness against abiotic variables (those with an * in Appendix 1). Strongly correlated variables $\left(r^{2}>0.9\right)$ were not used in the same modeling procedure. This method identifies subranges of explanatory variables, each of which has a linear relationship (determined using generalised linear models) with assemblage richness and creates a basis function for each (Friedman 1991; Hastie et al. 2001). Basis functions take the form of a coefficient multiplied by the maximum of either zero (if the measured value of the variable is outside the range of the variable in the function) or the difference between the value and a threshold representing one or other end of the function's range), for example:

$\log ($ richness $)=$ constant $x$ (maximum of ' 0 ' or 'threshold - value')

In this case, if the value of the variable is greater than the threshold then the constant is multiplied by zero, but if the value is less than the threshold then the constant is multiplied by the threshold minus the value. This means that there is a response to the variable only below the threshold.

The Leathwick and Elith routine generates basis functions for each variable and builds models using forward-stepwise addition and backwards pruning of these, with generalised cross-validation to assess model error at each step. Independent variables were allowed into the model-building process provided they showed an ecologically tenable relationship to richness in univariate plots that did not reflect outliers or gaps in sampling that would lead to over-fitting. The penalty value K (Hastie et al. 2001) was adjusted as required to give more parsimonious models. Simpler models were preferred where this did not substantially reduce adjusted $\mathrm{r}^{2}$. Variables selected by the modelbuilding process whose basis functions seemed to reflect gaps or outliers in the independent data or which had a non-significant relationship to richness $(P<0.05)$, were removed from the pool of available variables and the model-selection process re-run. 
Where more than one variable was thus removed sequentially, all were individually allowed back into the model-selection process (and the model reassessed) before a final model was produced. A Poisson error distribution was assumed for assemblage richness, and frequency plots of model residuals showed that errors did approximate Poisson distributions, albeit with greater right skew than expected. Models were assessed by calculating adjusted $\mathrm{r}^{2}$ values and 10 -fold cross-validation to provide mean and standard error estimates of the regression intercept and slope between predicted and observed richness.

\section{RESULTS}

\section{Chemical and physical features}

Water chemistry, sediment, macrophyte and climate data are provided in Appendix 1. Almost all wetlands were fresh, with salinity $>3 \mathrm{~g} / \mathrm{L}$ found only in some drying river pools, tidally influenced pools and a couple of inland salt marshes and creeks. Three-quarters of sites were dominated by sodium, largely with $\mathrm{Mg}^{2+}>\mathrm{Ca}^{2+}>\mathrm{K}^{+}$(mostly river pools and springs) or $\mathrm{Ca}^{2+}>\mathrm{Mg}^{2+}>\mathrm{K}^{+}$(mostly temporary wetlands such as claypans, shallow turbid pools in creeks and rockpools). Some claypans and turbid creek pools had $\mathrm{Na}^{+}>\mathrm{Ca}^{2+}>\mathrm{K}^{+}>\mathrm{Mg}^{2+}, \mathrm{Na}^{+}>\mathrm{K}^{+}>\mathrm{Ca}^{2+}>\mathrm{Mg}^{2+}$ or $\mathrm{Na}^{+}>\mathrm{Mg}^{2+}>\mathrm{K}^{+}>\mathrm{Ca}^{2+}$. In some of these samples, $\mathrm{Na}^{+}$ had only marginally higher concentration than $\mathrm{Mg}^{2+}$ or $\mathrm{Ca}^{2+}$. Some springs, and a few river pools, were dominated by $\mathrm{Mg}^{2+}$, either with $\mathrm{Na}^{+}>\mathrm{Ca}^{2+}>\mathrm{K}^{+}$ or $\mathrm{Ca}^{2+}>\mathrm{Na}^{+}>\mathrm{K}^{+}$. Several sites, mostly turbid pools and claypans but also a few pools and springs, were dominated by $\mathrm{Ca}^{2+}$, mostly with $\mathrm{Na}^{+}>\mathrm{Mg}^{2+}>\mathrm{K}^{+}$ or $\mathrm{Mg}^{2+}>\mathrm{Na}^{+}>\mathrm{K}^{+}$. Claypans and turbid pools tended to have higher $\% \mathrm{~K}^{+}$and lower $\% \mathrm{Mg}^{2+}$ compared to clear pools and springs, even where the order of dominance was not different. About half the sites (largely clear river pools and springs) were dominated by chloride, mostly with $\mathrm{HCO}_{3}>\mathrm{SO}_{4}{ }^{2-}$ but some with $\mathrm{SO}_{4}{ }^{2-}>\mathrm{HCO}_{3}^{-}$. Remaining sites, including almost all the claypans and turbid pools, but also some clear river pools, were dominated by bicarbonate, almost all with $\mathrm{Cl}>\mathrm{SO}_{4}{ }^{2-}$, though a few turbid creek pools had $\mathrm{HCO}_{3}>\mathrm{SO}_{4}{ }^{2}>\mathrm{Cl}$. Two
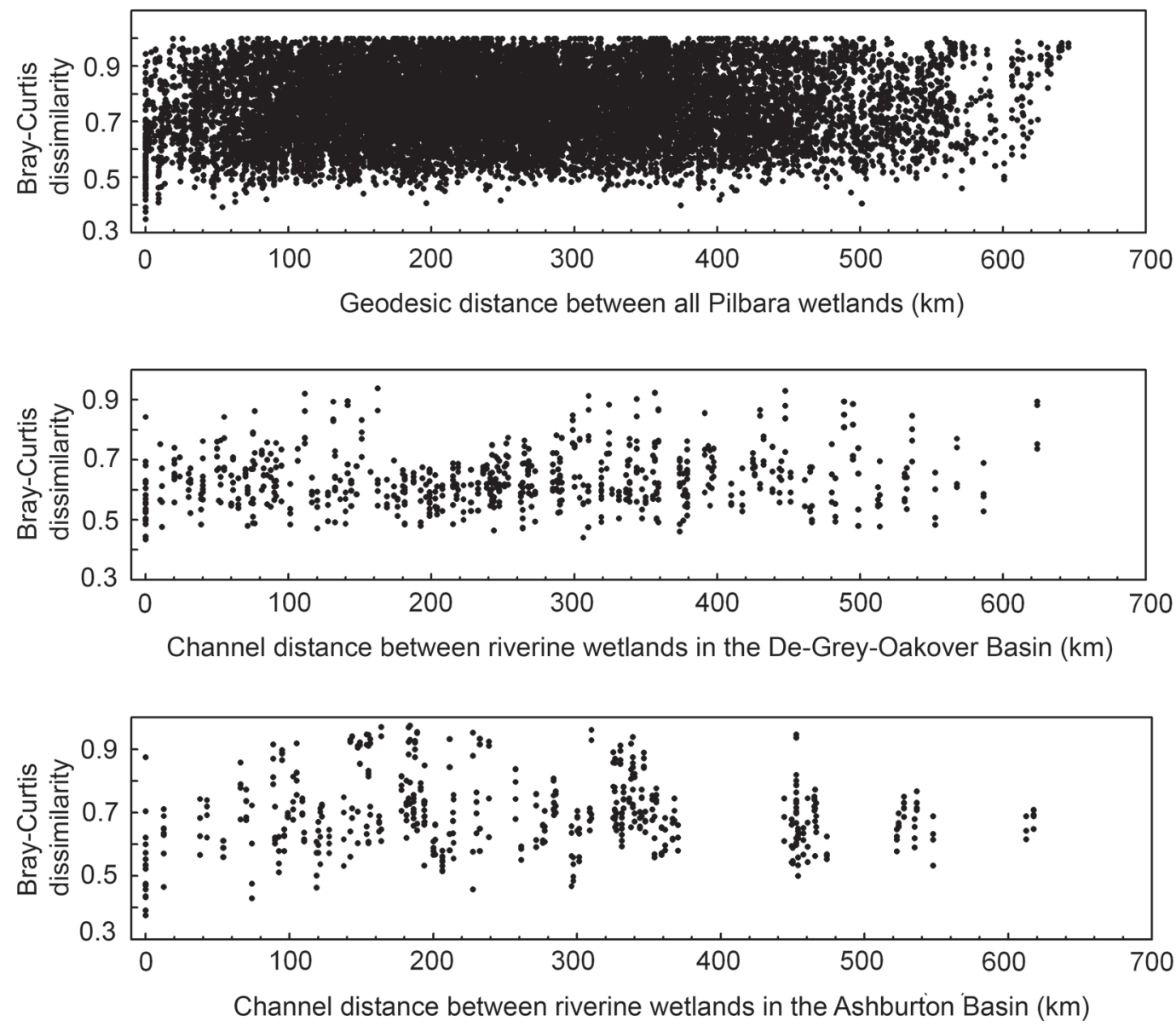

Figure 6 Bray-Curtis dissimilarity values between all samples versus: A, geodesic distance; B, channel distance between lotic wetlands in the De Grey Oakover Basin; and C, channel distances between lotic wetlands in the Ashburton Basin. 


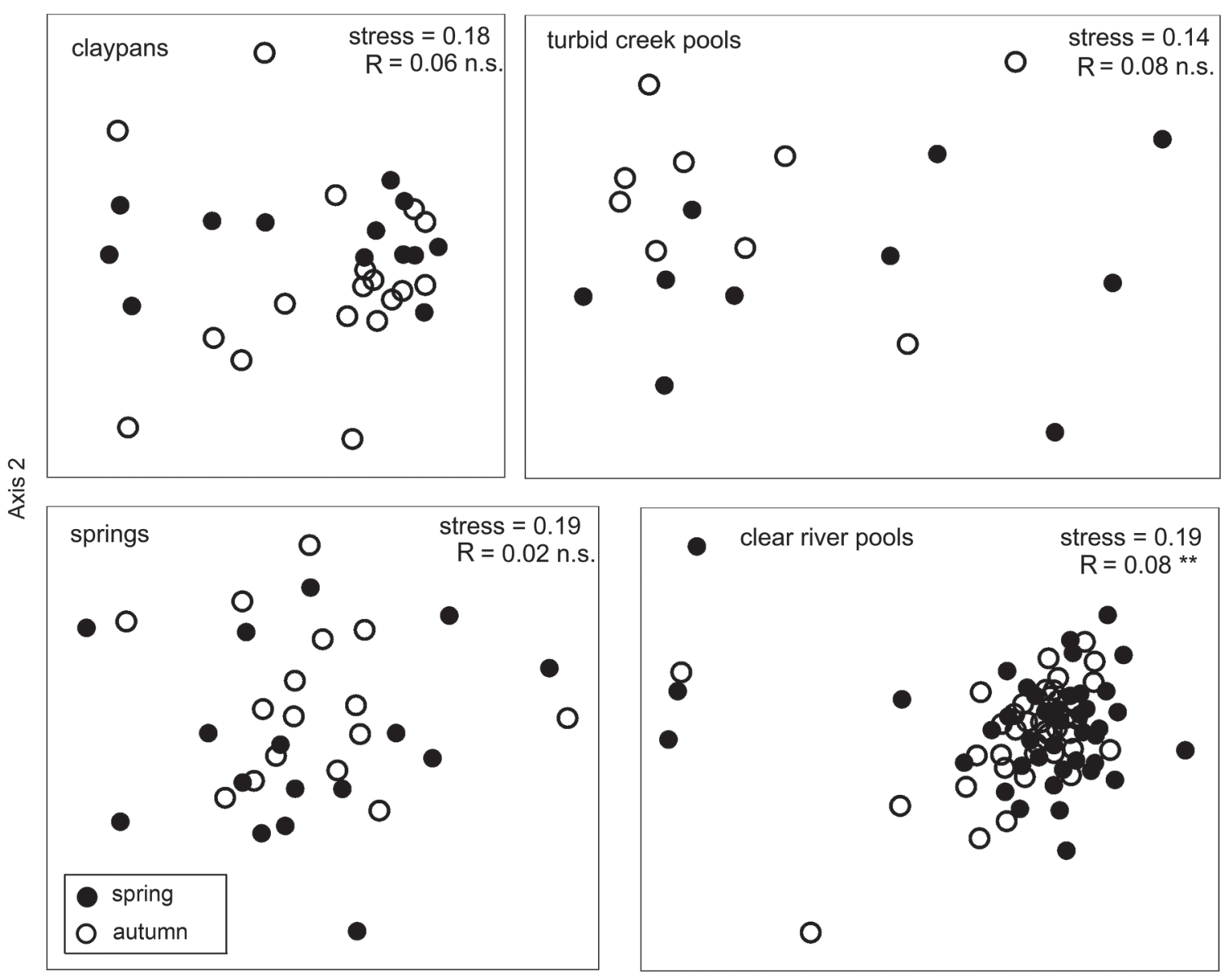

Axis 1

Figure $7 \quad 2 \mathrm{D}$ nMDS ordinations of invertebrate community composition of the four major wetland types showing autumn versus spring samples, with anosim global $R$ and significance values shown.

western Fortescue Marsh samples from site 3 had $\mathrm{SO}_{4}^{2-}>\mathrm{Cl}>\mathrm{HCO}_{3}^{-}$.

Three wetlands were marginally acidic (6.5 to 6.9) but otherwise there was an even spread of $\mathrm{pH}$ from neutral to 10.2. A wide range of turbidity was measured, with many turbid river pools and claypans having turbidity $>250$ NTU and, exceptionally, > 10,000 (maximum 200,000). Suspended solids seem to have inflated colour and total filterable nitrogen and phosphorus at some claypan sites, probably because of binding of nutrients to clay particles and incomplete removal of suspended particles through centrifugation (for samples too turbid to filter). For this reason, nutrient concentrations and colour were not used in modeling.

There are few active flow-gauging stations in the region and wetlands were visited only once or twice, hence knowledge of their hydrological regimes is sketchy. All springs had discharge, though this was too weak to measure where water was only seeping from the source. Many river pools are known to be permanent and most of those sampled are likely to retain water all year in most years. About a third of the river pools had flowing water in one or both seasons, mostly as an inflowing stream fed by groundwater or as flow from an upstream pool and/or water flowing out of the pool. Some lower-order creeks were ephemeral. Small shallow claypans are assumed to have been ephemeral, while larger examples would have been seasonal.

Sediment composition varied widely, ranging from river pools dominated by bedrock and cobbles through to more sand-dominated pools and claypans with fine sediments. Within rivers, the main change as stream order increased from one to seven was a reduction in the proportion of bedrock/boulder and a corresponding increase in cobble/pebble, gravel and sand, but not silt and clay. Sediment organic content was generally under $1 \%$, but a small number of springs had higher values where organic matter had built up around seepage areas.

Emergent macrophytes usually occupied $<10 \%$ of the sampled area but a few springs and pools 

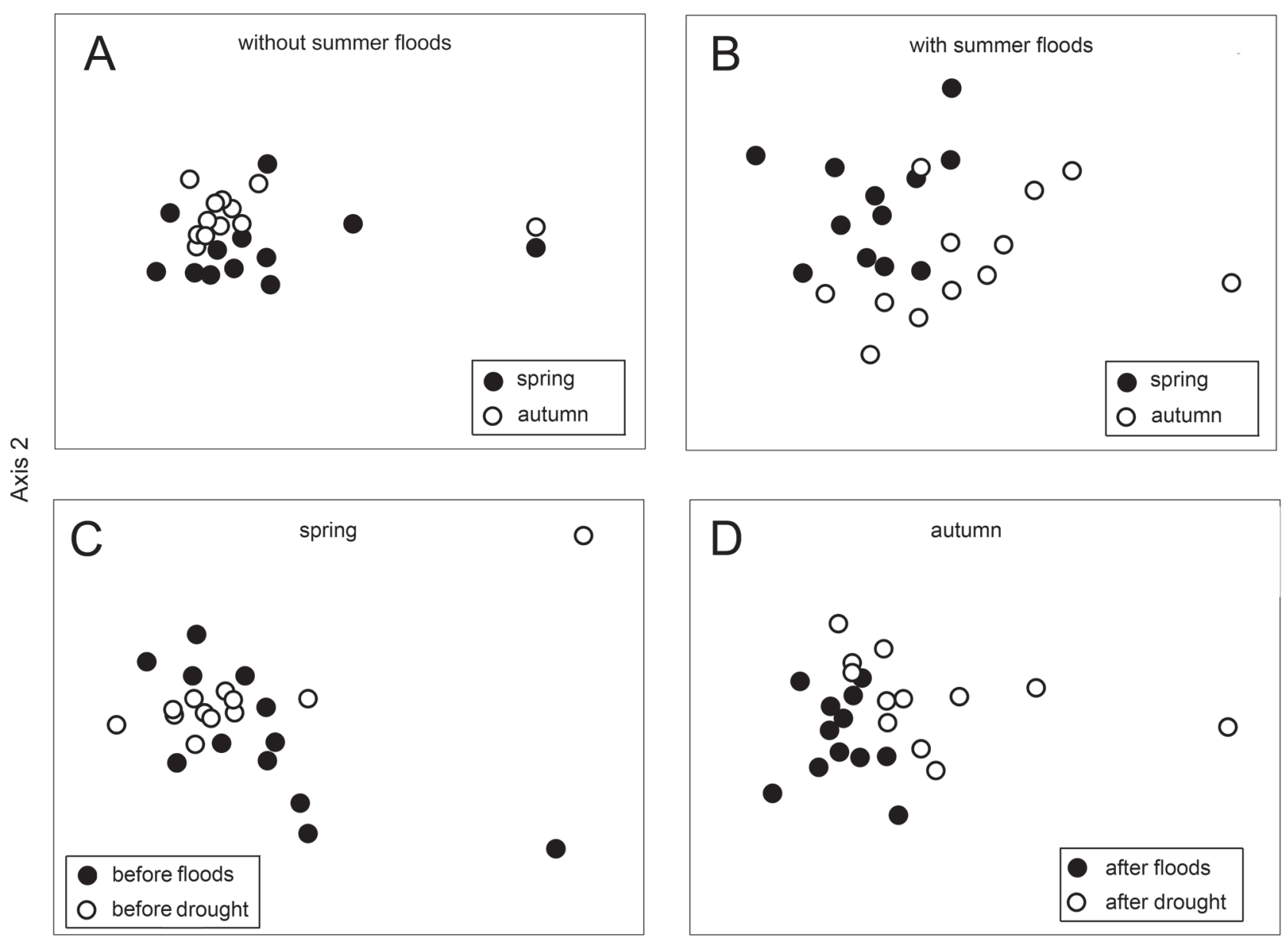

Axis 1

Figure 8 2D nMDS ordinations of: A, river pools sampled in spring and the following autumn without summer floods; $B$, river pools sampled in spring and the following autumn with summer floods; $C$, river pools sampled in spring either before a summer flood or before a summer drought; D, river pools sampled in autumn after a summer flood or after a summer drought.

(and one claypan) had emergents across > 50\% of the area sampled. The emergent vegetation of river and creek pools in the Pilbara was dominated by Schoenoplectus subulatus and Typha domingensis (M.N. Lyons, DEC, pers. comm.). These species typically formed dense beds along banks and shallower backwaters. Cyperus vaginatus and Eleocharis spp. occurred in briefly inundated sites and the shallowly inundated edges of pools and springs. Small claypans were often devoid of emergent plants. At larger examples of claypans and crab-hole flats the dominant vegetation was usually emergent grass, commonly Eragrostis benthamii but sometimes Leptochloa spp. and Pseudoraphis spinescens. Eucalyptus victrix also occurred across the bed and along the margins of some claypans.

About half of the sites had $<10 \%$ cover of submerged macrophytes and about a quarter had more than 50\% cover. Common taxa were Najas, Potamogeton, Myriophyllum and Characeae
(M.N. Lyons pers. comm.). Biomass of submerged macrophytes ranged from zero or close to it (at about half the sites) to $341.4 \mathrm{~g} / \mathrm{m}^{2}$ and was mostly under $100 \mathrm{~g} / \mathrm{m}^{2}$.

\section{Invertebrates}

\section{Sampling efficiency}

The total number of species collected in five $10 \mathrm{~m}$ sweep-net samples on one occasion from a spring (site 9), a claypan (site 31) and a river pool (site 90) were 143, 72 and 133, respectively. For these three sets of samples, species richness estimators in EstimateS produced curves that almost reached an asymptote by the fifth sample. These estimates suggested that we had collected $72 \%$ to $82 \%$ of the total richness present within the portion of each wetland sampled.

\section{Diversity}

Altogether, 1034 discrete taxa (marked with an 

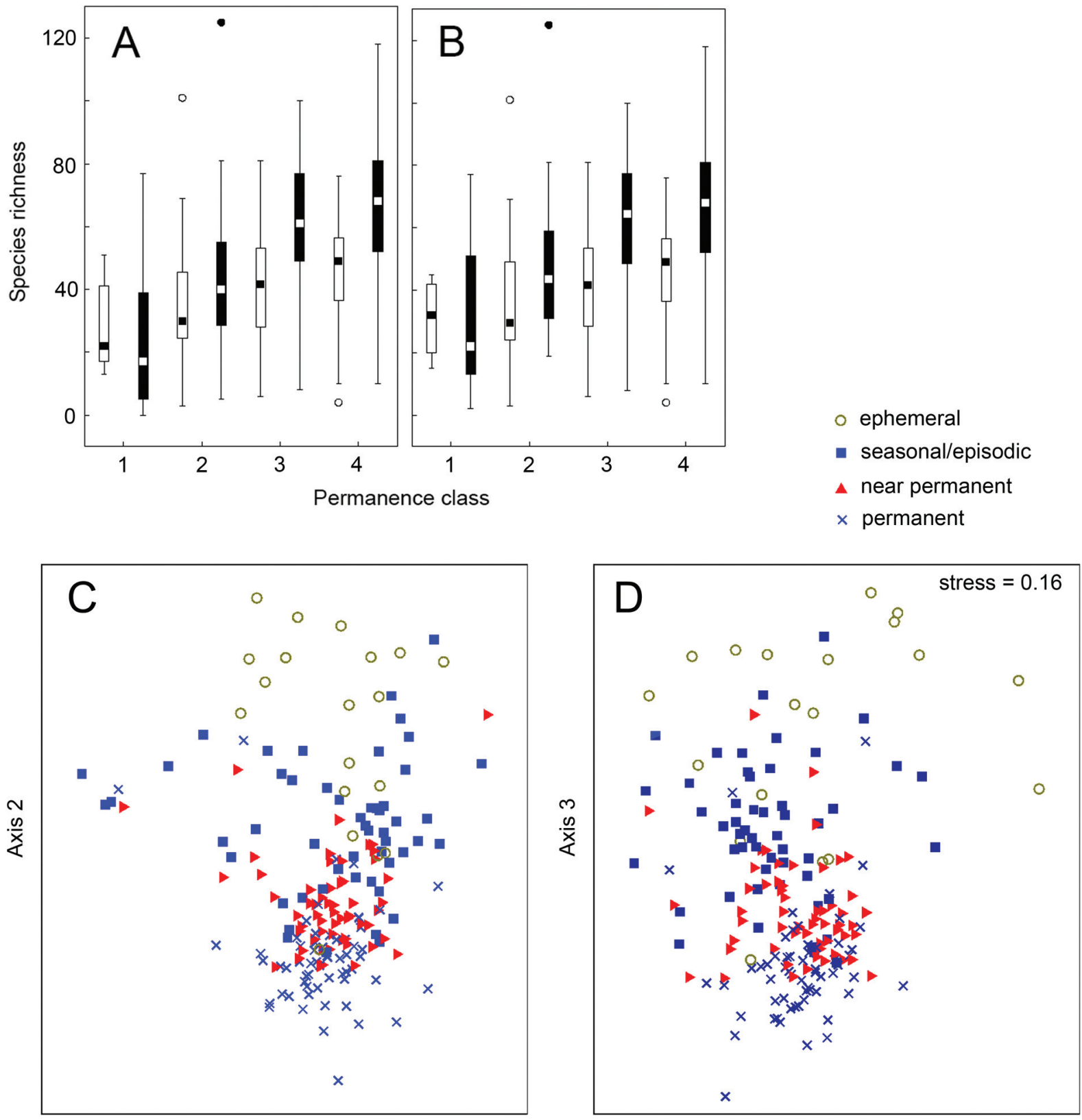

Axis 1

Figure 9 A: Box and whisker plots of species richness versus permanence category for all samples (black bars = insect richness, white $=$ non-insects); $\mathrm{B}$, same for riverine samples only; $\mathrm{C}$ and $\mathrm{D}$, axis 1 versus axes 2 and 3 of a 3D nMDS ordination of sample invertebrate composition, with samples coded by permanence class as per Appendix 1. For A and B the boxes are $25^{\text {th }}$ and $75^{\text {th }}$ percentiles with a median point, whiskers are 1.5 times standard deviation and open circles are outliers.

* in Appendix 2) were recorded during the study, though a few of these were higher taxa which undoubtedly represent multiple species. There were many specimens that could not be fully identified because they were the wrong sex or were too immature. About half the collected species are known to be described and some of the informally named larvae may also represent species described on the basis of adults. Richness per sample ranged from 14 to 226 and averaged $94 \pm 3$ (s.e.). Microinvertebrate richness (protozoans, rotifers, copepods, cladocerans and ostracods) ranged from
3 to 57 and averaged $25 \pm 0.8$. Macroinvertebrate richness (all other taxa) ranged from 4 to 170 and averaged $69 \pm 2$. Total richness at sites sampled twice ranged from 37 to 265 and averaged $147 \pm 5$. Beta diversity was $854 / 91=9.4$ for the samples taken in spring and $836 / 84=10.0$ for the summer/autumn samples. A lower $B_{w}$ of 7.2 was obtained when the two sampling occasions were combined for each site.

Regional richness was estimated to be at least 1166 (ICE) to 1217 (Chao2). The estimator curves did not reach an asymptote but the slope of the curve 
represented by the final $50 \%$ of samples was very shallow, with estimates of regional richness (and actual number of taxa collected) increasing only by about one species per additional sample after 189 samples.

Insects comprised $42 \%$ of taxa collected, mostly dipterans (17.9\%) and beetles (10.8\%) (Figure 3). Other species-rich faunal groups were rotifers $(20.9 \%)$, water mites $(8.7 \%)$ and microcrustacea: ostracods (6.7\%), copepods (3.5\%) and cladocerans (7.3\%). Leeches and leptophlebiid mayflies were notably rare. The former was represented by a single new species present at only four sites: two freshwater creeks in Rudall River National Park, an intermittent stream in Karijini National Park (Joffre Creek) and a permanent pool on the Harding River within Millstream National Park. Leptophlebiids had a similar pattern of occurrence, with Thraulus sp. AV1 occurring only at four sites in or near Millstream National Park and Atalophlebia sp. AV17 occurring only at Joffre Creek and Hamersley Gorge in Karijini National Park, although both of these species are known from outside the Pilbara (Dean 1999). Malacostracans were also rare, with just one stygal isopod (Pilbaraphreatoicus platyarthiticus), two stygal amphipods (Pilbarus millsi and Chydaekata sp.) and the atyid shrimp Caridina indistincta. Other significant records included the fairy shrimp genus Streptocephalus, recorded from one claypan and a granite outcrop pool. The only other record of this genus in WA is from the Carnarvon Basin although it is widely but sparsely distributed in inland and northern Australia (B.V. Timms, University of Newcastle, pers. comm.). A new genus of dytiscid beetle was collected at two river pools in the central and eastern Pilbara, one new genus of alonine cladoceran occurred in a lower Fortescue River pool and another was collected from a large claypan in the central Pilbara. Many other taxa were new to science (e.g. Pinder 2008; Timms 2008; Watts and McRae 2010).

About $21 \%$ of taxa were recorded in only one sample and another $9 \%$ in just two samples. The singleton and doubleton rates were about the same when the seasonal samples were combined for sites. On average, each taxon occurred in about $9 \%$ of samples and in $13 \%$ of sites. Figures $4 \mathrm{~A}$ and $4 \mathrm{C}$ show the richness of rare species in two classes: singletons and those that occurred in five or fewer samples. Rare species were distributed patchily across the Pilbara and did not exhibit a strong geographic pattern. Rotifers, cladocerans and large branchiopods were disproportionately represented in the list of singletons at the expense of most other groups, whereas taxa with $\leq 5$ records were taxonomically more representative of the whole fauna, except that the large branchiopods were still represented disproportionately. Figures $4 \mathrm{~B}$ and $4 \mathrm{D}$ show richness of rare species as proportions of total sample richness, with values ranging from 0 to $6 \%$ for singletons and from 0 to $23 \%$ for those with $\leq 5$ records. A small number of sites had particularly high representation of rare species, but these were mostly saline and/or ephemeral wetlands. Rare species were no richer in these sites but made up a larger proportion of the community because total richness tended to be lower in saline and ephemeral wetlands.

At least 130 species, mostly rotifers and microcrustaceans and mostly undescribed, are presently known only from the Pilbara. These are herein referred to as Pilbara 'endemics', though we recognise that some are likely to be found outside the region with further survey effort. This figure excludes some taxa, particularly most of the acarines and dipterans, that are too poorly known from other regions to determine distributions, but those taxa may also include species restricted to the Pilbara. Most of the endemic taxa occurred across a variety of wetland types and had apparently disjunct but not geographically restricted distributions. There was no difference in the proportion of the community made up by endemic species between any of the major wetland types or geographic subregions.

A number of the endemics were collected only in turbid wetlands (claypans and/or turbid pools), including several rotifers, hydrobiid snails, the new fairy shrimps (Branchinella pinderi and B. mcraeae), new clam shrimps (Limnadia sp. nov. and Eocyzicus sp. nov.) and ostracods (new Paralimnocythere, Limnocythere, Bennelongia and Cypretta). Several other taxa that occurred only once during the survey may also be claypan specialists, including two new Lynceus clam shrimps, a new genus of chydorid Cladocera and several additional ostracods. There was a tendency for these turbid water specialists to occur only in wetlands of the western or eastern Roebourne Plains or the middle to upper Fortescue Valley.

Numerous members of this endemic component (mostly representing all the occurrences of particular genera or families) were restricted to a subset of springs and spring-fed pools. This subset includes wetlands in Millstream National Park and/or in the gorges of Karijini National Park, as well as Running Waters and Skull Springs on the Oakover, Weeli Wolli Spring in the Fortescue system and Nyeetbury Spring on the Robe River. The taxa included the undescribed leech, a phreodrilid oligochaete (Insulodrilus sp. WA35), the only amphipods collected (Pilbarus millsi, Chydaekata sp.), all records of isopods (Pilbarophreatoicus), most riffle beetles (Coxelmis and Austrolimnius), the damselfly Nososticta pilbara and one of the pyralid lepidopterans (sp. 37). The same springs 


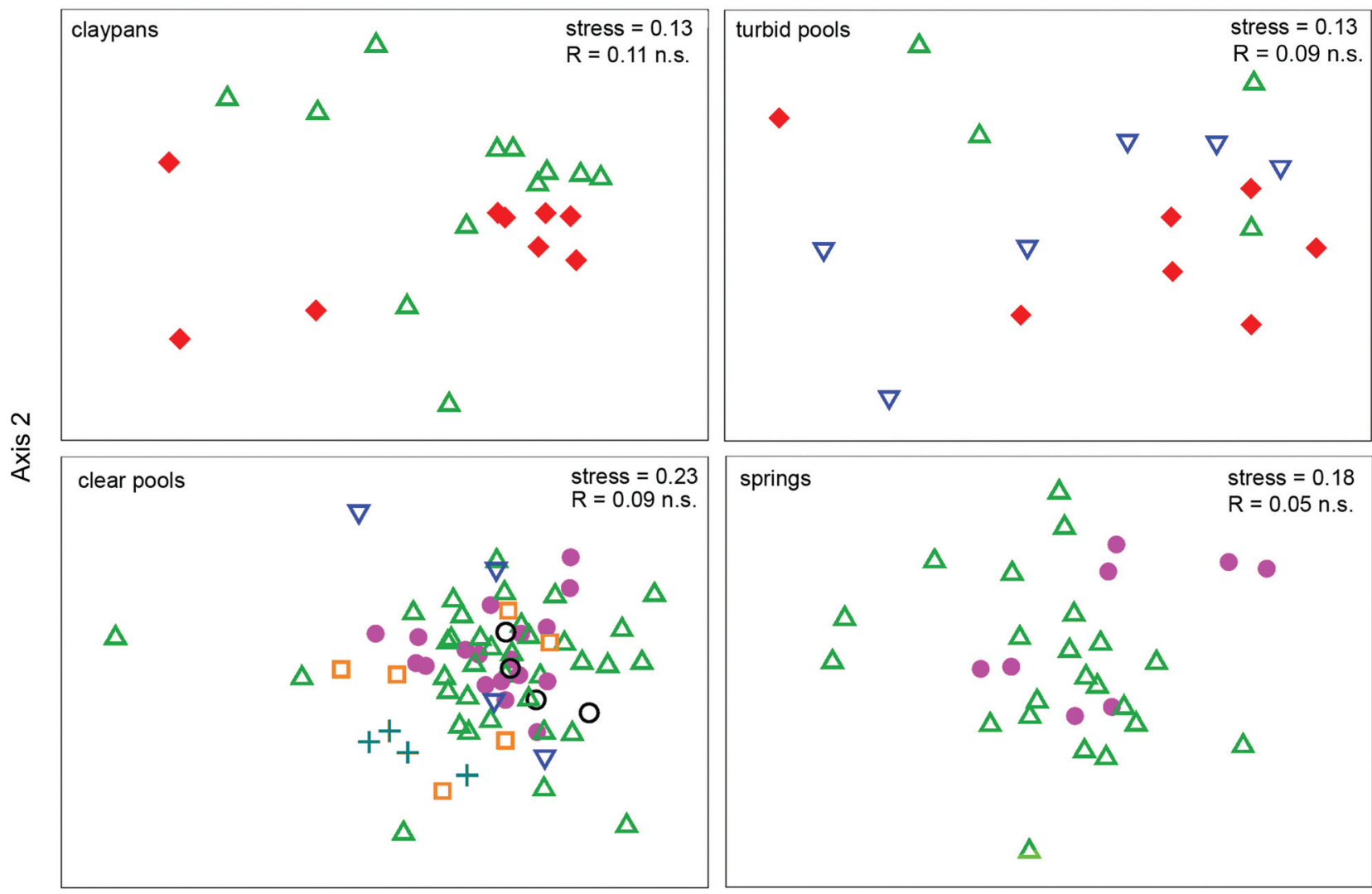

Axis 1

$\begin{array}{lll}\Delta \text { Chichester } & \text { Ashburton } \\ \nabla \text { Roebourne Plains } & \text { Fortescue } \text { O Augustus }\end{array}$

Figure 10 Separate 2D nMDS ordinations of invertebrate community composition of four major wetland types with samples coded by IBRA sub-region, with anosim global $R$ and significance values shown.

also supported a number of non-endemic taxa that were similarly rare, including Wundacaenis and leptophlebiid mayflies, assiminaeid snails, Ecnomina and Notalina caddisflies and Momoniella and Austraturus water mites. The hydraeinid beetle Tympanogaster sp., also known only from Karijini waterfalls in the Pilbara, was collected subsequent to this survey (Jackson et al. 2009). Some of these taxa are present in springs because they are essentially groundwater taxa, including the isopods, amphipods and darwinulid and candonid ostracods. Others belong to groups that have strong associations with permanently moist and/ or flowing habitats elsewhere (the mayflies, leeches, phreodrilid oligochaetes, elmid and Tympanogaster beetles). Additional endemic species associated with other springs and river pools were more widespread, or tended not to occur together as frequently as the taxa listed above.

Several potentially endemic species were collected only from Fortescue Marsh (a variant of the rotifer Brachionus angularis, a new Alona cladoceran and a new Ainudrilus oligochaete) or from this wetland plus Weelarrana Salt Marsh (a new Mytilocypris ostracod and Coxiella snails).

Invertebrates and a priori wetland classification

A priori wetland types (see Introduction) were superimposed on an nMDS ordination of all samples based on their invertebrate community composition in Figure 5. Most clear river pools, springs and ephemeral creeks are distinguishable from turbid creek pools and claypans. Clear river pools and springs also showed relatively little overlap. Rockpools and ephemeral creeks both have variable community composition, with the former tending to align with turbid water sites and the latter with clear water sites. Communities of claypans and turbid pools showed a strong overlap. Saline river pools, such as sites 18, 29 and 53, had community composition more like those recorded at some salt marshes (the four clear river pool samples near salt marshes in Figure 5).

Overall, there was greater heterogeneity in the fauna of claypans than riverine wetlands. An anosim analysis suggested there were significant differences in community composition between most wetland types (global $\mathrm{R}=0.494, P<0.001$ ), 


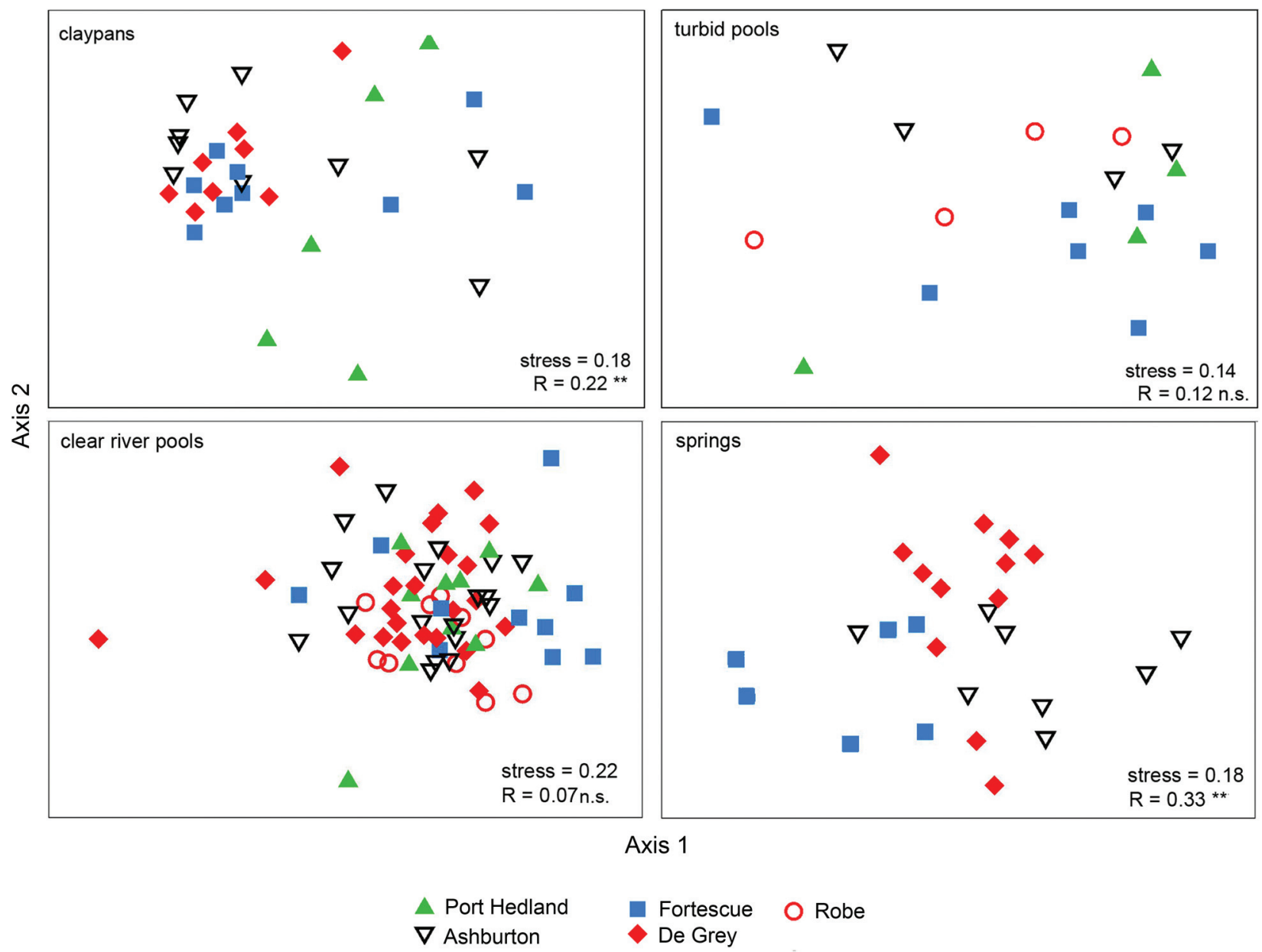

Figure 11 Separate 2D nMDS ordinations of invertebrate community composition of the four major wetland types with samples coded by drainage basin - anosim global $\mathrm{R}$ and significance values shown.

except between claypans and other turbid or ephemeral wetlands (turbid pools, salt marshes, ephemeral creeks and rockpools). Since some of the major wetland types tended to have different community composition, and because wetland types are not evenly represented across the region, comparisons of community composition between season, drainage basin and IBRA subregions were performed separately for each major wetland type (claypans, turbid pools, clear pools and springs).

\section{Environmental correlates of community composition}

\section{Spatial autocorrelation}

Spatial autocorrelation between biological communities (the tendency for communities in close proximity to be more similar to each other than to more distant communities) can lead to an overestimation of relationships between composition and environmental variables. Sampling units are not independent from one another (Legendre 1993) and some of the similarity in community composition may be due to ecological processes such as dispersal, rather than species' shared ecophysiological responses to their environment. An example in dryland rivers is the potential influence of recent and historical hydrological connectivity on community composition of floodplain wetlands (e.g. Marshall et al. 2006), which may confound relationships between the biota and site-based variables. However, there was little evidence of spatial autocorrelation within our biological matrix. Geodesic distance between wetlands was very slightly, albeit significantly, correlated with Bray-Curtis community dissimilarity $\left(\mathrm{r}^{2}\right.$ $=0.0038, P<0.001$ ) (Figure 6) but a Mantel test (using the RELATE routine in Primer) showed no significant rank correlation (Spearman p) between the community and geodesic dissimilarity matrices (Rho $=-0.048, P=0.96$ ). There was a very low, but again significant, linear correlation between channel distance (for riverine sites) and Bray-Curtis community dissimilarity for the De Grey-Oakover Basin $\left(\mathrm{r}^{2}=0.0158, P<0.05\right)$ but not 


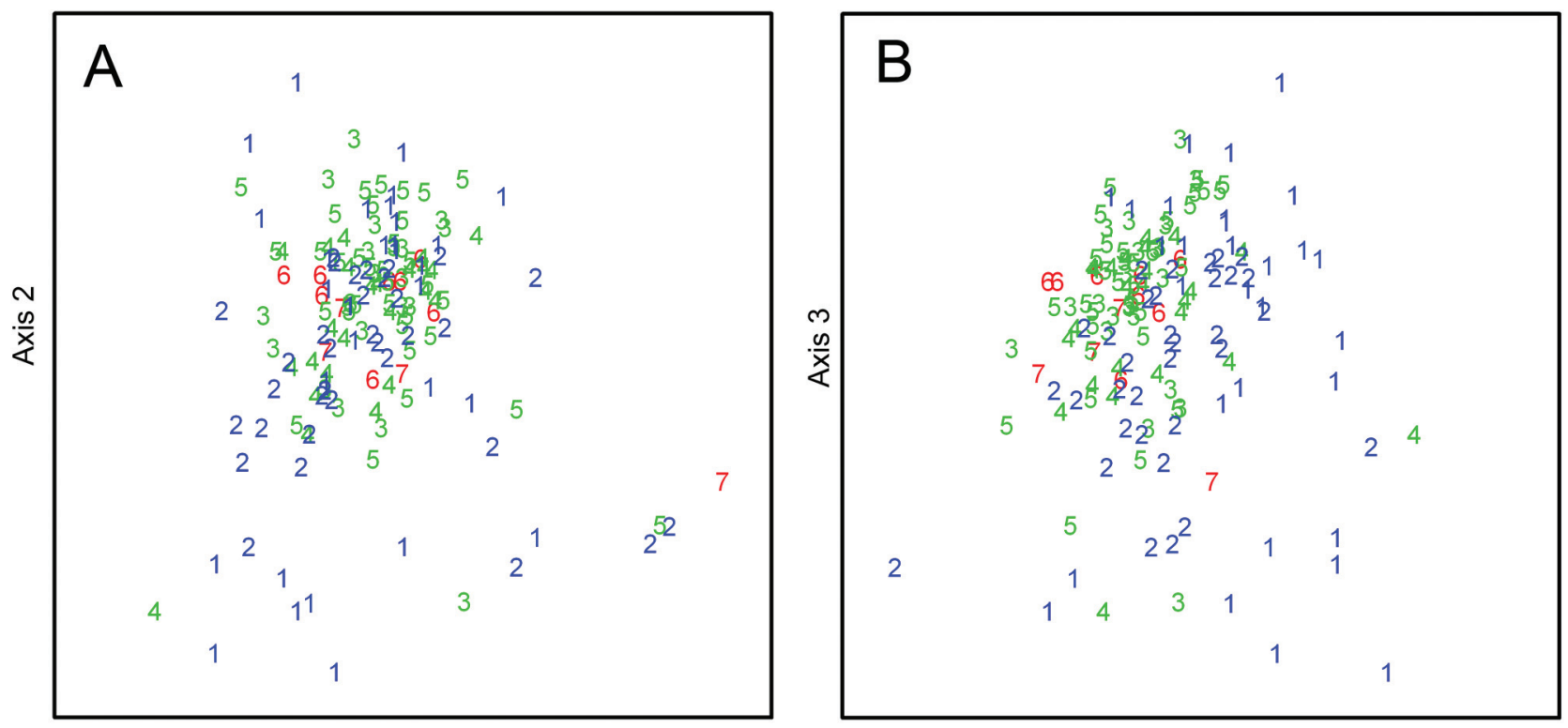

Axis 1

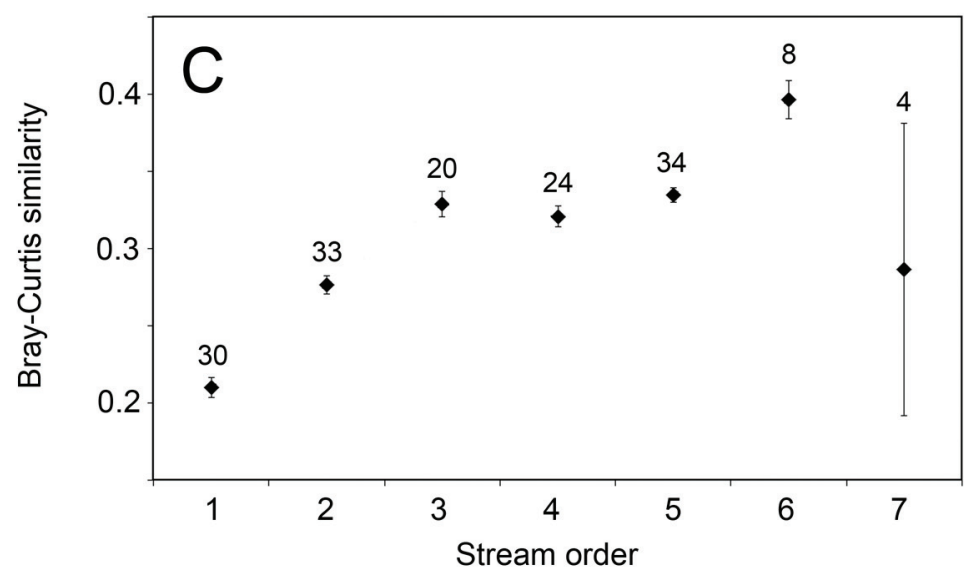

Figure $12 \mathrm{~A}$ and $\mathrm{B}$, axis 1 versus axes 2 and 3 of a 3D nMDS ordination of all riverine samples with stream order indicated by numbers (stress $=0.16)$; $C$, average $( \pm$ s.e.) Bray-Curtis similarity of pairs of samples within the seven stream orders, numbers of samples shown above points.

for the Ashburton Basin (Figure 6). Mantel tests showed no rank correlation between community dissimilarity and channel distance matrices for either river (Rho $=0.097, P=0.885$ and $\mathrm{Rho}=0.018$, $P=0.38$, respectively). These analyses suggest that relationships between faunal composition and measured environmental variables were not confounded by geographic proximity to any great extent.

\section{Seasonality}

In the cluster analysis of samples (not shown), two-thirds of the sites sampled in both spring and autumn fell within the same group and frequently occurred as sister samples. This indicates limited seasonal change in invertebrate community composition for many sites. Occurrence of spring and autumn samples in different cluster groups was most evident for some of the river pools. Also, the few samples in summer 2006, mostly from ephemeral wetlands, tended to cluster apart from other samples. Changed salinity or turbidity between seasons was probably the cause of some samples from the same site clustering apart, e.g. composition at site 53 changed significantly following an increase in salinity from 6.8 to $14 \mathrm{~g} / \mathrm{L}$. Average species richness for sites was the same in autumn $(85 \pm 4)$ as it was in spring $(92 \pm 4)$ and none of the individual assemblages identified below was significantly richer in one season than the other (t-tests, $P>0.05)$. Thirty percent of species were collected in only one season, with about the same number of species absent in autumn (140) as in spring (152). However, two-thirds of these occurred only once during the survey, so their occurrence in a single season probably represents rarity rather 
seasonality. Average frequency of occurrence within a season was the same for autumn (9.5 samples/species) and spring (9.7) so there was no tendency for species to be more common in one season. Ordinations showed little obvious separation of spring from autumn communities for the main types of wetlands (Figure 7), and anosim analyses suggested there was only a very slight seasonal effect on community composition for clear river pools $(R=0.096)$ and no effect for other wetland types.

\section{Cyclones}

Twelve river pools were sampled in the spring prior to cyclonic summer flooding (see Figure 2 ) and again in the following autumn (in 2003/4 or 2005/6), while thirteen pools were sampled in spring and the following autumn without intervening floods (2004/5). Neither season nor occurrence of flooding had a significant effect on species richness in these pools $(F=0.005$ for season, 0.016 for floods, 1.1819 for interaction, $P$ $>0.1$ for all terms). Figure 8 shows the results of four separate nMDS ordinations of these river pool communities by season and presence/ absence of flooding. Figures $8 \mathrm{a}$ and $8 \mathrm{~b}$ suggest there was a greater difference between spring and autumn communities where there was an intervening cyclone and that post-flood autumn communities were more heterogeneous than autumn communities that did not experience flooding, although the group of sites experiencing a cyclone was more variable beforehand (Figure 8c). Anosim analyses showed weak significant differences between seasonal communities whether or not floods occurred, though the effect was slightly larger where there was a flood $(R=0.24, P$ $<0.01$ for sites with floods and $\mathrm{R}=0.19, P<0.01$ for sites without flooding). Figures $8 \mathrm{c}$ and $8 \mathrm{~d}$ indicate greater separation of the two groups of pools from each other in autumn (after flooding) than in spring (before flooding). Anosim analyses indicated weak, albeit significant, separation of communities that experienced flooding from those that did not in both seasons but differences were greater in autumn $(\mathrm{R}=0.10, P<0.01$ in spring, $\mathrm{R}=0.22, P<$ 0.01 in autumn).

\section{Hydroperiod}

Both richness and species composition showed differences between estimated permanence classes. Figure 9 shows richness of insects (capable of aerial colonisation) and other invertebrates of the four permanence classes across all samples (Figure 9A) and in riverine samples only (Figure 9B). Both insect and non-insect richness increased as permanence increased from ephemeral to nearpermanent, though the increase was greater for insects and there was little difference in richness between wetlands classed as near permanent and permanent (ANOVA, $P<0.001$ for all samples, $P$ $<0.05$ for riverine samples). A 3D nMDS analysis (Figure 9C) showed a gradient in community composition between permanence classes 1 to 4 . However, this effect is difficult to separate from wetland type (Figure 5) and related variables such as flow and turbidity, because most of the ephemeral sites are claypans and most of the permanent sites are springs and river pools.

\section{Geography}

Anosim and nMDS analyses (Figure 10) suggested that there were no differences in community composition between IBRA subregions for the four major wetland types. In an initial analysis, clear river pools appeared to differ between some subregions but this reflected the influence of three saline pools (almost all other pools were fresh to sub-saline). Once these sites were removed from the analysis there were no significant differences between clear river pool communities of different subregions. Ordinations suggested differences in community composition between some drainage basins, especially for springs and claypans (Figure 11). Anosim analyses confirmed that there were some differences between communities of springs of the Fortescue Basin and those of both the Ashburton and De Grey basins ( $R=0.39$ and 0.41 respectively) and between communities of claypans in the Port Hedland Coast Basin and those of both the De Grey and Ashburton basins ( $R=0.62$ and 0.39 respectively).

An nMDS ordination of riverine sites indicated some separation of samples from $1^{\text {st }}$ and $2^{\text {nd }}$ order streams from those collected in higher order streams (Figure 12A,B), but an anosim analysis suggested that differences in community composition between stream orders were negligible (Global $\mathrm{R}=0.091, P<0.001$ ). There were significant differences between $1^{\text {st }}$ and $2^{\text {nd }}$ order streams and between these lower orders and some of the intermediate orders $\left(1^{\text {st }}\right.$ and $4^{\text {th }}, 1^{\text {st }}$ and $5^{\text {th }}$ and $2^{\text {nd }}$ and $\left.5^{\text {th }}\right)$ but significant pairwise $R$ values were small $(<0.22)$. There was greater community heterogeneity among the lower order samples than among samples from higher order sites (Figure 12C). The latter reflects greater physical diversity among low order sites, which included both headwater springs with clear flowing water and rocky substrates and static creek pools on clay flats with turbid water and fine sediments. High order sites tended to be more uniform, with clear water and sandy to cobbly beds.

\section{Assemblage distributions}

Figure 13 shows the results of the cluster analysis 
of species. At the lowest level of similarity $(<0.45)$ there are three groups. Group 1 includes species that tended to occur primarily in freshwater wetlands with longer hydroperiods. Within this group, seven subgroups (assemblages 1 to 7 ) differed primarily in their occurrence in relation to hydroperiod, lentic versus lotic wetlands, flow and turbidity. The second group, assemblage 8 below, comprises a small number of species that mostly co-occurred in pools and springs in or near Millstream National Park and, to a less extent, a few other springs. The third major group of species was those with a tendency to occur in more ephemeral, more highly turbid or saline lentic wetlands. This group included several subgroups (assemblages 9 to 13) that differed in their occurrence primarily along those gradients.

These assemblages, and their distribution along environmental gradients, are described in more detail below. Where possible, MARS models were developed to investigate which combination and ranges of variables best explain distribution patterns. Table 2 shows the number of species in each assemblage, the median and maximum representation in samples and $\mathrm{r}^{2}$ values for the MARS models. Most assemblages tended to become compositionally more similar as richness increased, except for 12 and 13. Assemblages 8, 9, 12 and 13 were not modelled because of their small size, uniformly low representation and/or lack of nested structure (Table 2). Figures 14 to 19 show maps with richness of each assemblage in autumn and spring, graphs showing some of the univariate relationships between environmental variables and richness and the MARS models.

\section{Assemblage 1}

This contains 153 species from a wide range of taxonomic groups. Higher richness was most strongly associated with increasing alkalinity (up to $315 \mathrm{mg} / \mathrm{L}$ ), biomass of submerged macrophytes (up to $80 \mathrm{~g} / \mathrm{m}^{2}$ ) and depth (up to $77 \mathrm{~cm}$ ), but richness declined once salinity exceeded about $3 \mathrm{~g} / \mathrm{L}$ and as $\% \mathrm{~K}^{+}$increased to $13 \%$ (Figure 14). The positive association between richness and median annual temperature range, up to about $29^{\circ} \mathrm{C}$, reflects the slightly higher richness in wetlands in the central band of the Pilbara. The model incorporating these variables had an adjusted $r^{2}$ of 0.67 . The assemblage was also associated with mediumgrained sediments (high gravel, low silt, some bedrock) and with the presence of flowing water (at least at one end of a river pool). Overall, this assemblage is best represented in longer-lasting springs and river pools with abundant macrophytes and gravelly sediments. The assemblage was under-represented in the Fortescue and Roebourne Plains subregions, which have few springs, but was otherwise geographically widespread (Figure 14) and represented in almost all samples.

\section{Assemblage 2}

This assemblage is the sister group to the previous assemblage and comprised 52 species, most of which were common, widespread insects and the rest microcrustaceans and rotifers. Its widespread, generalist nature is reflected in its

Table 2 Summary statistics for assemblages and performance of MARS models.

$\begin{array}{ccccccc}\text { Assemblage } & \begin{array}{c}\text { Number of taxa } \\ \text { in assemblage }\end{array} & \begin{array}{c}\text { Median } \\ \text { richness per } \\ \text { sample }\end{array} & \begin{array}{c}\text { Average } \\ \text { richness per } \\ \text { sample }\end{array} & \begin{array}{c}\text { Maximum } \\ \text { richness per } \\ \text { sample }\end{array} & \begin{array}{c}\text { Composition } \\ \text { converges } \\ \text { as richness } \\ \text { increases }\end{array} & \begin{array}{c}\text { MARS model } \\ \text { adjusted r }{ }^{2}\end{array} \\ 1 & 153 & 34 & 36.1 & 102 & \text { strongly } & 0.67 \\ 2 & 52 & 18 & 17.6 & 37 & \text { strongly } & 0.45 \\ 3 & 42 & 1 & 1.6 & 31 & \text { moderately } & 0.34 \\ 4 & 97 & 4 & 8.1 & 43 & \text { strongly } & 0.73 \\ 5 & 69 & 4 & 4.9 & 18 & \text { strongly } & 0.28 \\ 6 & 56 & 5 & 7.8 & 30 & \text { moderately } & 0.6 \\ 7 & 147 & 3 & 3.1 & 12 & \text { moderately } & 0.25 \\ 8 & 24 & 0 & 0.4 & 14 & \text { weakly } & - \\ 9 & 21 & 0 & 0.5 & 9 & \text { weakly } & - \\ 10 & 39 & 0 & 1.4 & 12 & \text { moderately } & 0.63 \\ 11 & 40 & 0 & 0.7 & 10 & \text { weakly } & 0.62 \\ 13 & 20 & 0 & 0 & 0.4 & 9 & \text { no }\end{array}$


species occurring in deeper wetlands with flowing water and long hydroperiods

common species occurring primarily in river pools

sparsely distributed assemblage with low richness other than in a few mostly permanent river pools

species occurring mostly in springs but also groundwater/hyporheic fed pools

species occurring mostly in large claypans and non-flowing river pools

species mostly occurring in seasonal fresh to subsaline lentic waters, including moderately turbid claypans and pools

uncommon species occurring in a wide range of wetlands

species mostly occurring in Millstream NP wetlands plus a few other springs

species mostly occurring in rockpools and mildly turbid claypans and river pools

species tending to occur in mildy to moderately turbid waters

species of ephemeral wetlands, including highly turbid claypans, rock pools and creeks

species with a preference for saline waters

a small number of rare species occurring primarily in claypans, especially site 74

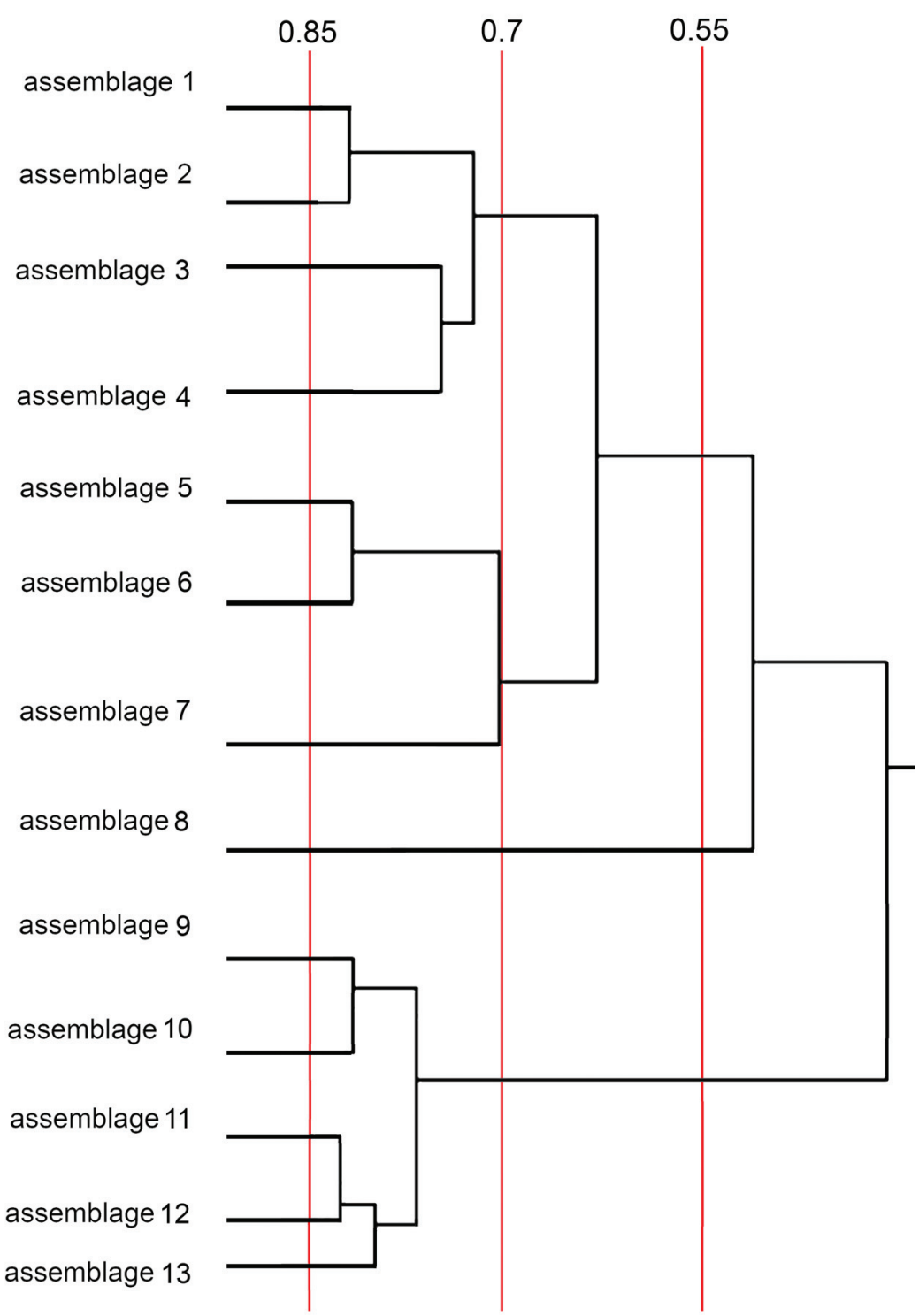

Figure 13 Results of a cluster analysis (UPGMA) of species according to their presence/absence in all 189 samples, showing assemblages 1 to 13 with summaries of their patterns of occurrence. Vertical lines are Bray-Curtis similarity values.

relatively weak relationships with the measured environmental variables. The MARS model had an adjusted $r^{2}$ of just 0.45 and indicated that richness was negatively correlated with salinity (above 3.3 $\mathrm{g} / \mathrm{L}$ ) and water temperature, but increased with depth (up to $77 \mathrm{~cm}$ ), silica (to $53 \mathrm{mg} / \mathrm{L}$ ) and \% sand (above 16\%). Other associations not included in the model include higher richness in seasonal to nearpermanent wetlands and wetlands with higher macrophyte cover. Assemblage 2 was thus best represented in clear seasonal to near permanent fresh river pools with sandy sediments (Figure 14).

\section{Assemblage 3}

These 42 species, almost all insects, rotifers and water mites, appear to have clustered together largely because of their co-occurrence at a number of small, near-permanent to permanent, clear river pools, particularly site 21 (a seasonal river pool with 31 species) and/or site 16 (a small spring-fed pool with 15 species) in spring 2003. The assemblage also occurred in a range of other wetlands at low densities (Figure 15). The sample collected from site 21 in spring 2003 was removed before modelling because of its strong leverage. Higher richness was weakly associated (MARS adjusted $\mathrm{r}^{2}=0.34$ ) with increasing alkalinity (to $345 \mathrm{mg} / \mathrm{L}$ ), bicarbonate (to $23 \mathrm{mg} / \mathrm{L}$ ), submerged macrophyte biomass (to $78 \mathrm{~g} / \mathrm{m}^{2}$ ) and lower annual mean temperatures (below $26^{\circ} \mathrm{C}$ ). The latter, and an association between high richness and higher altitude, reflected a tendency for the assemblage to occur primarily on the Chichester and northern Hamersley Ranges. There were also positive associations with longer 
hydroperiod, low turbidity, high $\% \mathrm{Mg}^{2+}$ and gravelly sediments.

\section{Assemblage 4}

This assemblage of 97 species, over two-thirds of which were insects, occurred in 147 samples from 86 wetlands. Several members of this assemblage have known associations with flowing water (e.g. Austrolimnius sp. 2 and Simulium clathrinum) or with hyporheic or groundwater habitats (e.g. Pilbarophreatoicus platyarthricus and Darwinula stevensoni). Richness increased with flow (to 0.35 $\mathrm{m} / \mathrm{s}$ ), higher cover of emergent macrophytes, higher $\% \mathrm{Mg}^{2+}$ (above about 13\%) and longer hydroperiod, but declined at temperatures exceeding $18^{\circ} \mathrm{C}$. The MARS model incorporating these variables had an adjusted $r^{2}$ value of 0.73 (Figure 15). The radiation seasonality and annual rainfall parameters in the model reflect highest richness in the central northern Pilbara. These species were most likely to be encountered in flowing vegetated springs, but also occurred in spring and hyporheic fed river pools, particularly in the Hamersley and eastern Chichester subregions, plus the Millstream wetlands (western Chichester; Figure 15).

\section{Assemblage 5}

This assemblage comprised 69 species, half of which were microinvertebrates (rotifers, ostracods and cladocerans) and the rest almost all insects, present in 173 samples from 97 wetlands. Richness was highest in seasonal to near-permanent freshwater wetlands with low flow, low alkalinity, intermediate $\% \mathrm{Mg}^{2+}$ (richness peaking around $16 \%$ ), moderate depth (richness increasing to about 75 $\mathrm{cm}$ ) and low to moderate turbidity (Figure 16). The MARS model incorporated some of these variables but had an adjusted $r^{2}$ of only 0.28 and tended to grossly underestimate high richness. These species occurred in a wide range of wetlands, but were best represented in mildly turbid claypans and static river pools rather than in springs and highly turbid claypans. There was also a tendency for richness to be higher in the northern and eastern Pilbara, especially in autumn (Figure 16).

\section{Assemblage 6}

This was a small group of 56 taxa, about half insects and the rest mostly microcrustaceans and rotifers. Several species, such as Bennelongia ostracods and the conchostracan Caenestheriella packardi commonly occur in turbid ephemeral waters. The species occurring in Fortescue Marsh and some other saline wetlands, such as the dragonfly Diplacodes bipunctata and rotifer Polyarthra dolichoptera, are freshwater species tolerant of low salinity rather than halophiles (cf. some members of assemblage 13). High richness was most closely associated with increasing $\% \mathrm{~K}^{+}$(to $7 \%$ ) and \% sand (to $30 \%$ ) but declining $\% \mathrm{Mg}^{2+}$ (to $30 \%$ ) and flow (to $0.56 \mathrm{~m} / \mathrm{s}$ ) (Figure 16) in a model with adjusted $\mathrm{r}^{2}$ of 0.6 . These were most frequently recorded in turbid claypans and creek pools, most of which were in the Fortescue and Roebourne subregions, and in Fortescue Marsh when salinity was low (Figure 16).

\section{Assemblage 7}

A large group of 148 uncommon species, about $30 \%$ rotifers and $40 \%$ insects present in 166 samples from 97 wetlands, but reaching a maximum of only 12 species in a sample. Composition did not converge strongly with increasing richness, suggesting that it is a loose grouping of species, probably with varying environmental responses not amenable to quantitative analysis of ecological tolerances. This is reflected in the poor model performance (adjusted $r^{2}=0.25$ ). Higher richness was weakly associated with longer hydroperiod, increasing flow (to $0.35 \mathrm{~m} / \mathrm{s}$ ), depth (to $91 \mathrm{~cm}$ ) and alkalinity (to $87 \mathrm{mg} / \mathrm{L}$ but also with higher altitude, to $237 \mathrm{~m}$ ) and with latitudes north of $22^{\circ} \mathrm{S}$. The latter two variables reflect higher richness in the Chichester and northern Hamersley Ranges (Figure 17). Richer sites also tended to have coarser sediments and have higher $\% \mathrm{Mg}^{2+}$. This patchily distributed assemblage showed little fidelity to any particular wetland type, though was generally richer in longer-lasting springs and clear river pools with flow than in claypans and turbid river pools.

\section{Assemblage 8}

A small group of 24 species that clustered together largely because they tended to co-occur in a number of Fortescue River wetlands in or near Millstream National Park (Figure 17), with sporadic occurrences elsewhere. Millstream species included the short-range endemic damselfly Nososticta pilbara, the dragonfly Nanophlebia injibandi, one of the two leptophlebiid mayflies (Thraulus sp.), two of the four species of elmid beetles, the caenid mayfly Wundacaenis dostini and one of the two amphipods recorded during the survey (Pilbarus millsi). A few members of this assemblage, such as Chydaekata amphipods and a Gondwanabates water mite, also occurred at one or more other permanent spring-fed sites (especially Running Waters, Weeli Wolli Spring and Skull Springs) in the southern and eastern Pilbara. This appears to be a group of species with a preference for permanent flowing water. Due to the small size and very sparse distribution of this assemblage, its richness was not modelled.

\section{Assemblage 9}

A group of 21 species, largely microcrustacea and rotifers, collected in just 41 samples from 

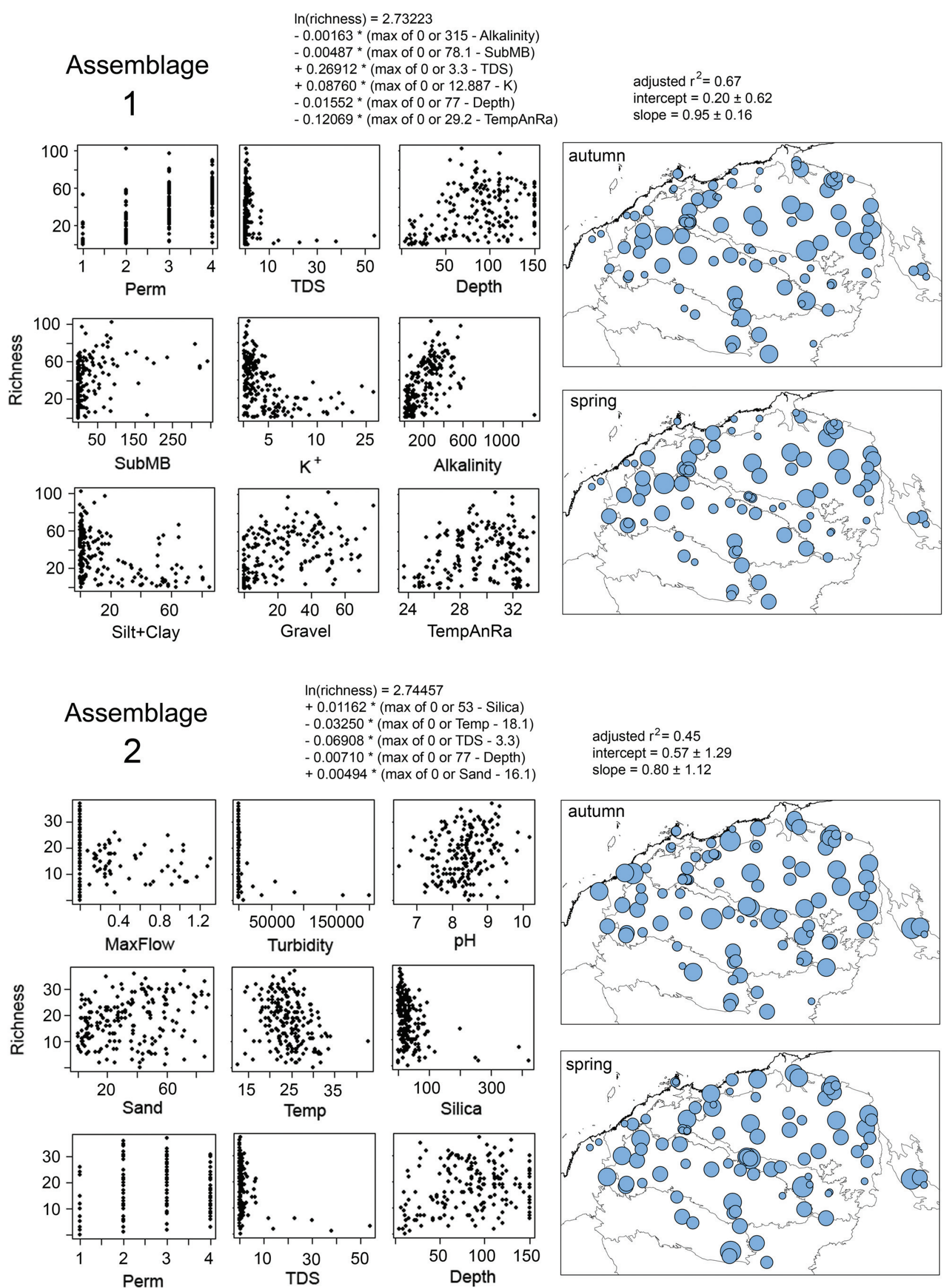

Figure 14 Results of MARS modeling and maps showing richness of assemblages 1 and 2 in spring and autumn. Shown for each assemblage are graphs of richness versus selected environmental variables, the model equation, adjusted $r^{2}$ and the slope and intercept of the regression line with standard deviations. See Appendix 1 for units of environmental variables. Sizes of symbols on the maps are proportional to maximum richness in either season. Internal boundaries on the maps are IBRA sub-regions. 

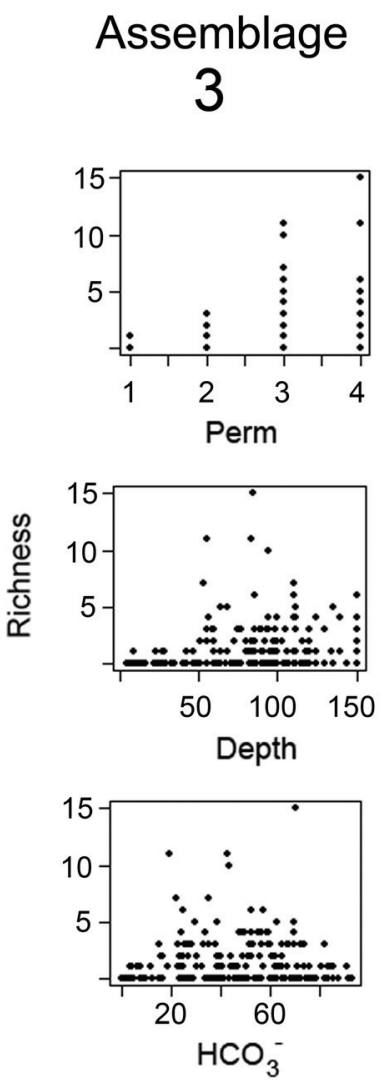
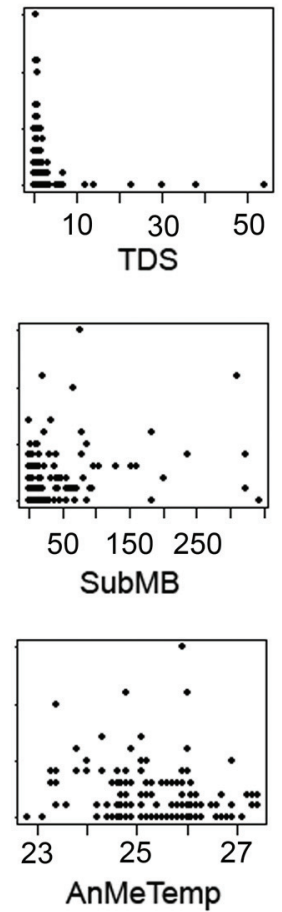

In(richness $)=1.37521$

$-0.00361 *$ (max of 0 or 345 -Alkalinity)

$-0.01191 *$ (max of 0 or 78.1 - SubMB)

-0.08725 * (max of 0 or $23.26-\mathrm{HCO})$

$-0.08725^{*}(\max$ of 0 or $23.26-\mathrm{HCO})$
$+0.41423^{*}(\max$ of 0 or $25.6-$ AnMeTemp adjusted $r^{2}=0.34$

intercept $=0.21 \pm 0.35$

slope $=0.43 \pm 0.31$
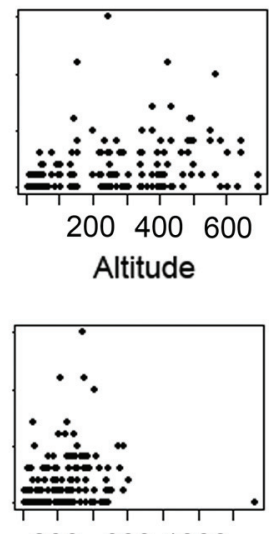

2006001000

Alkalinity

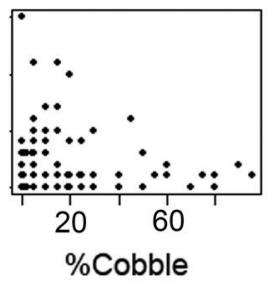

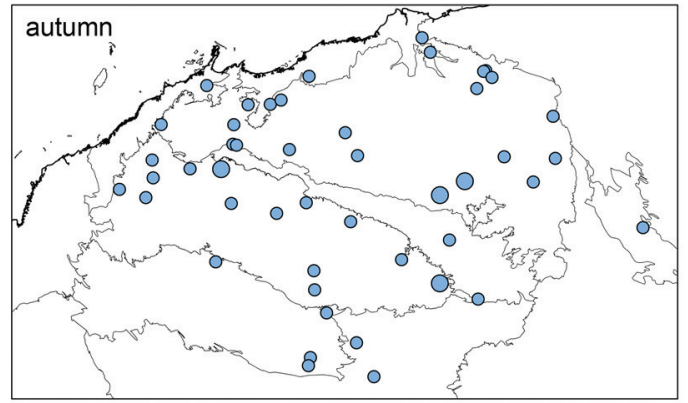

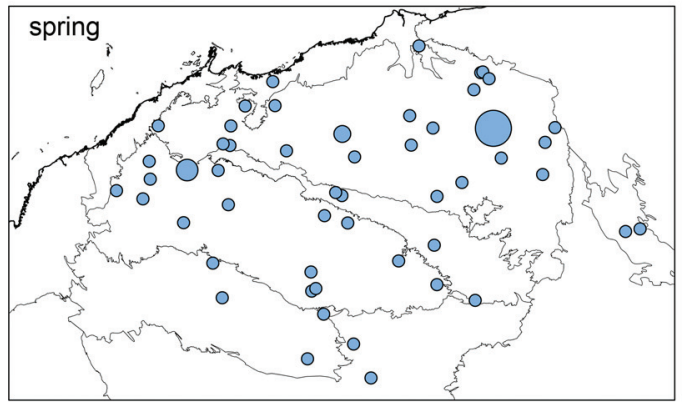

$\ln ($ richness $)=1.65586$

2.06107 * (max of 0 or 0.35 - MaxFlow)

+0.48284 * Perm -1

+0.01245 * EMC -0

$+0.02566^{*}(\max$ of 0 or $\mathrm{Mg}-13.48)$

$-0.00935^{*}$ (max of 0 or $352-$ AnnPreci)

-1.26865 * (max of 0 or 25.9 - RadiWetQ)

adjusted $r^{2}=0.73$

intercept $=0.07 \pm 0.43$

slope $=0.97 \pm 0.14$
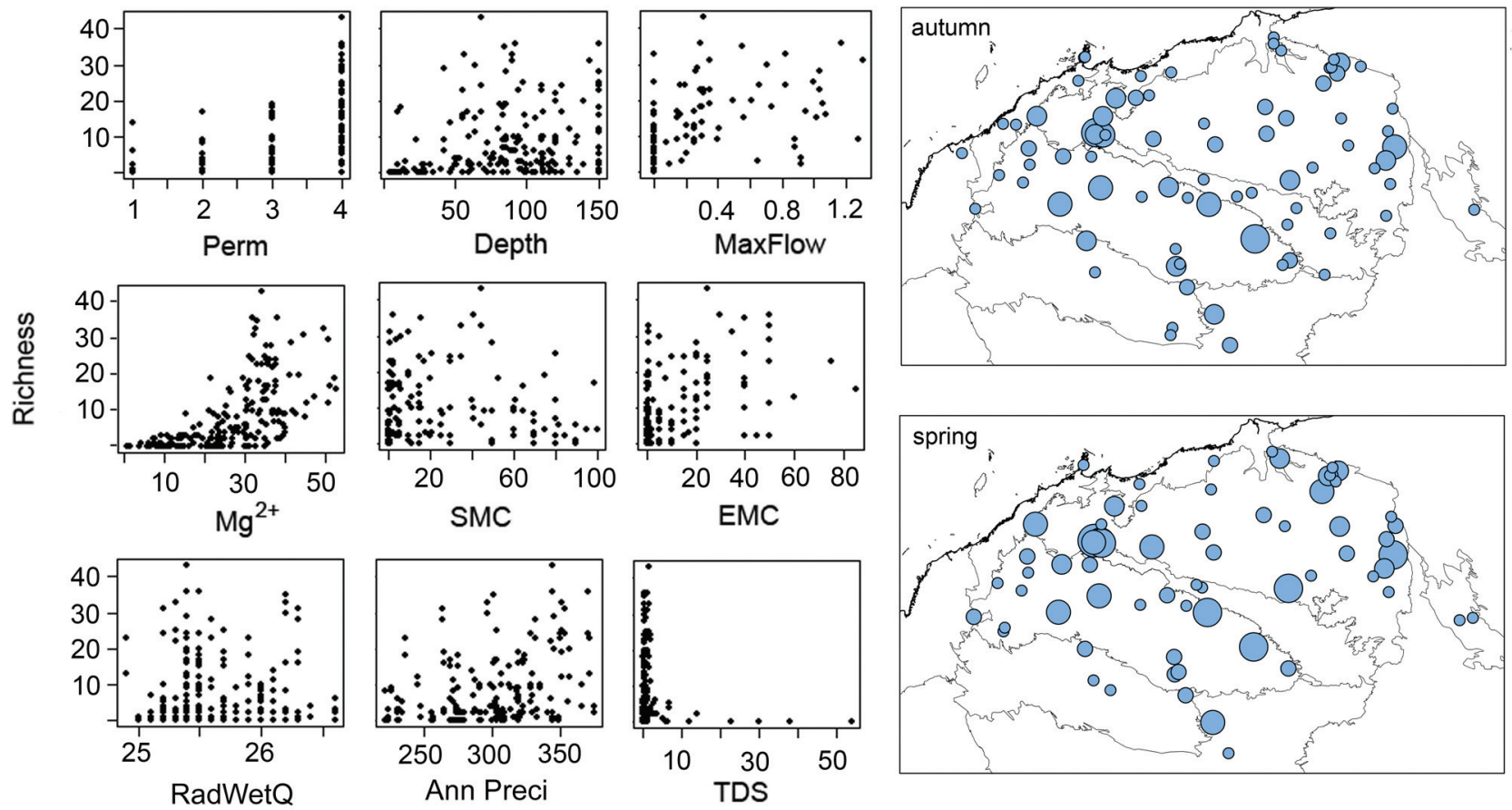

Figure 15 Results of MARS modeling and maps showing richness of assemblages 3 and 4 in spring and autumn. Shown for each assemblage are graphs of richness versus selected environmental variables, the model equation, adjusted $\mathrm{r}^{2}$ and slope and intercept of the regression line with standard deviations. See Appendix 1 for units of environmental variables. Sizes of symbols on the maps are proportional to maximum richness in either season. Internal boundaries on the maps are IBRA sub-regions. 

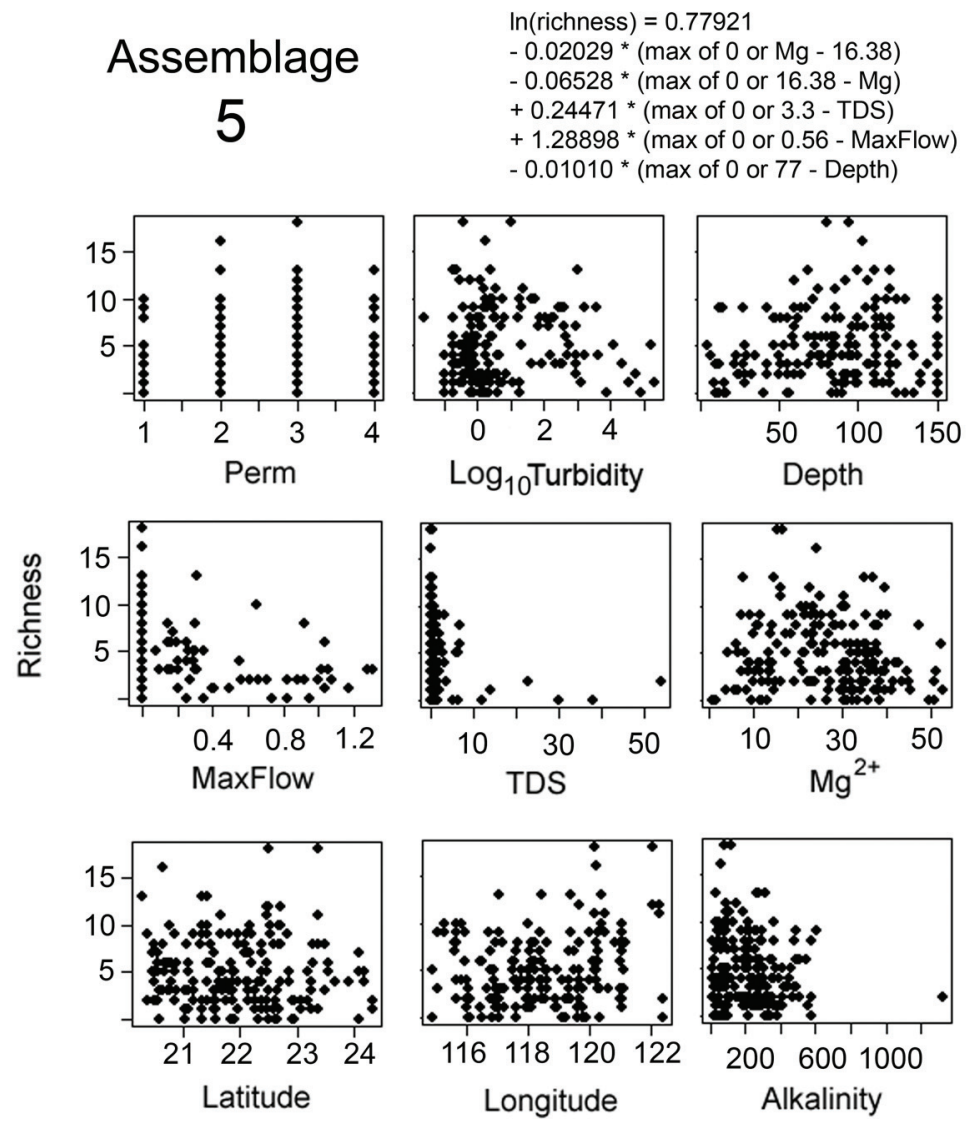

$-0.01010 *$ (max of 0 or 77 - Depth)

adjusted $r^{2}=0.28$

intercept $=0.46 \pm 0.53$

slope $=0.70 \pm 0.34$
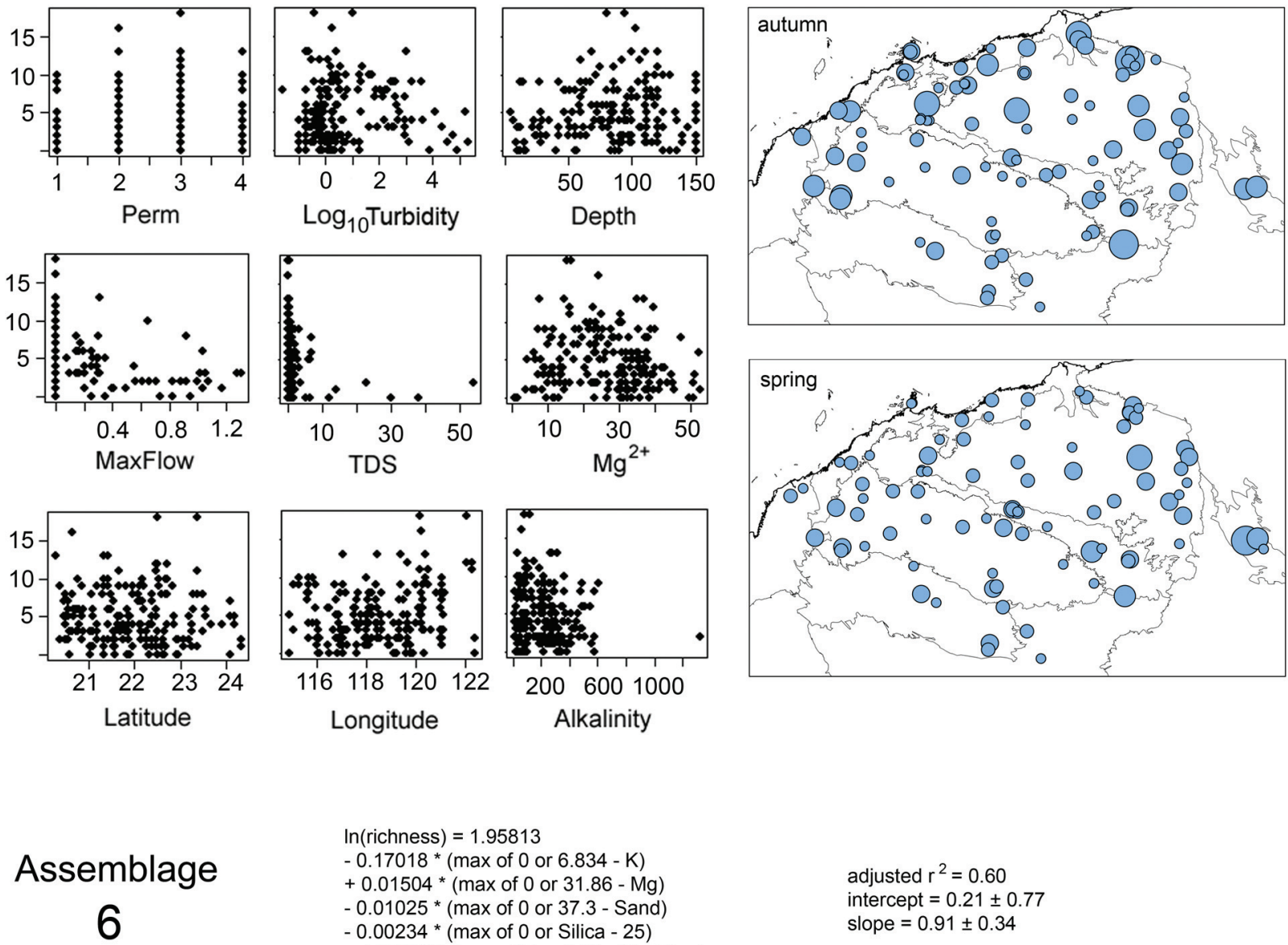

$\ln$ (richness) $=1.95813$

-0.17018 * (max of 0 or $6.834-\mathrm{K})$

+0.01504 * (max of 0 or $31.86-\mathrm{Mg})$

- $0.01025^{*}(\max$ of 0 or 37.3 - Sand $)$

-0.00234 * (max of 0 or Silica - 25)

+1.22420 * ( $\max$ of 0 or $0.56-$ MaxFlow)

adjusted $\mathrm{r}^{2}=0.60$

intercept $=0.21 \pm 0.77$

slope $=0.91 \pm 0.34$
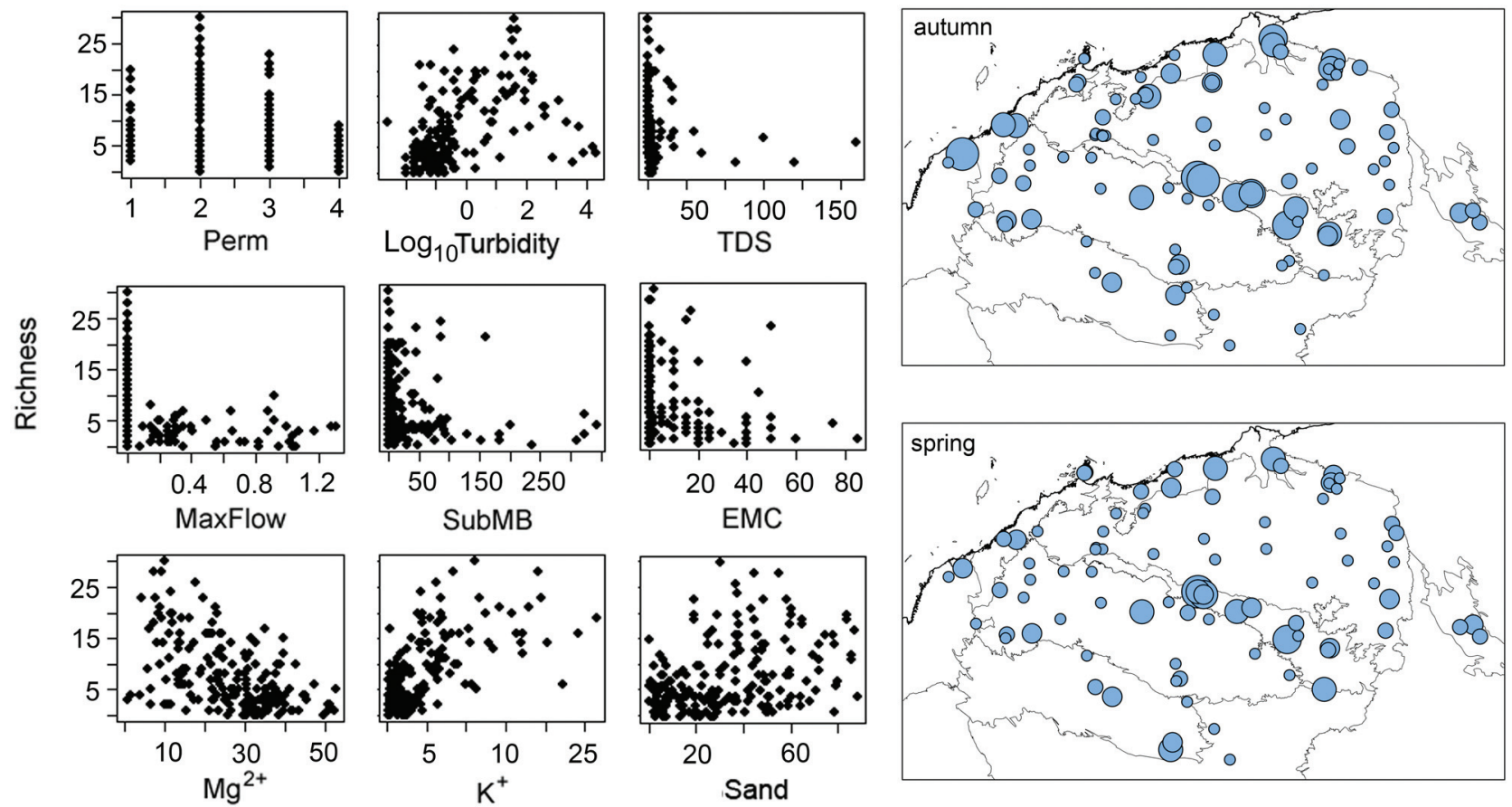

50150250

SubMB

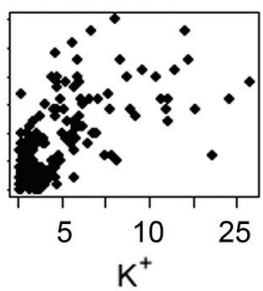

$20 \quad 40 \quad 60 \quad 80$ EMC

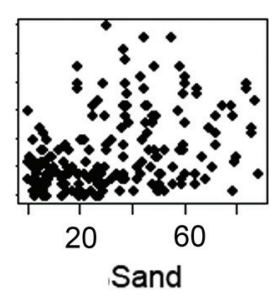

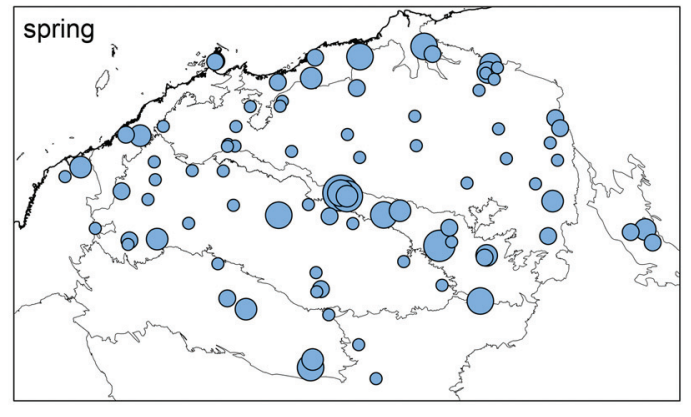

Figure 16 Results of MARS modeling and maps showing richness of assemblages 5 and 6 in spring and autumn. Shown for each assemblage are graphs of richness versus selected environmental variables, the model equation, adjusted $r^{2}$ and slope and intercept of the regression line with standard deviations. See Appendix 1 for units of environmental variables. Sizes of symbols on the maps are proportional to maximum richness in either season. Internal boundaries on the maps are IBRA sub-regions. 


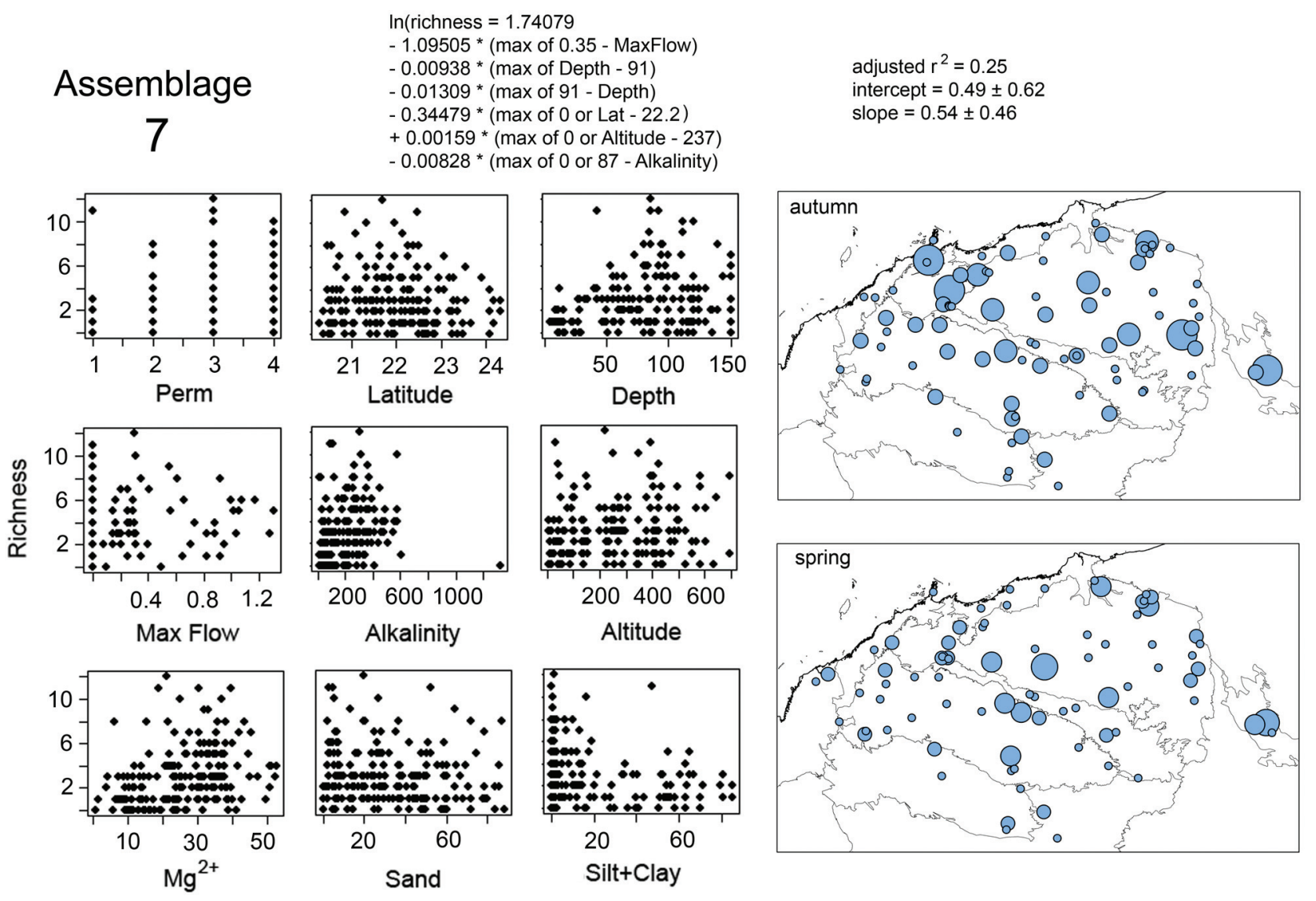

\section{Assemblage 8}
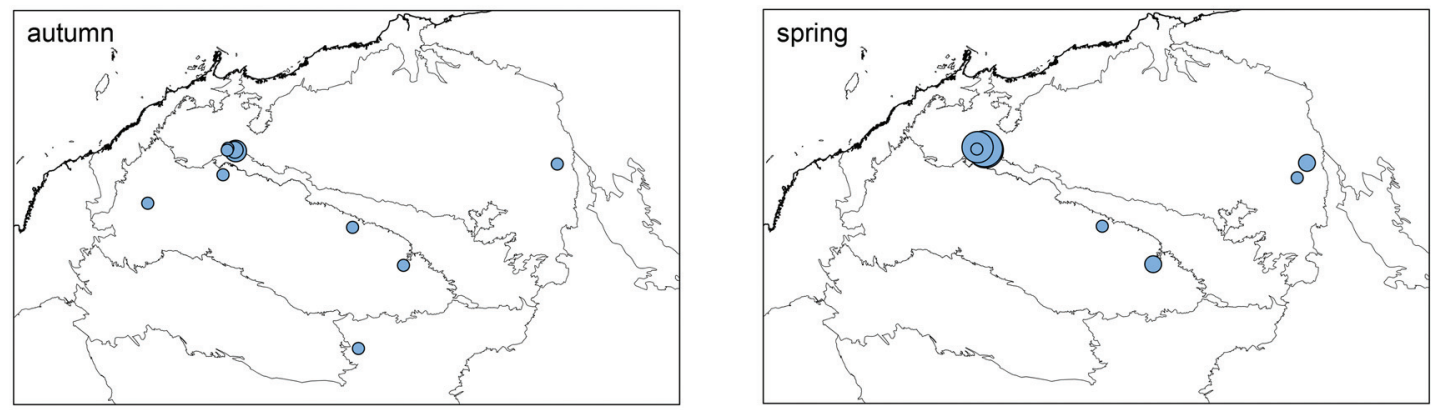

\section{Assemblage 9}
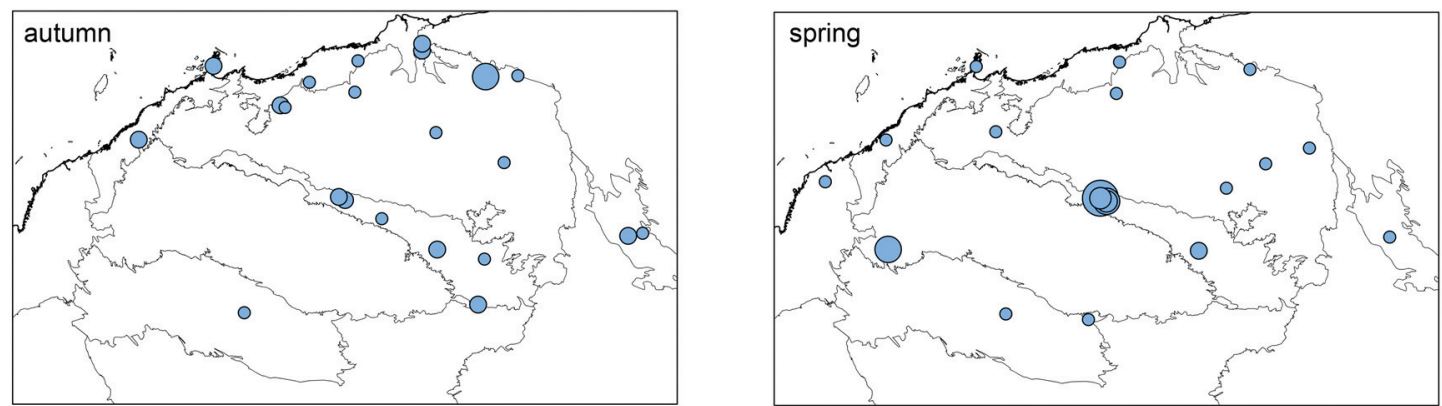

Figure 17 Assemblages 7 to 9, showing (for all three assemblages) maps of richness in spring and autumn and (for assemblage 7 only) graphs of richness versus selected environmental variables, the model equation, adjusted $\mathrm{r}^{2}$ and slope and intercept of the regression line with standard deviations. See Appendix 1 for units of environmental variables. Sizes of symbols on the maps are scaled to the maximum richness recorded in either season. Internal boundaries of the maps are IBRA sub-regions. 

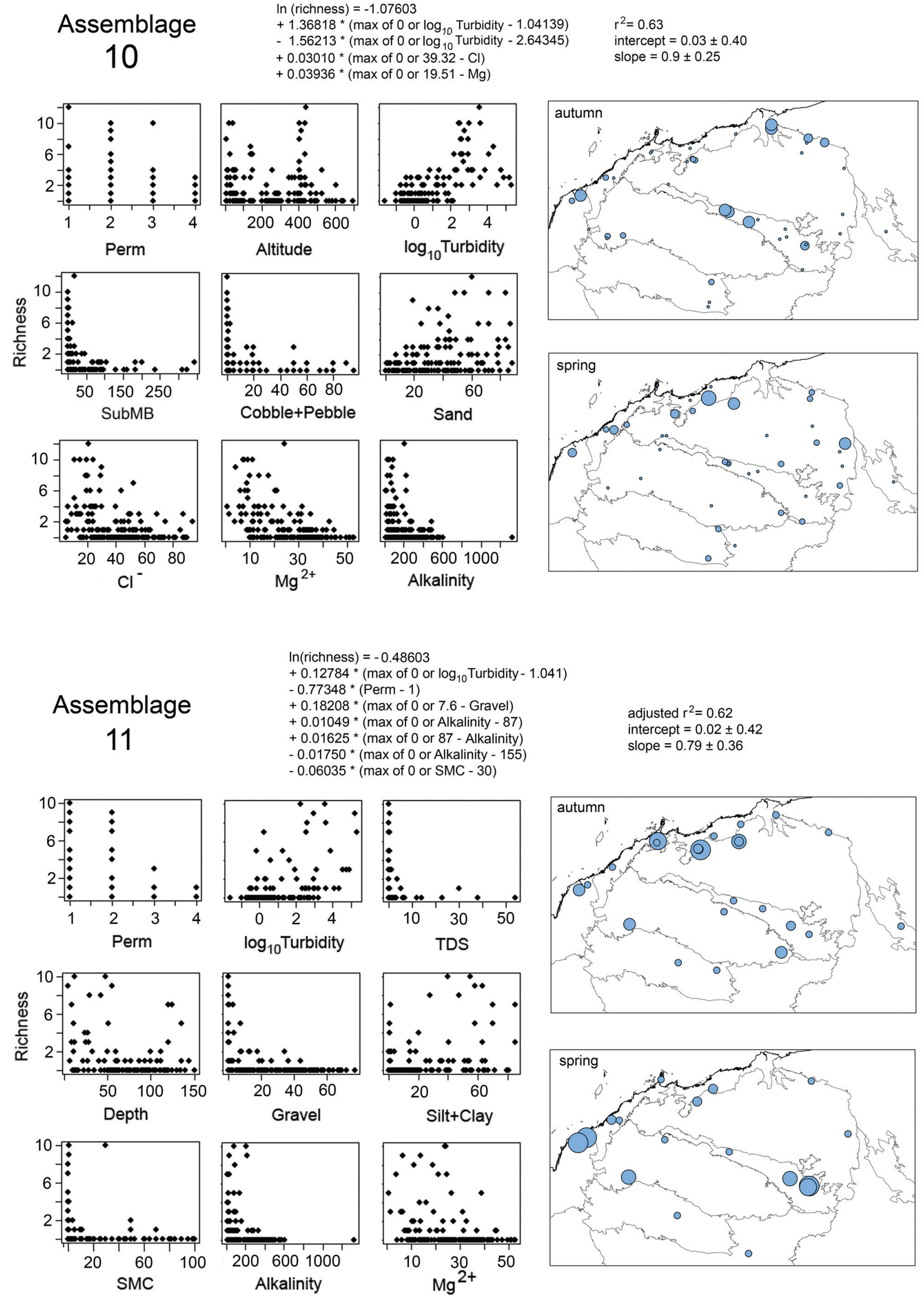

Figure 18 Results of MARS modeling and maps showing richness of assemblages 10 and 11 in spring and autumn. Shown for each assemblage are graphs of richness versus selected environmental variables, the model equation, adjusted $r^{2}$ and slope and intercept of the regression line with standard deviations. See Appendix 1 for units of environmental variables. Sizes of symbols on the maps are proportional to maximum richness in either season. Internal boundaries on the maps are IBRA sub-regions. 

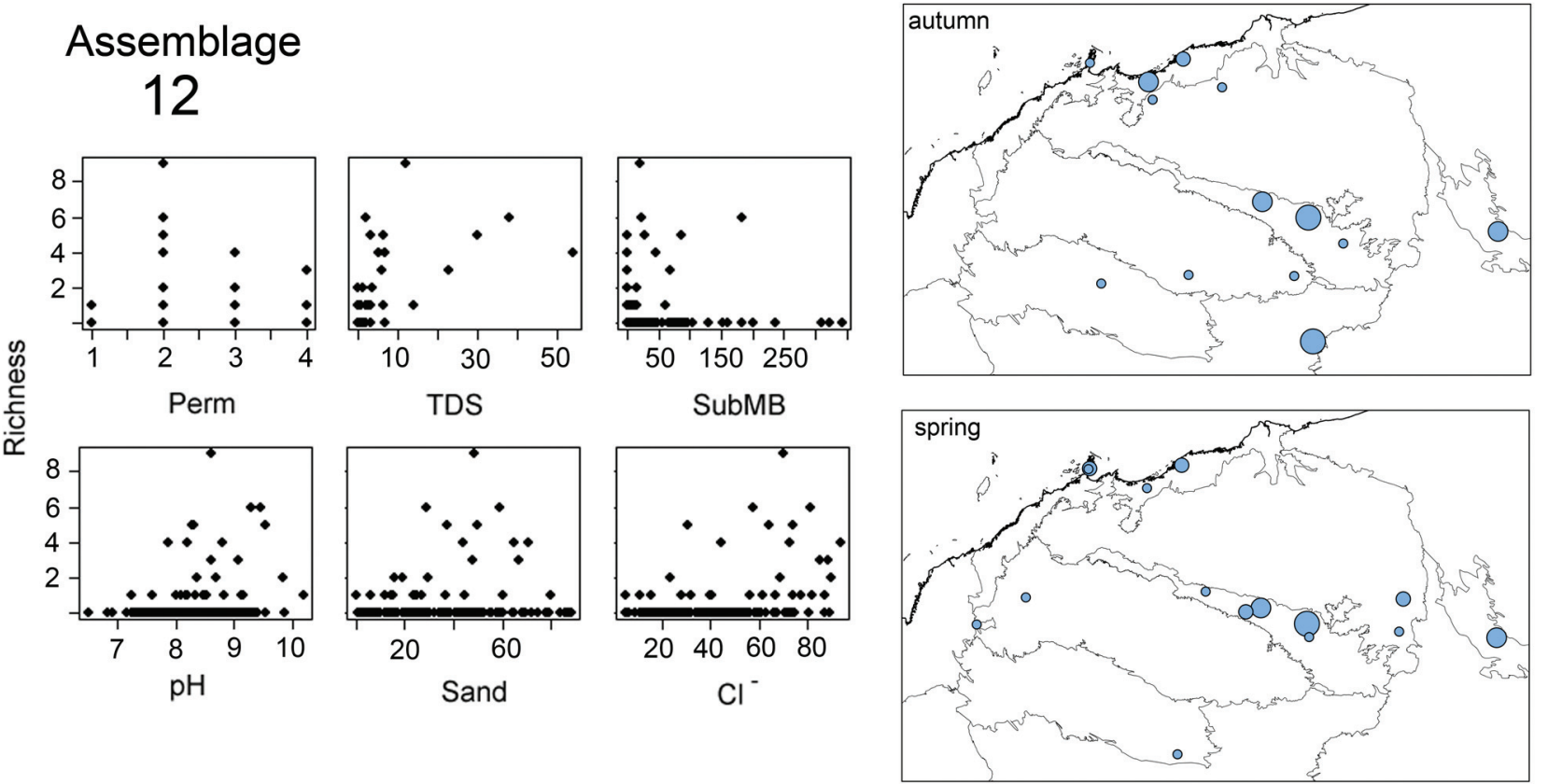

\section{Assemblage}

\section{3}
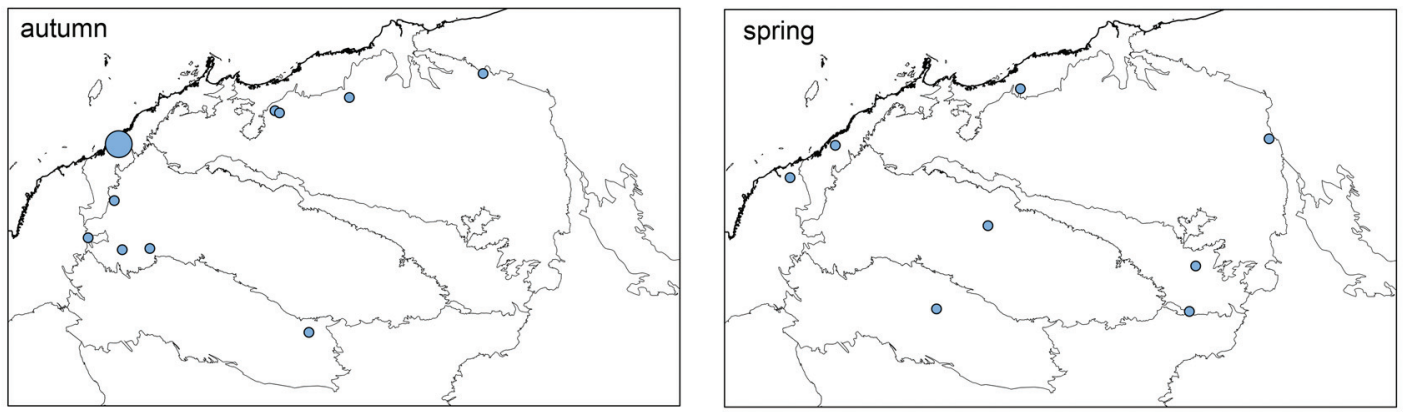

Figure 19 Assemblages 12 and 13, showing (for both assemblages) maps of richness in spring and autumn and (for assemblage 12) univariate relationships with assemblage richness. See Appendix 1 for units of environmental variables. Sizes of symbols on the maps are scaled to the maximum richness recorded in either season. Internal boundaries on the maps are IBRA sub-regions.

30 wetlands, most of which were mildly turbid claypans, rockpools, turbid river pools and some other non-flowing river pools. These were collected mostly from wetlands on the coastal plains, lower De Grey-Oakover catchment and middle to upper Fortescue Valley, where most of the claypans occur (Figure 17). Only four wetlands had more than three representatives and the assemblage was not modeled.

\section{Assemblage 10}

A group comprised of 39 species, about half microcrustacea and rotifers and the rest mostly beetles and dipterans, present in 81 samples from 55 wetlands. Included are several species known to be associated with turbid waters, including the ostracods Ilyocypris sp. nov. (also recorded from the northern WA wheatbelt), and Limnocytheridae sp.
419 (Carnarvon Basin) and the copepod Calamoecia baylyi. Other species are new, including the new Eocyzicus conchostracan, which is probably also a claypan specialist. As with assemblage 11 below, some species (e.g. the beetle Berosus nutans and hemipteran Anisops gratus) are likely to be present simply because the wetlands are lentic rather than because of a preference for ephemerality or turbidity. The distribution of this assemblage reflected the distribution of claypans-mostly coastal and along the middle Fortescue Valley (Figure 18), as indicated by the bimodal response of richness to altitude (Roebourne Plains with the lowest altitude and middle to upper Fortescue Valley at about $400 \mathrm{~m}$ Figure 18). Richness was highest at ephemeral to seasonal wetlands with moderate turbidities (richness increasing between 
about 11 and 440 NTU) and in wetlands with low $\mathrm{Mg}^{2+}$ and $\mathrm{Cl}^{-}$(reflecting the ionic composition of claypans). The MARS model, incorporating these variables, had an adjusted $\mathrm{r}^{2}$ of 0.63 . These showed a strong preference for mildly to moderately turbid waters.

\section{Assemblage 11}

Only 41 samples from 31 wetlands contained any of these 41 species. Included are species known to be claypan or ephemeral wetland specialists, such as Branchinella and Streptocephalus fairy shrimps, the cladoceran Australospilus elongatus, shield shrimps (Triops), the copepod Calamoecia halsei and Bennelongia ostracods. Several new species are probably also claypan specialists, including new Lecane and Keratella rotifers, Cypretta ostracods and Branchinella fairy shrimp. The model suggests that high richness was most strongly associated with short hydroperiods, increasing turbidity (above 10 NTU), declining alkalinity (below $155 \mathrm{mg} / \mathrm{L}$ ), low gravel content in sediments (below $8 \%$ ) and low submerged macrophyte cover (below 30\%). The assemblage is thus most prevalent in ephemeral and highly turbid claypans, but with some species also present in ephemeral creeks and gnammas on rock outcrops.

\section{Assemblage 12}

Twenty species, primarily microcrustaceans, rotifers and dipterans, occurring in 29 samples from 21 wetlands (Figure 19). These are largely species already known to be halotolerant or halophilic, such as Hexarthra spp. and Tanytarsus barbitarsus, but some, including Coxiella sp. and Mytilocypris sp. nov., are probably additional halophiles. These tended to occur in the more saline wetlands with higher $\mathrm{pH}$, fine sediments, low biomass of submerged macrophytes (but not low cover) and low turbidity. However, a MARS model that converged could not be found.

\section{Assemblage 13}

Ten species, mostly microcrustaceans and rotifers, seemingly united by their co-occurrence in one sample (Yarraloola Claypan, site 74, in autumn, Figure 19), but very sporadically occurring in a few other wetlands (18 samples from 19 wetlands). Some are commonly found in ephemeral habitats (e.g. the rotifer Lecane curvicornis, the cladoceran Macrothrix flabelligera and beetle Sternolophus immariginatus). This assemblage was not modelled due to its sparse and probably artificial nature.

\section{DISCUSSION}

\section{Adequacy of sampling}

The common wetland types of the Pilbara were well represented in the survey but there are some gaps where further sampling is likely to add to knowledge of the region's aquatic invertebrate diversity. Almost all sampling was undertaken in either autumn or spring, but communities in ephemeral wetlands sampled in late summer tended to cluster apart from spring and autumn samples. A few species (e.g. Aedes pseudonormanensis, Calamoecia ultima and Limnadia sp. P1) were more common in these few summer samples than in the many spring or autumn samples, so there may be an immediate post-flood fauna in ephemeral wetlands that was under-sampled by this survey. Significant areas that were poorly sampled, or not sampled, include the wetlands in dunes south of the Kunderong Range, south-west of Newman, which were not sampled due to difficult access. Areas of mulga flats fed by endorheic drainage in the Hamersley Range (e.g. Mount Bruce, Wanna Munna and Coondawanna Flats) were dry whenever visited during the survey and also represent a wetland type not sampled. High-order river pools above tidal influence on the Roebourne Plains were under-sampled. Finally, the middle Fortescue River between Millstream and Mulga Downs station, which is not so well defined as most other major Pilbara rivers, and which includes some braided and deltaic sections, was not sampled.

These gaps notwithstanding, the sampling regime appears to have captured a very significant proportion of the aquatic invertebrate diversity inhabiting the region's dominant wetland types. There is no consensus on what proportion of site or regional richness is required to have been sampled before conclusions about biodiversity patterning can be drawn, other than that it should be high (New 1998). Chao et al. (2009) suggested that 90-95\% may be a reasonable objective, but did not comment on how adequate this might be for various purposes. Our analyses suggest that we have captured up to $85 \%$ of the regional fauna inhabiting the types of wetlands sampled, though this is probably an overestimate for the region considering the lack of an asymptote on the richness estimator curves and the sampling gaps identified above. Recent collecting in Pilbara river pools (Pinder and Leung 2009) revealed an additional 18 macroinvertebrate taxa from 10 high-order river pools on the Roebourne Plains. Given that the work excluded rotifers and microcrustacea, this number of additional species is greater than predicted from richness estimator curves, but lowland river pools are one of the sampling gaps noted above.

The proportion of the estimated regional fauna that we collected in the Pilbara survey appears to be higher than for most other large-scale biodiversity surveys. In a survey of aquatic invertebrates in the Carnarvon Basin, Halse et al. (2000) recorded 
476 species, which is $78 \%$ of the regional richness estimated using the same methods. However, the estimate of regional richness did not quite reach an asymptote and the observed and estimated regional richness were still increasing by one or two species per sample near the end of the curve. In the wheatbelt region of south-western Australia, Pinder et al. (2004) collected 957 species, which is about $73 \%$ of the estimated regional richness, but again the curve did not flatten out and observed and estimated regional richness were increasing by about two taxa per sample near the end of the curve. Compared to these studies, and probably most others listed below, we appear to have sampled a comparatively high proportion of the fauna in the Pilbara. Undetected taxa are undoubtedly rare at the regional scale and are unlikely to have altered outcomes of our analyses significantly (Arscott et al. 2006).

At the individual wetland scale, the sampling methods employed captured about $75-85 \%$ of species estimated to have been present at three test sites. These are very similar to estimates of invertebrate sampling efficiency recorded by Halse et al. (2002), who concluded that this was sufficient to contrast invertebrate faunas of different wetlands. However, for some larger heterogeneous wetlands, such as Carawine Gorge and Paradise Pool, use of a single sampling site is unlikely to have captured such a large proportion of the wetlands' overall diversity.

\section{Diversity}

While there are some taxonomic publications that focus on north-west faunas, such as Lansbury (1984) and Smit (1997, 1998), and many others with some Pilbara records, there are very few studies providing information about the aquatic invertebrate communities of the Pilbara region. As part of a continental-scale river condition assessment, Kay et al. (1999, supplemented by later data) recorded 76 macroinvertebrate families from 18 river pools, including four families not recorded in this survey. Ponder (1987) undertook a small survey of springs (Millstream, Fortescue Falls, Running Waters and Skull Springs) and concluded that these contained rare and/or restricted species, which was confirmed during this study. Halse et al. (2002) recorded 159 species (including 18 groundwater species) in a study that examined the extent to which springs provide habitat for both groundwater and surface water faunas. Our survey recorded most of these species but few additional groundwater taxa (detailed below). Pilbara odonates were fairly well known prior to this survey (Watson 1969) and our survey supports the established view that Nososticta pilbara is restricted to the Millstream wetlands. However, the limited previous sampling effort means that most of the species in listed in Appendix 2 are new records for the region and many are new records for Western Australia. The 10\% of species that are 'new to science' is similar to results of surveys of other Western Australian regions (e.g. Halse et al. 2000; Pinder et al. 2004).

With an estimate of about 1200 species of aquatic invertebrates, and an average of 94 species recorded per sample, the Pilbara fauna appears to be rich. This is in contrast to some other studies that have suggested that Australian arid zones have a depauperate fauna (e.g. Marshall et al. 2006), but few of these studies have had the taxonomic breadth and depth of the Pilbara survey. The Carnarvon Basin, south-west of the Pilbara, has similar annual rainfall $(200-400 \mathrm{~mm})$ but is only a third the size of the Pilbara. Halse et al. (2000), using the same sampling protocol and taxonomic scope and resolution as used in the Pilbara, but with half the number of samples and sites, recorded 476 micro and macroinvertebrate taxa, from at least 600 estimated to be present in the region. Average richness was only 31 taxa per sample and 41 per site (two dates combined for most sites). Lower regional richness would be expected in a smaller, more topographically homogeneous region, especially since a greater proportion of the wetlands sampled by Halse et al. (2000) were ephemeral and/or saline. However, even for the same wetland types, alpha richness seemed to be lower in the Carnarvon Basin. Richness in river pools (38 \pm 2 ) and claypans $(24 \pm 3)$ was only about a third of that recorded for such wetlands in the Pilbara. Salinity in these wetland types was similar when sampled in both projects, but groundwater is mostly saline in the Carnarvon Basin and higher salinities may, at times, represent a bottle-neck for invertebrate diversity. Carnarvon Basin river pools also tend to have finer and more homogeneous sediments compared to the Pilbara (unpublished data, see Halse et al. 2006) which reduces habitat diversity. Whatever the cause, lower richness in river pools represents a smaller species pool available to colonise the more ephemeral wetlands during floods or via aerial dispersal (Anderson and Smith 2004).

The semi-arid wheatbelt region is comparable in size to the Pilbara but has little permanent water (and virtually no permanent freshwater other than reservoirs), despite higher rainfall (300-600 mm per annum) and significant interaction between surface water and the mostly saline groundwater. A survey of the wheatbelt (Pinder et al. 2004), using protocols and sampling effort similar to those used in the Pilbara, collected 957 taxa from an estimate of $>1300$ in the region, but alpha diversity

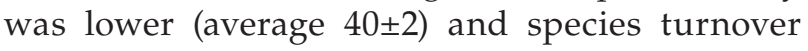


or beta diversity much greater $\left(\beta_{w}=24\right)$ than in the Pilbara. The high proportion of ephemeral and/or naturally or secondarily saline wetlands included in the survey reflects their preponderance in the wheatbelt but contributed to the low alpha diversity. The very high diversity of wetland types, large latitudinal range of the study area and numerous salt lakes with strongly heterogeneous faunas probably explain the high beta and regional diversity in the wheatbelt.

The arid Lake Eyre Basin (LEB) is larger than the Pilbara (approximately 1.1 million $\mathrm{km}^{2}$ ) but has lower annual rainfall (average $125 \mathrm{~mm}$ ). This basin has very few permanent fresh waterbodies (Bunn et al. 2006), some waterholes are saline and most are reliant on surface flows rather than groundwater, so salinity often rises between flood events due to evapoconcentration (Costelloe 2004) and/or saline seepage. In studies of this region's aquatic fauna, Shiel et al. (2006) collected 423 zooplankton species (protozoans, rotifers, copepods and cladocerans) from 56 wetlands in the LEB. This is comparable with the 346 species in these faunal groups collected in the Pilbara, given that protozoans were not well sampled in the Pilbara survey. Madden et al. (2002), Costelloe et al. (2004) and Marshall et al. (2006) collected about 170 macroinvertebrate taxa (mostly identified to genus) from about 90 wetlands in the southern and eastern LEB. The number of macroinvertebrate species is likely to be at least twice the number of genera (macroinvertebrate species to genus ratios were 2 to 2.5 in the Pilbara and other large Western Australian surveys mentioned above), so the regional aquatic invertebrate fauna is likely to be over 800 species, especially since ostracods were not identified. Data on richness at individual wetlands was not provided in these studies.

Most wetlands in the arid Paroo region of inland New South Wales are intermittent, although many fill in most years. Timms and Boulton (2001) recorded 217 invertebrate taxa in 87 wetlands in this region. Some groups (e.g. ostracods and cladocerans) were under-sampled or not identified to species, while rotifers were rarely identified at all, so it is likely the species list substantially underestimates richness of individual wetlands as well as the region. Richness of individual wetlands ranged from 10 to 36 in saline lakes, 39 to 71 in freshwater lakes and 27 to 29 in claypans. Compared to the present survey, samples were much smaller but were collected more frequently.

In central Australia, Davis (1997), Davis et al. (1993) and Brim Box et al. (2008) recorded 130 macroinvertebrate species from 42 central Australian wetlands. Richness ranged from 4 to 64 per wetland but several groups likely to be speciose were not identified to species. For the same range of taxa, in the Pilbara we collected 6 to 190 per wetland with an average of 93.

There are few comparable datasets from arid zones outside Australia. Hall et al. (2004) collected 107 macroinvertebrate taxa, mostly identified to species level, from 73 freshwater playas in Texas, each sampled three times. Richness at a wetland ranged from 24 to 33 per sampling event, compared with 10 to 98 (median 55) for equivalent wetlands in the Pilbara (claypans), though some of the Pilbara claypans were ten times as large as the largest Texan playas. De Moor et al. (2004) collected 216 macroinvertebrate species from 27 riverine sites along a $340 \mathrm{~km}$ stretch of the permanently flowing Cunene River in south-western Africa. This compares to 325 to 398 macroinvertebrate species in fewer pools along the longest Pilbara rivers (Ashburton, Fortescue, De Grey-Oakover).

Based on these limited comparisons with other parts of Australia and other continents, the Pilbara appears to have particularly high diversity at the wetland level, although it is less outstanding at the regional level because of low beta diversity. A partial explanation of the observed richness is the high sampling effort, broad taxonomic scope and fine taxonomic resolution employed in this survey, but aspects of Pilbara wetlands may also promote high diversity. Invertebrate richness in desert rivers has been associated with the duration of flow and water permanence, substrate diversity, habitat complexity and proximity to permanent refugia (Sheldon et al. 2002; Boulton et al. 2006). Pilbara river pools tend to have high habitat diversity, with multiple emergent and submerged macrophyte communities, organic litter and debris, flowing water at one or both ends of the pool (often from springs or alluvial discharge), dense submerged root mats along pool edges and a variety of inorganic substrates (often with clay, gravel, cobble and bedrock in the same pool). This does not explain high diversity in Pilbara claypans, however, which are as structurally simple as those elsewhere, although high biotic diversity in riverine refugia may promote high floodplain diversity following floods.

Although the Pilbara is an arid zone, its geology (extensive aquifers) and climate (relatively regular summer rainfall occurring in intense events) result in an abundance of permanent fresh refugia, including springs and river pools maintained by springs and hyporheic flows. Permanent waters affect regional and wetland richness in at least two ways. Firstly, the abundance of permanent water, combined with the latitudinal position of the Pilbara, is likely to have allowed both southern and tropical taxa to extend into the region in a way that may be uncommon in arid regions (see Biogeography below). Secondly, in arid zones 
permanent waters tend to have higher species richness than temporary waters (Halse et al. 1998; Brendonck and Williams 2000; Sheldon et al. 2002; Eitam et al. 2004; Boulton et al. 2006; Brim Box et al. 2008; Waterkeyn et al. 2008). In our survey, invertebrate richness of wetlands increased with increasing hydroperiod class, especially amongst the more mobile insects which are able to colonise river pools after they have become isolated. Longer hydroperiod allows more species to colonise and greater habitat complexity to develop (Boulton and Jenkins 1998; Sheldon et al. 2002). Longer-lasting wetlands are also frequently deeper and larger, which may also promote greater habitat diversity. An abundance of permanent wetlands may also translate to high regional richness by allowing the region to maintain a large species pool during drought periods and by increasing the probability of colonisation by irregular immigrants. Regular frequency of inundation also promotes high invertebrate diversity in non-permanent wetlands (Boulton and Lloyd 1992) and, in the Pilbara, few wetlands would go more than a couple of years without some inundation.

In the river pools of some arid zones, water quality deteriorates as water volume declines during drought periods, even in permanent wetlands, and especially where water levels are controlled by surface water flows and/or where saline groundwater intrudes when water levels are low (Costelloe et al. 2005; Hamilton et al. 2005). Such pools can experience raised salinity and temperature, concentration of nutrients and increased solar radiation as pools contract away from banks, with subsequent problems associated with algal blooms (Lake 2003). These impacts have well-known effects on aquatic invertebrates, including reduced species richness (reviewed in Lake 2003). Hamilton et al. (2005) suggested that waterholes maintained by fresh groundwater would be 'exceptionally important' refugia in the Cooper Creek system of the Lake Eyre Basin. By contrast, in the Pilbara, pools maintained by fresh hyporheic or spring flows are not unusual and water quality tends to remain high during dry periods. This probably also contributes to high invertebrate richness between floods.

\section{Biogeography}

There is sufficient information for about twothirds of the species collected to comment on the fauna's biogeographic affinities. About half of the species are widespread in Australia or their known distributions are patchy. These do not have welldefined, sub-continental distributions, though a few occur mostly in the inland. About a quarter have a northern distribution, with a few of these also occurring in Asia, some extending well inland and a few extending around both northern and western Australia. About 5\% have broader Western Australian distributions, occurring primarily south of the Pilbara, including a few apparently arid zone species not known outside the state. About 2\% have broad southern Australian distributions and are at their known north-western limit in the Pilbara. The regionally endemic component described earlier comprises the remaining 19\%. It is very likely that some of these will be found outside the Pilbara with further survey effort. For instance, the newly described Haliplus fortescuensis Watts and McRae, 2010, first collected during the present project, was recently recorded in the Kimberley region (Daniel et al. 2009). Similarly, numerous species first collected in the Carnarvon Basin (Halse et al. 2000) have now been collected in the Pilbara (e.g. Keratella sp. nov., Bennelongia sp. 414, Branchinella halsei). The Pilbara fauna is thus a blend of widespread species, species near their northern limits, species shared with tropical northern Australia that rarely extend further south, plus a north-west fauna. Absent from the Pilbara is a larger tropical fauna that does not extend west of the Kimberley region. This includes many genera and species of odonates, mayflies, leeches, and most species of atyid shrimps and palaemonid prawns (though one palaemonid, Macrobrachium, has recently been collected from the lower De Grey by Pinder and Leung [2009]). Short et al. (2004) suggest that north Queensland may have been a centre for dispersal of species of Macrobrachium to other parts of tropical Australia owing to its proximity to Papua New Guinea (where Macrobrachium diversity is higher), and that regional diversity in Australia may be related to distance from north Queensland (the Kimberley region is relatively depauperate). They also suggest that past and present aridity may limit occurrence of Macrobrachium outside of the tropics and, in this respect, the Great Sandy Desert is probably a formidable barrier to westward extension of many tropical species. Some species restricted to the Pilbara have congeners that are restricted to either the Kimberley or to the northern tropics more broadly (e.g. the damselflies Eurysticta coolawanyah and Nososticta pilbara in the Pilbara and Eurysticta kununurra and Nososticta kalumburu in the Kimberley region) and the Pilbara species may represent lineage divergence through isolation.

The limited subregional patterning within the Pilbara was associated with the uneven geographic distribution of wetland habitats. Assemblages occupying springs and spring-fed pools were richer in upland areas (where there is more surface groundwater discharge) whereas those occupying turbid waters were richer in the valleys and lowlands. The faunas of springs and claypans also showed some differentiation between drainage basins. Species in these habitats are generally 
less mobile and less likely to be moved around by floods, possibly contributing to subregionally distinctive faunas. River pool faunas were more uniform across the region and showed little longitudinal variation along rivers. The lack of strong patterning in rivers within the region is consistent with results of a survey of north-western fish faunas (Morgan and Gill 2004) which showed that, while the Pilbara has a distinct fish fauna, compared to the west-flowing rivers south of the Pilbara, it represents a single biodiversity province for fish.

Davis (1997) and Brim Box et al. (2008) suggested that permanent waters of central Australia are important because they provide a refuge from drought for indigenous species and mesic relicts. In the Pilbara this is true of the subset of springs and spring-fed pools that support a small mesicadapted fauna (including assemblage 8), some of which are probably regional endemics. These sites include the Millstream wetlands, springs in Karijini gorges and a few other springs. A few of these species are groundwater taxa, for which the springs are potential points of dispersal rather than refuges, but most belong to faunal groups that have known associations with permanently moist habitats. It is not clear why this group of species is seemingly restricted to only a subset of the springs, although differences in the hydrology and vegetation structure of the springs may be part of the explanation. The springs supporting these species are shaded by tall riparian woodlands or are within deep gorges, have strong base flows, and most have some deep pools and lacked a dense cover of benthic algae. By contrast, springs without this faunal component tended to lack canopy cover and/or had just trickles or seepage when sampled, or had just a shallow creek rather than deep pools, and frequently had substrates covered with dense filamentous algae. Another explanation may be that the few springs supporting this mesic element are those that have been consistently wet for longer periods. The occurrence of mesic species restricted to the most permanent wetlands in central Australia led Davis (1997) and Brim Box et al. (2008) to suggest that conservation of permanent wetlands could protect more native biological diversity than conservation of temporary ones. To some extent this is borne out in the Pilbara, where a quarter of the regionally endemic component of the fauna was collected only from permanent river pools and springs, compared to $12 \%$ collected only in ephemeral to seasonal wetlands. However, for this $12 \%$, and for many other species, conservation of temporary wetlands is critical.

Williams (1998) and Williams and Kokkin (1988) argued that arid zone wetlands tend not to support regionally endemic species, but this was based on the assumption that arid wetlands are episodic (infrequently and unpredictably flooded) rather than intermittent (more regularly and predictably flooded). Regional endemism in intermittent wetlands is actually very common (Simovich 1998; Watts 1999; Halse et al. 2000; Costelloe et al. 2004; Pinder et al. 2004; Shiel et al. 2006), whereas episodic wetlands seem to have much less regional endemism, at least in Australia (Timms 2001, 2007). Temporary wetlands in the Pilbara are generally intermittent rather than episodic, so the presence of a regionally endemic component to their faunas would be expected.

Despite $19 \%$ of the Pilbara fauna possibly being regionally endemic, our data suggest that very few of the region's surface water invertebrates are likely to be short-range endemics (sensu Harvey 2002). While many species were encountered rarely, their occurrences tended to be widely separated. Rare exceptions to this include the Pilbara damselfly Nososticta pilbara (restricted to Millstream wetlands) and the fairy shrimp Branchinella pinderi (known only from the western Roebourne Plains).

The stygofauna component of the Pilbara survey has revealed a groundwater fauna that is particularly diverse compared to similarly sized regions elsewhere, with 350 species recorded from an estimate of at least 500 species for the region (Eberhard et al. 2005, 2009; S.A. Halse, pers. obs.). Since many springs and river pools are areas of contact between groundwater and surface water, it might be expected that such wetlands would be zones of overlap between stygal and epigean faunas. We recorded most of the 18 stygal species that Halse et al. (2002) recorded in Pilbara springs, plus a few additional ones: a number of phreodrilid oligochaetes, a copepod (Parastenocaris jane), two ostracods (Humphreyscandona adorea and Sarscypridopsis cf. ochracea), plus the amphipods Chydaekata and Pilbarus and the isopod Pilbarophreatoicus platyarthricus. These occurred mostly in springs but some were recorded in permanent river pools with spring inflows or coarse sediments that presumably had hyporheic flow. However, the occurrence of stygal species in surface water wetlands was relatively uncommon compared to the frequency with which epigean species were recorded in groundwater (S.A. Halse, pers. comm.).

\section{Environmental correlates of biodiversity patterns}

The 13 species assemblages clearly differed in their associations with water chemistry, habitat variables, geographic distribution and climate: some responded to the same variables but with different slopes, thresholds or polarity. This provides some understanding of how the region's aquatic invertebrate fauna is distributed across 
many of the major environmental gradients. The predictive power of the models produced for nine of these assemblages was rarely high, but nonetheless the models highlighted which combinations of variables were most strongly correlated with high representation of the assemblages and identified response thresholds. Four smaller assemblages were not amenable to modeling, but some of these were narrowly distributed in relation to environmental gradients (e.g. halophilic species in assemblage 12 and species of permanently flowing springs in assemblage 8).

Broad-scale surveys such this one often reveal a large number of relationships between the biota and the environment, not all of them causal. Climate variables showed subtle univariate relationships with all assemblages but few were selected in models. Those included in models had primarily coastal to inland gradients (cooler and less variable temperatures and higher rainfall near the coast) aligned with patterns in richness of three assemblages (1, 3 and 4). The climate parameters were amongst the strongest parameters in those models, but it is not clear whether such correlations reflect ecophysiological tolerances (e.g. to temperature or reliability of inundation) or are correlations with some other factors, such as the distribution of particular wetland habitats not as well described by latitude, longitude and altitude.

Variables describing hydrology, salinity, turbidity, aquatic vegetation and sediment composition were also associated with the distributions of different assemblages. These variables are considered to be primary drivers of invertebrate community composition in dryland rivers (Boulton and Lloyd 1991; Timms 2001; Timms and Boulton 2001; Sheldon et al. 2002; Costelloe et al. 2004; Shiel et al. 2006) but their effects are difficult to separate in survey datasets such as this.

There was a gradient in overall community composition from ephemeral wetlands through to those considered to be permanent. This is in line with most previous studies that have examined the influence of hydroperiod and invertebrate communities (e.g. Boulton and Lloyd 1992; Collinson et al. 1995; Schneider and Frost 1996; Eitam et al. 2004; Waterkeyn et al. 2008). Permanence class and/or flow were associated with richness of most assemblages and were parameters in some of the models. Depth may also have reflected hydroperiod: the depth thresholds in richness models were in the range 70 to $100 \mathrm{~cm}$, coinciding with the transition from wetlands that would have been ephemeral to those deemed to be near permanent. A range of other hydrological variables describing timing, frequency and extent of flows and inundation also influence wetland faunas of arid zone wetlands (Walker et al. 1995; Boulton 1999) but we did not have information on most of these for our study sites. A number of major flood events during the survey did allow us to investigate the effects of these on seasonal changes in invertebrate communities. Numerous studies have demonstrated the resilience to major flood events of the aquatic invertebrate faunas of arid zones (Fischer et al. 1982; Stanley et al. 1994; Anderson and Smith 2004). Our data suggest that, within a few months of flooding, river pool communities were as rich as they were before flooding and as rich as pools that did not experience floods. There was some indication that pre- and postflood communities had different composition but the difference was not large. Thomaz et al. (2007) suggested that floods tend to homogenise river faunas. Some features of riverine communities in the Pilbara are consistent with this. Thus, stream order had little bearing on overall community composition below $2^{\text {nd }}$ order, and riverine wetlands generally had more homogeneous communities compared to floodplain wetlands, despite the latter generally being structurally simpler wetlands.

Where there is a salinity gradient, it is also normally one of the strongest influences on aquatic invertebrates (Hammer 1986). Many wetlands of arid zones are normally saline, and some freshwater wetlands become saline either through concentration of salts or intrusion of saline groundwater as water levels decline (Timms and Boulton 2001; Costelloe et al. 2005; Shiel et al. 2006). Almost all wetlands in the Pilbara were fresh when surveyed, other than the two salt marshes, a couple of river pools influenced by tidal flows, and pools and streams on the Burrup Peninsula possibly affected by sea spray. With many Pilbara river pools being maintained by fresh groundwater, salinisation between flows appears to be relatively uncommon in the region (sites 29 and 53 were exceptions in this study). The only assemblage dominated by halotolerant or halophilic species was assemblage 12 , which had lowest richness in freshwater and maximum richness in the two salt marshes. Other halotolerant species were distributed across several assemblages that had greatly reduced richness as salinity increased. Where salinity was a parameter in models, it indicated a decline in richness above about $3.3 \mathrm{~g} / \mathrm{L}$. This threshold is close to the value of $4.1 \mathrm{~g} / \mathrm{L}$ below which Pinder et al. (2005) found aquatic invertebrate richness to decline (2.6 when halophilic species were excluded). Alkalinity was also a feature in many of the models, with richness responding either positively or negatively to this variable. Alkalinity has been correlated with invertebrate composition and biomass in numerous studies (Koetsier et al. 1996; Death and Joy 2004), for reasons that are not fully understood but often attributed to an effect on primary production (e.g. Dickman 1973), microbial processing of detritus or biomineralisation (Mackie 
and Flippance 1983). Other components of ionic composition have physiological consequences for aquatic invertebrates, although more so in saline waters (e.g. Radke et al. 2003). We observed strong relationships between richness of many of the assemblages and proportional contributions of ions, most notably $\mathrm{Mg}^{2+}$ and $\mathrm{K}^{+}$. There may have been a degree of direct biological response in these relationships but it is likely that these correlations were acting as surrogates for a range of characteristics that distinguish lentic from lotic wetlands not represented as well by other variables. Lentic wetlands in the Pilbara had relatively high $\% \mathrm{~K}^{+}$, perhaps due to the tendency for clay soils to concentrate potassium more than the coarser sediments of the larger river channels, whereas lotic wetlands had proportionally higher $\% \mathrm{Mg}^{2+}$.

Turbidity is often naturally very high in arid zone wetlands with clay sediments (Bunn et al. 2006) and is certainly associated with very distinctive communities (Timms and Boulton 2001; Timms 2002). The role that turbidity plays, independent of shallow depth and ephemerality (also typical of claypans), is not well understood, but it limits macrophyte growth and affects algal production through light limitation, resulting in benthic primary productivity being largely restricted to the edge of the waterbody (Bunn et al. 2003; Fellows et al. 2007). Turbidity probably also allows the occurrence of the larger crustaceans such as Branchinella and Triops that would otherwise be prone to predation by waterbirds, although ephemerality frequently eliminates fish which would also predate on such invertebrates. Many of the pools in smaller lowland creeks were turbid in the Pilbara, as were all the claypans, with the shallowest of the latter having extremely high turbidity ( $>10,000 \mathrm{NTU})$. This variable was present in the models of the two assemblages primarily occurring in claypans (10 and 11). Richness of both of these assemblages was associated positively with high turbidity, with assemblage 10 increasing in richness only between 10 and 440 NTU (then declining) and assemblage 11 increasing in richness more continuously from about 10 NTU.

The importance of macrophytes and sediments as structural features of arid zone wetlands has not been as much of a focus as have the roles of hydrology, salinity and turbidity, but some authors have indicated their importance (Boulton and Lloyd 1991; Sheldon et al. 2002). They are certainly known to influence invertebrate communities more generally (Williams and Mundie 1978; Cyr and Downing 1988; Wollheim and Lovvorn 1996). Our analyses showed both positive and negative relationships between assemblage richness and macrophyte variables, though the negative relationships were for species preferring turbid or saline conditions, so low macrophyte abundance may be incidental to these other factors. Where there was a positive relationship (e.g. assemblages 1, 3 and 4) there was generally an initial increase in richness as cover and/or biomass increased to some moderate level, then no further response or even a decline in richness (e.g. response of assemblage 4 to submerged macrophyte cover). This may have been because habitat heterogeneity would be increased by the presence of moderate amounts macrophytes but reduced by more complete coverage or very high density of macrophytes. Other studies have reported similar non-linear relationships (e.g. Collier et al. 1999). Strong positive or negative relationships were observed between richness and percentage contribution of sediment size fractions, but this relationship was usually only for the range before the fraction became dominant. This might also reflect a heterogeneity effect. In our survey, the single large invertebrate samples were frequently taken across multiple sediment types and macrophyte communities (including absence of macrophytes) and this may have weakened our ability to describe richness-habitat relationships.

\section{CONCLUSIONS}

The Pilbara has a particularly high diversity of aquatic invertebrates for an arid zone, at least at the level of the individual wetland. We suggest that this high richness partly reflects the abundance of consistently fresh, permanent water maintained by extensive groundwater aquifers. About a fifth of the fauna is presently known only from the Pilbara but there is also a substantial pan-northern element and smaller western and southern elements. The fauna is generally widespread within the region, with little evidence of local endemism. Of particular note is a group of relatively rare and mostly mesic taxa that are heterogeneously distributed across a limited range of springs and spring-fed pools, including those of Millstream and Karijini National Parks.

The limited sub-regional patterning largely reflects the distribution of wetland habitats, such as more ephemeral turbid waters along the coast and broader inland valleys and more permanent flowing water in upland areas. There were some differences in composition of springs and claypans between drainage basins but river pool communities are generally homogeneous within and between basins. Aquatic invertebrate faunas of river pools regain similar richness and composition within a few months of catastrophic floods.

The fauna is distributed along a range of environmental gradients, including hydroperiod, flow, salinity, turbidity, sediment composition and extent of aquatic vegetation. Conservation of aquatic invertebrate diversity in the Pilbara is dependent on the persistence of wetland habitats along these gradients. 


\section{ACKNOWLEDGEMENTS}

Numerous pastoralists and indigenous communities generously shared their knowledge of Pilbara wetlands (and provided the occasional shower and bed). We particularly thank Pilbara DEC staff, including Peter Kendrick and Stephen van Leeuwen, for providing advice on wetland locations, contacts and working in the Pilbara, and other Pilbara staff for assisting with logistics. Leah Stratford assisted in the laboratory and Lauryne Grant and Harley Barron assisted in the field. Anna Leung and Ross Gordon helped prepare data and tables. Numerous taxonomists verified or identified voucher specimens: Brian Timms (large branchiopods), Chris Watts (beetles), Alena Glaister (Elmidae), Fredric Govedich (leeches), Phil Suter (mayflies), Tom Weir (hemipterans), Ros St Clair (leptocerid caddisflies), John Dean (hydropyschid caddisflies), Hendrik Segers (rotifers), Gunther Theischinger (odonates) and Winston Ponder (molluscs). Some climatic data were provided by the Bureau of Meteorology's National Climate Centre and was dated 2008. The GIS section of DEC provided geodesic distances between wetlands.

\section{REFERENCES}

Anderson, J. and Smith, L. (2004). Persistence and colonization strategies of playa wetland invertebrates. Hydrobiologia 513: 77-86.

Arscott, D.B., Jackson, J.K. and Kratzer, E.B. (2006). Role of rarity and taxonomic resolution in a regional and spatial analysis of stream macroinvertebrates. Journal of the North American Benthological Society 25: 977-997.

Australian Government (2004). Interim Biogeographic Regionalisation of Australia v6.1. Commonwealth of Australia. http://www.environment.gov.au/parks / nrs/science/bioregion-framework/ibra/index.html.

Australian National University (2000). ANUCLIM 5.1. The Fenner School of Environment and Society, Australian National University: Canberra, Australia.

Boulter, C.A. (1986). One billion years of Archean history, Pilbara Craton, Western Australia. Geology Today 106: 106-111.

Boulton, A.J. (1999). Why variable flows are needed for invertebrates of semi-arid rivers (pp. 113-128). In: Kingsford, R.T. (ed.), A free-flowing river: the ecology of the Paroo River. New South Wales Parks and Wildlife Service: Sydney, Australia.

Boulton, A.J. and Jenkins, K.M. (1998). Flood regimes and invertebrate communities in floodplain wetlands (pp. 137-148). In: Williams, W.D. (ed.), Wetlands in a dry land: understanding for management. Environment Australia: Canberra, Australia.

Boulton, A.J. and Lloyd, L.N. (1991). Macroinvertebrate assemblages in floodplain habitats of the lower River Murray, South Australia. Regulated Rivers Research and Management 6: 183-201.

Boulton, A.J. and Lloyd, L.N. (1992). Flooding frequency and invertebrate emergence from dry floodplain sediments of the River Murray. Regulated Rivers Research and Management 7: 137-151.

Boulton, A.J., Sheldon, F. and Jenkins, K.M. (2006). Natural disturbance and aquatic invertebrates in desert rivers (pp. 133-153). In: Kingsford, R. (ed.), Ecology of desert rivers. Cambridge University Press: Cambridge, U.K.

Brandis, A.J. (2009). Rescuing the rangelands : management strategies for restoration and conservation of the natural heritage of the Western Australian rangelands after 150 years of pastoralism. Western Australian Department of Conservation and Land Management: Perth, Australia.

Brendonck, L. and Williams, W.D. (2000). Biodiversity in wetlands of dry regions (drylands) (pp. 181-194). In: Gopal, B., Junk, W.J. and Davis, J.A. (eds), Biodiversity in wetlands: assessment, function and conservation. Vol. 1. Backhuys Publishers: Leiden, Netherlands.

Brim Box, J., Duguid, A., Read, R.E., Kimber, R.G., Knapton, A., Davis, J. and Bowland, A.E. (2008). Central Australian waterbodies: the importance of permanence in a desert landscape. Journal of Arid Environments 72: 1395-1413.

Brooks, T.M., da Fonseca, G.A.B. and Rodrigues, A.S.L. (2004). Protected areas and species. Conservation Biology 18: 616-618.

Bunn, S.E., Davies, P.M. and Winning, M. (2003). Sources of organic carbon supporting the food web of an arid zone floodplain river. Freshwater Biology 48: 619-635.

Bunn, S.E., Thoms, M., Hamilton, S.K. and Capon, S.J. (2006). Flow variability in dryland rivers: boom, bust and the bits in between. River Research and Applications 22: 179-186.

Bureau of Meteorology Australia (2008). Mean monthly and mean annual rainfall and temperature data (base climatological datasets). Bureau of Meteorology Australia: Melbourne, Australia.

Chao, A. (1987). Estimating the population size for capture-recapture data with unequal catchability. Biometrics 43: 783-791.

Chao, A., Colwell, R.K., Lin, C. and Gotelli, N.J. (2009). Sufficient sampling for asymptotic minimum species richness estimators. Ecology 90: 1125-1133.

Collier, K., Champion, P. and Croker, G. (1999). Patch- and reach-scale dynamics of a macrophyteinvertebrate system in a New Zealand lowland stream. Hydrobiologia 392: 89-97.

Collinson, N., Biggs, J., Corfield, A., Hodson, M., Walker, D., Whitfield, M. and Williams, P. (1995). Temporary and permanent ponds: an assessment of the effects of drying out on the conservation value of aquatic macroinvertebrate communities. Biological Conservation 74: 125-133.

Colwell, R.K. (2004). EstimateS: Statistical estimation of species richness and shared species from samples, Version 7. User's Guide and application published at: http:/ / purl.oclc.org/estimates.

Costelloe, J.F. (2004). Hydrological results (pp. 175-259). In: Costelloe, J.F., Hudson, P.J., Pritchard, J.C., Puckridge, J.T. and Reid, J.R.W. (eds). ARIDFLO Scientific Report: Environmental flow requirements of arid zone rivers with particular reference to the Lake 
Eyre drainage basin. Final report to South Australian Department of Water, Land and Biodiversity Conservation and Commonwealth Department of Environment and Heritage. School of Earth and Environmental Sciences, University of Adelaide: Adelaide, Australia.

Costelloe, J.F., Grayson, R.B., McMahon, T.A. and Argent, R.M. (2005). Spatial and temporal variability of water salinity in an ephemeral, arid-zone river, central Australia. Hydrology Processes 19: 3147-3166.

Costelloe, J.F., Hudson, P., Pritchard, J.C., Puckridge, J.T. and Reid, J.R.W. (2004). ARIDFLO Scientific Report: Environmental flow requirements of arid zone rivers with particular reference to the Lake Eyre drainage basin. Final report to South Australian Department of Water, Land and Biodiversity Conservation and Commonwealth Department of Environment and Heritage. School of Earth and Environmental Sciences, University of Adelaide: Adelaide, Australia.

Cyr, H. and Downing, J.A. (1988). The abundance of phytophilous invertebrates on different species of submerged macrophytes. Freshwater Biology 20: 365-374.

Daniel, G., Kern, S., Pinder, A. and Nowicki, A. (2009). Resource condition report for a significant Western Australian wetland: Lake Eda. Prepared for the Inland Aquatic Integrity Resource Condition Monitoring Project. Western Australian Department of Environment and Conservation: Perth, Australia.

Davis, J.A. (1997). Conservation of aquatic invertebrate communities in central Australia. Memoirs of the Museum of Victoria 56: 491-503.

Davis, J.A., Harrington, S.A. and Friend, J.A. (1993). Invertebrate communities of relict streams in the arid zone - the George Gill Range, central Australia. Australian Journal of Marine E Freshwater Research 44: 483-505.

de Moor, F.C., Barber-James, H.M., Harrison, A.D. and Lugo-Ortiz, C.R. (2004). The macroinvertebrates of the Cunene River from the Ruacana Falls to the river mouth and assessment of the conservation status of the river. African Journal of Aquatic Science 25: 105-122.

Dean, J.C. (1999). Preliminary keys for the identification of Australian mayfly nymphs of the family Leptophlebiidae. Identification guide no. 20. Cooperative Centre for Freshwater Ecology: Albury, Australia.

Death, R. and Joy, M. (2004). Invertebrate community structure in streams of the Manawatu-Wanganui region, New Zealand: the roles of catchment versus reach scale influences. Freshwater Biology 49: 982-997.

Dickman, M. (1973). Changes in periphytic algae following bicarbonate additions to a small stream. Journal of the Fisheries Research Board of Canada 30: 1882-1884.

Eitam, A., Blaustein, L., Van Damme, K., Dumont, H.J. and Martens, K. (2004). Crustacean species richness in temporary pools: relationships with habitat traits. Hydrobiologia 525: 125-130.

Fellows, C.S., Wos, M.L., Pollard, P.C. and Bunn, S.E. (2007). Ecosystem metabolism in a dryland river waterhole. Marine and Freshwater Research 58: 250-262.

Fischer, S.G., Gray, L.J., Grimm, N.B. and Busch, D.E. (1982). Temporal succession in a desert stream ecosystem following flash flooding. Ecological Monographs 52: 93-110.

Friedman, J.H. (1991). Multivariate adaptive regression splines. The Annals of Statistics 19: 1-141.

Gaston, K.J. (2000). Global patterns in biodiversity. Nature 405: 220-227.

Geological Survey of Western Australia (1990). Geology and mineral resources of Western Australia. Memoir 3. Western Australian Geological Survey: Perth, Australia.

Haila, Y. and Margules, C.R. (1996). Survey research in conservation biology. Ecography 19: 323-331.

Hall, D.L., Willig, M.R., Moorhead, D.L., Sites, R.W., Fish, E.B. and Molhagen, T.R. (2004). Aquatic macroinvertebrate diversity of playa wetlands: the role of landscape and island biogeographic characteristics. Wetlands 24: 77-91.

Halse, S., Shiel, R.J. and Williams, W.D. (1998). Aquatic invertebrates of Lake Gregory, northwestern Australia, in relation to salinity and ionic composition. Hydrobiologia 381: 15-29.

Halse, S.A., Cale, D., Jasinska, E.J. and Shiel, R.J. (2002). Monitoring change in aquatic invertebrate biodiversity: sample size, faunal elements and analytical methods. Aquatic Ecology 36: 395-410.

Halse, S.A., Lyons, M.N. and Pinder, A.M. (2004). Biodiversity patterns and their conservation in wetlands of the Western Australian wheatbelt. Records of the Western Australian Museum, Supplement 67: 337-364.

Halse, S.A., Scanlon, M.D. and Cocking, J.S. (2002). Do springs provide a window to the groundwater fauna of the Australian arid zone? Balancing the groundwater budget: proceedings on CD of an International Groundwater Conference, 12-17 May 2002, Darwin, Australia.

Halse, S.A., Scanlon, M.D. and Cocking, J.S. (2006). First national assessment of river health: Western Australian program. milestone report 5 and final report. Western Australian Department of Environment and Conservation: Perth, Australia.

Halse, S.A., Shiel, R.J., Storey, A.W., Edward, D.H.D., Lansbury, I., Cale, D.J. and Harvey, M.S. (2000). Aquatic invertebrates and waterbirds of wetlands and rivers of the southern Carnarvon Basin, Western Australia. Records of the Western Australian Museum, Supplement 61: 217-265.

Hamilton, S.K., Bunn, S.E., Thoms, M.C. and Marshall, J.C. (2005). Persistence of aquatic refugia between flow pulses in a dryland river system (Cooper Creek, Australia). Limnology \& Oceanography 50: 743-754.

Hammer, U.T. (1986). Saline lake ecosystems of the world. Dr. W. Junk Publishers: Dordrecht, Netherlands.

Harvey, M.S. (2002). Short-range endemism among the Australian fauna: some examples from non-marine environments. Invertebrate Systematics 16: 555-570.

Hastie, T., Tibshirani, R. and Friedman, J.H. (2001). The elements of statistical learning: data mining, inference and prediction. Springer: New York, U.S.A.

Jackson, J., Kern, S., Pinder, A., Nowicki, A. and Daniel, G. (2009). Resource condition report for a significant Western Australian wetland: Fortescue Marshes. Prepared for the Inland Aquatic Integrity Resource Condition Monitoring Project. Western Australian Department of 
Environment and Conservation: Perth, Australia.

Johnson, S.L. and Wright, A.H. (2001). Central Pilbara groundwater study. Western Australian Water and Rivers Commission: Perth, Australia.

Kay, W.R., Smith, M.J., Pinder, A.M., McRae, J.A., Davis, J.A. and Halse, S.A. (1999). Patterns of distribution of macroinvertebrate families in rivers of north-western Australia. Freshwater Biology 41: 299-316.

Keighery, G.J., Gibson, N., Lyons, M.N. and Burbidge, A.H. (2000). Flora and vegetation of the southern Carnarvon Basin, Western Australia. Records of the Western Australian Museum, Supplement 61: 77-154.

Koetsier, P., Minshall, W. and Robinson, C.T. (1996). Benthos and macroinvertebrate drift in six streams differing in alkalinity. Hydrobiologia 317: 41-49.

Lake, P. (2003). Ecological effects of perturbation by drought in flowing waters. Freshwater Biology 48: 1161-1172.

Lansbury, I. (1984). Some Nepomorpha (Corixidae, Notonectidae and Nepidae) (Hemiptera-Heteroptera) of north-west Australia. Transactions of the Royal Society of South Australia 108: 35-49.

Leathwick, J.R., Roew, D., Richardson, J., Elith, J. and Hastie, T. (2005). Using multivariate adaptive regression splines to predict the distributions of New Zealand's freshwater diadromous fish. Freshwater Biology 50: 2034-2052.

Lee, S.-M. and Chao, A. (1994). Estimating population size via sample coverage for closed capture-recapture models. Biometrics 50: 88-97.

Legendre, P. (1993). Spatial autocorrelation: trouble or new paradigm? Ecology 74: 1659-1673.

Lyons, M.N., Gibson, N., Keighery, G.J. and Lyons, S.D. (2004). Wetland flora and vegetation of the wheatbelt of southwestern Australia. Records of the Western Australian Museum, Supplement 67: 39-89.

Mackie, G. and Flippance, L. (1983). Relationships between buffering capacity of water and the size and calcium content of freshwater mollusks. Freshwater Invertebrate Biology 2: 48-55.

Madden, C.P., McEvoy, P.K., Taylor, D.J., Tsymbal, V., Venus, T.A. and Goonan, P.M. (2002). Macroinvertebrates of watercourses in the Lake Eyre Basin, South Australia. Verhandlungen Internationale Vereinigung für theoretische und angewandte Limnologie 28: 591-600.

Magurran, A.E. (2004). Measuring biological diversity. Blackwell Science Ltd: Malden, U.K.

Margules, C.R., Pressey, R.L. and Williams, P.H. (2002). Representing biodiversity: data and procedures for identifying priority areas for conservation. Journal of Bioscience 27: 309-326.

Marshall, J.C., Sheldon, F., Thoms, M. and Choy, S. (2006). The macroinvertebrate fauna of an Australian dryland river: spatial and temporal patterns and environmental relationships. Marine and Freshwater Research 57: 61-74.

McKenzie, K.G., Halse, S.A. and Gibson, N. (2000). Some gaps in the reserve system of the southern Carnarvon Basin, Western Australia. Records of the Western Australian Museum, Supplement 61: 547-567.

McKenzie, K.G., May, J.E. and McKenna, S. (2002).
Bioregional summary of the biodiversity audit for Western Australia. Western Australian Department of Conservation and Land Management: Perth, Australia.

McKenzie, N.L., Gibson, N., Keighery, G.J. and Rolfe, J.K. (2004). Patterns in the biodiversity of terrestrial environments in the Western Australian wheatbelt. Records of the Western Australian Museum, Supplement 67: 293-336.

McKenzie, N.L., van Leeuwen, S. and Pinder, A.M. (2009). Introduction to the Pilbara Biodiversity Survey, 2002-2007. Records of the Western Australian Museum, Supplement 78: 3-89.

Metson, A.I. (1956). Methods of chemical analysis of soil survey samples. New Zealand D.S.I.R. Soil Bureau Bulletin 12: 193-204.

Morgan, D. and Gill, H. (2004). Fish fauna in inland waters of the Pilbara (Indian Ocean) Drainage Division of Western Australia - evidence for three sub-provinces. Zootaxa 636: 1-43.

New, T.R. (1998). Invertebrate surveys for conservation. Oxford University Press: Oxford, U.K.

Nicholls, A.O. (1989). How to make biological surveys go further with generalised linear models. Biological Conservation 50: 51-75.

Pinder, A.M. (2008). Phreodrilidae (Clitellata: Annelida) in north-western Australia with descriptions of two new species. Records of the Western Australian Museum 24: 459-468.

Pinder, A.M., Halse, S.A., McRae, J.M. and Shiel, R.J. (2004). Aquatic invertebrate assemblages of wetlands and rivers in the wheatbelt region of Western Australia. Records of the Western Australian Museum 67: 7-37.

Pinder, A.M., Halse, S.A., McRae, J.M. and Shiel, R.J. (2005). Occurrence of aquatic invertebrates of the wheatbelt region of Western Australia in relation to salinity. Hydrobiologia 543: 1-24.

Pinder, A.M. and Leung, A. (2009). Conservation status and habitat associations of aquatic invertebrates in Pilbara coastal river pools. Western Australian Department of Environment and Conservation: Perth, Australia.

Ponder, W.F. (1987). Report on a preliminary survey of springs in the Pilbara region of Western Australia. Australian Museum: Sydney, Australia.

Pressey, R.L. (2004). Conservation planning and biodiversity: assembling the best data for the job. Conservation Biology 18: 1677-1681.

Quinlan, K., Pinder, A.M. and Cale, D. (2009). Assessment of the aquatic fauna conservation values of wetlands in the Hutt River/Hutt Lagoon catchments. Western Australian Department of Environment and Conservation: Perth, Australia.

R Development Core Team (2008). R: a language and environment for statistical computing. R Foundation for Statistical Computing: Vienna, Austria.

Radke, L.C., Juggins, S., Halse, S.A., De Deckker, P. and Finston, T. (2003). Chemical diversity in south-eastern Australian saline lakes II: biotic implications. Marine and Freshwater Research 54: 895-912.

Schneider, D. and Frost, T. (1996). Habitat duration and community structure in temporary ponds. Journal of the North American Benthological Society 15: 64-86. 
Sheldon, F., Boulton, A.J. and Puckridge, J.T. (2002). Conservation value of variable habitat connectivity: aquatic invertebrate assemblages of channel and floodplain habitats of a central Australian arid-zone river, Cooper Creek. Biological Conservation 103: 13-31.

Shiel, R.J., Costelloe, J.F., Reid, J.R.W., Hudson, P. and Powling, J. (2006). Zooplankton diversity and assemblages in arid zone rivers of the Lake Eyre Basin, Australia. Marine and Freshwater Research 57: 49-61.

Simovich, M.A. (1998). Crustacean biodiversity and endemism in California's ephemeral wetlands (pp. 107-114). In: Witham, C.W., Bauder, E.T., Belk, D., Ferren, W.R. and Ornduff, R. (eds), Ecology, conservation and management of vernal pool ecosystems - proceedings from a 1996 conference. California Native Plant Society: Sacramento, U.S.A.

Smit, H. (1997). Australian water mites of the genus Arrenurus, with the description of twelve new species from northern and Western Australia (Acari: Hydrachnellae: Arrenuridae). Records of the Western Australian Museum, Supplement 18: 233-261.

Smit, H. (1998). The water mite family Limnesiidae from northern and Western Australia (Acari: Actinedida), with descriptions of two new species. Records of the Western Australian Museum 18: 347-355.

Stanley, E., Buschman, D., Boulton, A., Grimm, N. and Fisher, S. (1994). Invertebrate resistance and resilience to intermittency in a desert stream. American Midland Naturalist 131: 288-300.

Stork, N.E., Samways, M.J. and Eeley, H.A.C. (1996). Inventorying and monitoring biodiversity. Trends in Ecology and Evolution 11: 39-40.

Strahler, A.N. (1952). Hypsometric (area-altitude) analysis of erosional topography. Bulletin of the Geological Society of America 63: 1117-1142.

Strayer, D.L. (2006). Challenges for freshwater invertebrate conservation. Journal of the North American Benthological Society 25: 271-287.

Taylor, G. (1994). Landscapes of Australia: their nature and evolution (pp. 60-79). In: Hill, R.S. (ed.), History of the Australian vegetation: Cretaceous to Recent. Cambridge University Press: Cambridge, U.K.

Thomaz, S., Bini, L. and Bozelli, R.L. (2007). Floods increase similarity among aquatic habitats in riverfloodplain systems. Hydrobiologia 579: 1-13.

Timms, B.V. (2001). Large freshwater lakes in arid Australia: a review of their limnology and threats for their future. Lakes and Reservoirs 6: 183-196.

Timms, B.V. (2002). Limnology of the claypans of The Paroo, arid-zone Australia. Verhandlungen Internationale Vereinigung für theoretische und angewandte Limnologie 28: 130-133.

Timms, B.V. (2007). The biology of the saline lakes of central and eastern inland of Australia: a review with special reference to their biogeographical affinities. Hydrobiologia 576: 27-37.

Timms, B.V. (2008). Further studies on the fairy shrimp genus Branchinella (Crustacea, Anostraca, Thamnocephalidae) in Western Australia, with descriptions of new species. Records of the Western Australian Museum 24: 289-306.
Timms, B.V. (2009). A revision of the Australian endemic clam shrimp genus Limnadopsis Spencer and Hall (Crustacea: Branchiopoda: Spinicaudata: Limnadiidae). Records of the Australian Museum 61: $49-72$.

Timms, B.V. and Boulton, A.J. (2001). Typology of arid-zone floodplain wetlands of the Paroo River (inland Australia) and the influence of water regime, turbidity, and salinity on their aquatic invertebrate assemblages. Archiv für Hydrobiologie 153: 1-27.

Vinson, M.R. and Hawkins, C.P. (1998). Biodiversity of stream insects: variation at local, basin and regional scales. Annual Review of Entomology 43: 271-293.

Walker, K.F., Sheldon, F. and Puckridge, J.T. (1995). A perspective on dryland river ecosystems. Regulated Rivers: Research and Management 11: 85-104.

Walshe, T.V., Halse, S.A., McKenzie, N.L. and Gibson, N. (2004). Toward identification of an efficient set of conservation recovery catchments for Western Australian wheatbelt biodiversity. Records of the Western Australian Museum, Supplement 67: 365-384.

Water and Rivers Commission (1996). Pilbara region water resources review and development plan, summary report 4. Western Australian Water and Rivers Commission: Perth, Australia.

Waterkeyn, A., Grillas, P., Vanschoenwinkel, B. and Brendonck, L. (2008). Invertebrate community patterns in Mediterranean temporary wetlands along hydroperiod and salinity gradients. Freshwater Biology 53: $1802-1822$.

Watson, J.A.L. (1969). Taxonomy, ecology and zoogeography of dragonflies (Odonata) from the north-west of W.A. Journal of Zoology 17: 65-112.

Watts, C.H.S. and McRae, J.M. (2010). The identity of Haliplus Latrielle (Coleoptera: Haliplidae) from the Pilbara region of Australia including the description of four new species. Records of the Western Australian Museum 25: 387-398.

Watts, R.J. (1999). Biodiversity in the Paroo River and its wetlands (pp. 13-22). In: Kingsford, R.T. (ed.), A freeflowing river: the ecology of the Paroo River. New South Wales National Parks and Wildlife Service: Sydney, Australia.

Williams, D.D. and Mundie, J.H. (1978). Substrate size selection by stream invertebrates and the influence of sand. Limnology and Oceanography 23: 1030-1033.

Williams, W.D. (1998). Diversity and evolution of the fauna of the dryland wetlands (pp. 167-171). In: McComb, A.J. and Davis, J.A. (eds), Wetlands for the future: INTECOL's 5th International Wetlands Conference, 1996. Gleneagles Press: Adelaide, Australia.

Williams, W.D. and Kokkin, M.J. (1988). The biogeographical affinities of the fauna in episodically filled salt lakes: a study of Lake Eyre South, Australia. Hydrobiologia 158: 227-236.

Wilson, M.V. and Shmida, A. (1984). Measuring beta diversity with presence-absence data. Journal of Ecology 72: 1055-1064.

Wollheim, W.M. and Lovvorn, J.R. (1996). Effects of macrophyte growth forms on invertebrate communities in saline lakes of the Wyoming High Plains. Hydrobiologia 323: 83-96. 


\section{APPENDIX 1}

Environmental variables for the 189 sampling events during the survey. Those marked with an asterisk were included in assemblage modeling.

See CD inside the back cover, or visit:

http://www.museum.wa.gov.au/research/records-supplements/attachments

\section{APPENDIX 2}

Occurrence of aquatic invertebrate species in the 189 samples collected during the survey. In the matrix, 1 = presence, blank = absence, ${ }^{*}$ indicates distinct species (i.e. not just juveniles or females of a taxon potentially listed in another row). Column 2 indicates reasons for excluding rows from analysis (see Methods for details): 1) protozoans, 2) higher taxa probably comprising numerous unidentified species, 3) uncertain taxonomic resolution, 4) species merged to genus or family level for analysis, or 5) incompletely identified specimens (e.g. wrong sex or juvenile).

See CD inside the back cover, or visit:

http://www.museum.wa.gov.au/research/records-supplements/attachments

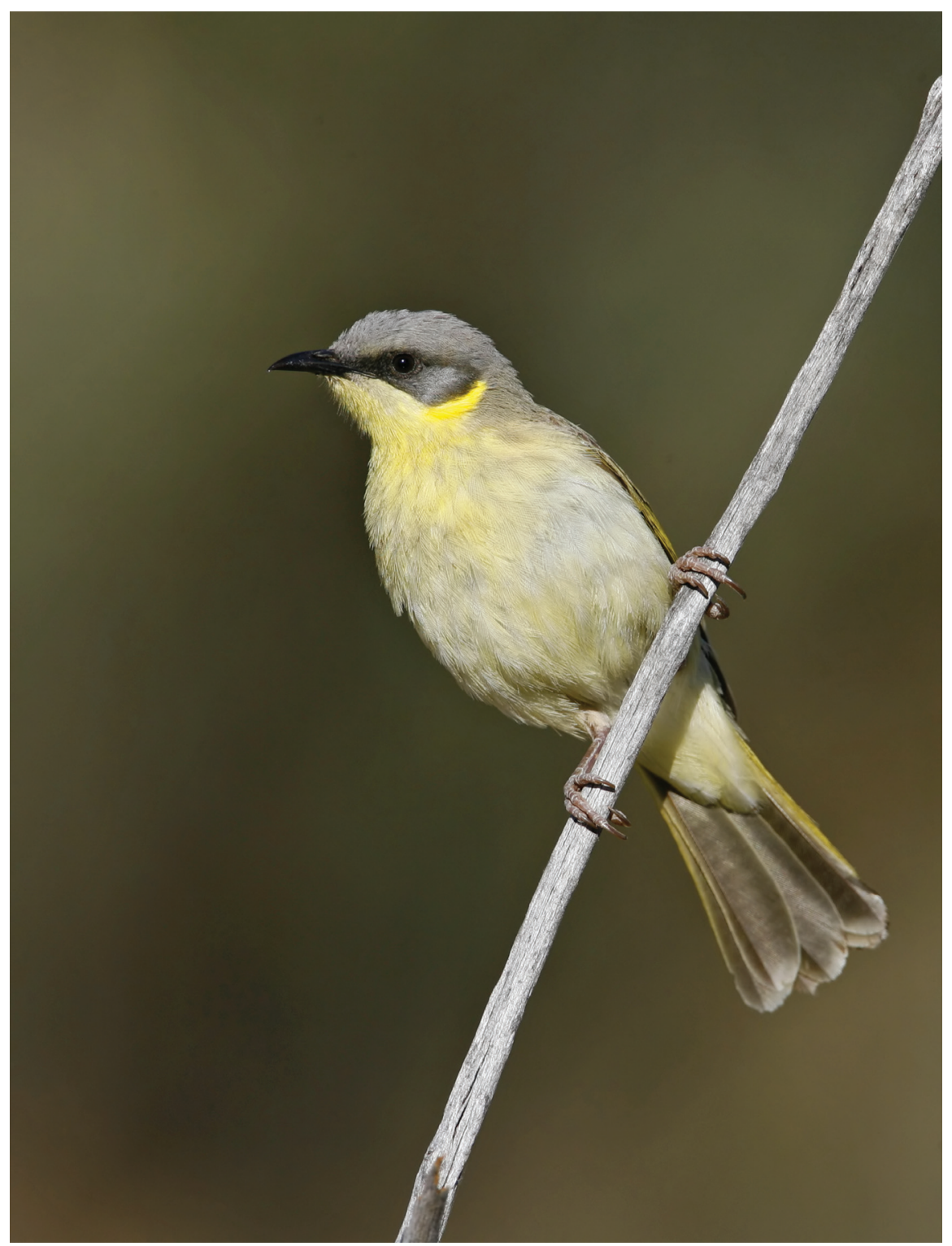

Grey-headed Honeyeater (Lichenostomus keartlandi) forages in shrub and tree canopies throughout the region (Lochman). 